\title{
Climate change vulnerability assessment of forests and forest-dependent people
}

A framework methodology

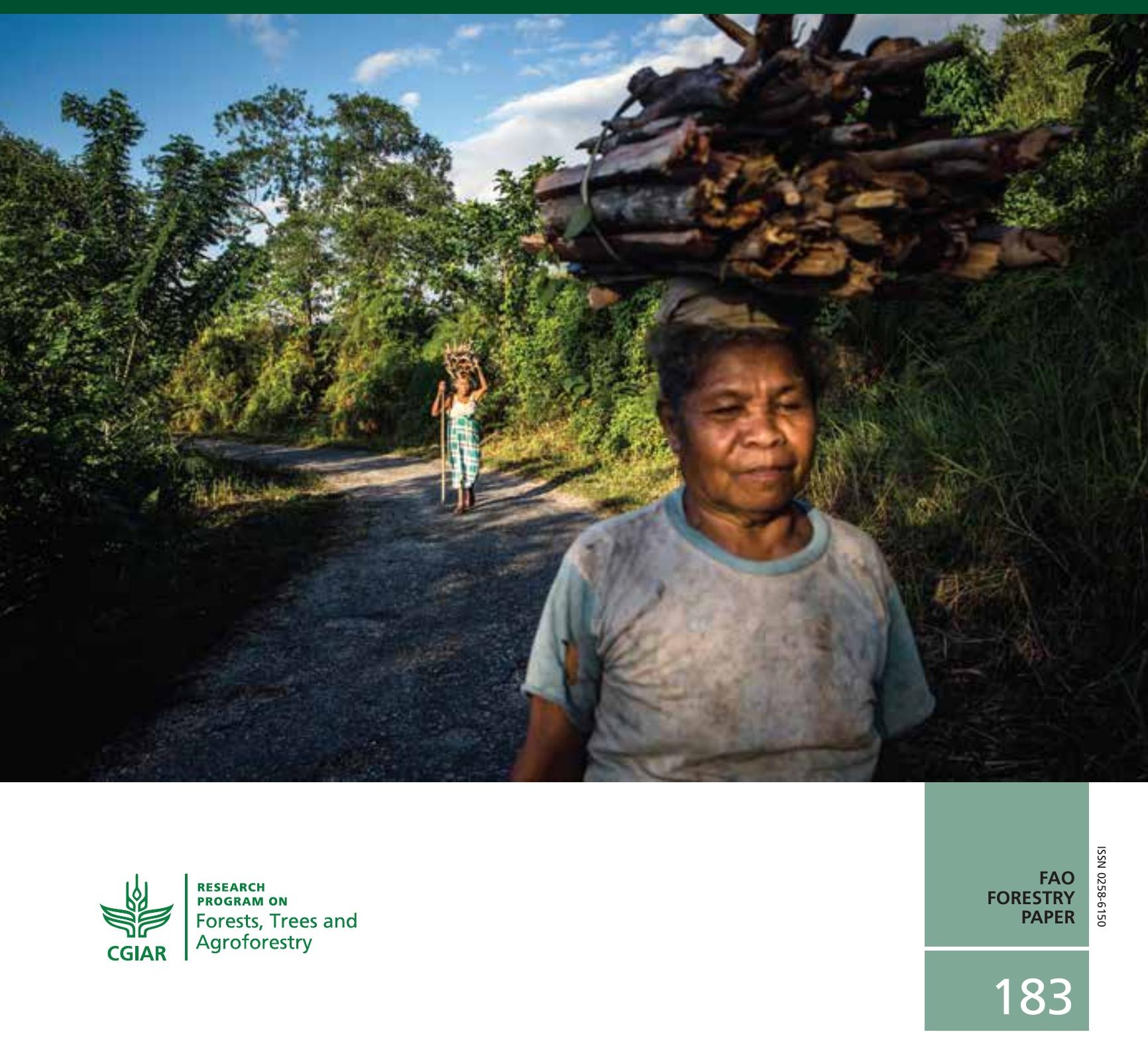




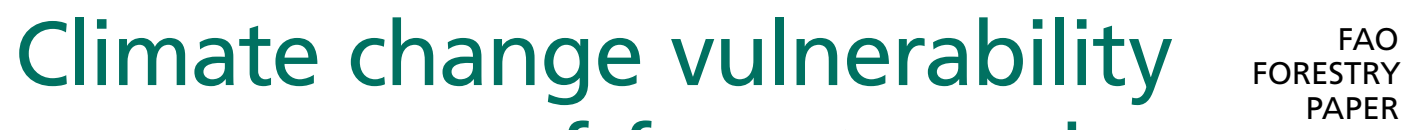 assessment of forests and forest-dependent people \\ 183}

A framework methodology

by

A. Meybeck

S. Rose

V. Gitz

FOOD AND AGRICULTURE ORGANIZATION OF THE UNITED NATIONS

Rome, 2019 
Required citation:

\author{
FAO and CIFOR. 2019. FAO Framework Methodology for Climate Change \\ Vulnerability Assessments of Forests and Forest Dependent People. Rome.
}

The designations employed and the presentation of material in this information product do not imply the expression of any opinion whatsoever on the part of the Food and Agriculture Organization of the United Nations (FAO) or the Center for International Forestry Research (CIFOR) concerning the legal or development status of any country, territory, city or area or of its authorities, or concerning the delimitation of its frontiers or boundaries. The mention of specific companies or products of manufacturers, whether or not these have been patented, does not imply that these have been endorsed or recommended by FAO or CIFOR in preference to others of a similar nature that are not mentioned.

The views expressed in this information product are those of the author(s) and do not necessarily reflect the views or policies of FAO or CIFOR.

ISSN 0258-6150 [Print]

ISSN 2706-8773 [Online]

ISBN 978-92-5-131981-9

(c) FAO, 2019

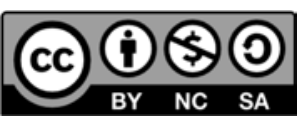

Some rights reserved. This work is made available under the Creative Commons Attribution-

NonCommercial-ShareAlike 3.0 IGO licence (CC BY-NC-SA 3.0 IGO; https://creativecommons.org/licenses/ by-nc-sa/3.0/igo/legalcode).

Under the terms of this licence, this work may be copied, redistributed and adapted for non-commercial purposes, provided that the work is appropriately cited. In any use of this work, there should be no suggestion that FAO endorses any specific organization, products or services. The use of the FAO logo is not permitted. If the work is adapted, then it must be licensed under the same or equivalent Creative Commons license. If a translation of this work is created, it must include the following disclaimer along with the required citation: "This translation was not created by the Food and Agriculture Organization of the United Nations (FAO). FAO is not responsible for the content or accuracy of this translation. The original English edition shall be the authoritative edition."

Disputes arising under the licence that cannot be settled amicably will be resolved by mediation and arbitration as described in Article 8 of the licence except as otherwise provided herein. The applicable mediation rules will be the mediation rules of the World Intellectual Property Organization http://www. wipo.int/amc/en/mediation/rules and any arbitration will be in accordance with the Arbitration Rules of the United Nations Commission on International Trade Law (UNCITRAL)

Third-party materials. Users wishing to reuse material from this work that is attributed to a third party, such as tables, figures or images, are responsible for determining whether permission is needed for that reuse and for obtaining permission from the copyright holder. The risk of claims resulting from infringement of any third-party-owned component in the work rests solely with the user.

Sales, rights and licensing. FAO information products are available on the FAO website (www.fao.org/ publications) and can be purchased through publications-sales@fao.org. Requests for commercial use should be submitted via: www.fao.org/contact-us/licence-request. Queries regarding rights and licensing should be submitted to: copyright@fao.org.

\title{
Cover photo:
}

Villagers dependent on the forest for fuelwood, Maluku Province, Indonesia OUlet Ifansasti/CIFOR 


\section{Contents}

Foreword .............................................................................................. vii

Acknowledgements ..................................................................................viii

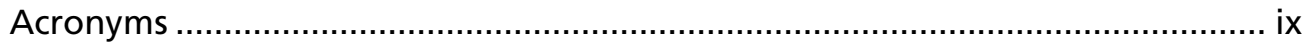

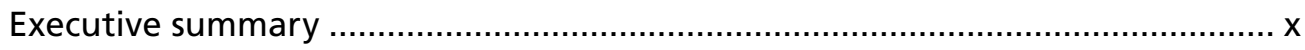

1 Introduction..................................................................................... 1

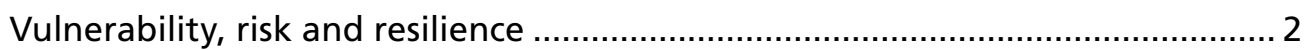

What is a vulnerability assessment?................................................................. 4

Moving from vulnerability assessment to adaptive measures............................ 5

Using the framework methodology .................................................................

2 Defining the objectives, scope and means ..........................................11

Identifying the project team .........................................................................11

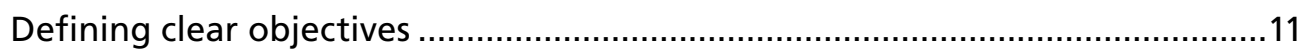

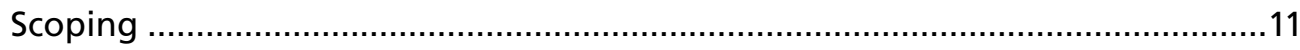

Means and resources ................................................................................. 12

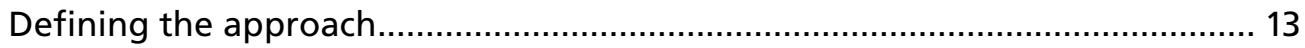

Engaging with stakeholders........................................................................... 16

3 Describing the situation and state of the forests and trees...................19

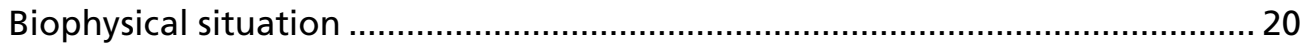

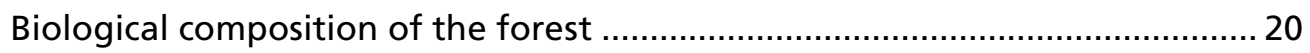

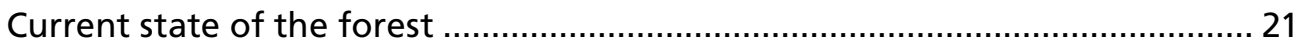

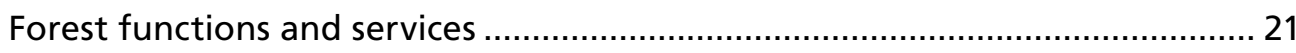

Trends and potential vulnerabilities unrelated to climate change ..................... 24

4 Legal status, institutions and governance .........................................27

Legal status and institutions governing the forest......................................... 27

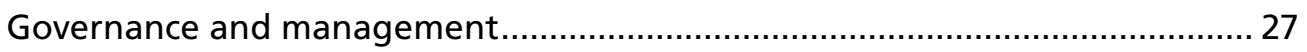

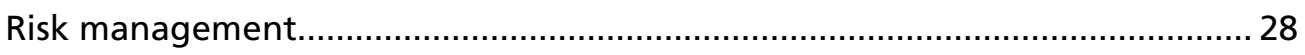

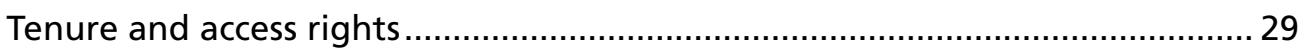

Prospective institutional and governance trends and plans ............................ 30 
5 Describing the forest-dependent people .......................................... 33

Number and characteristics of forest-dependent people ................................. 34

Socio-economic contribution of the forest ..................................................... 35

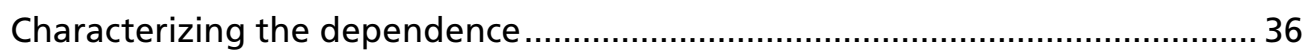

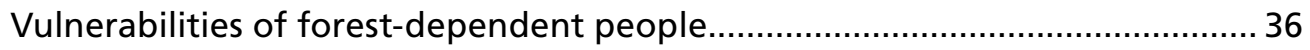

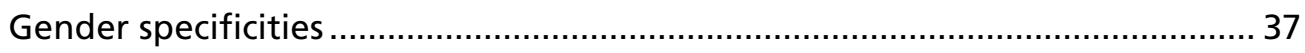

6 Climate change and climate-related risks in the region where the forest is located ................................................................. 39

Analysis of historical and current climate-related events and risks ................... 39

Climate change projections ............................................................................ 39

7 Potential impacts of climate change on forests and trees, and their specific vulnerabilities ............................................................ 43

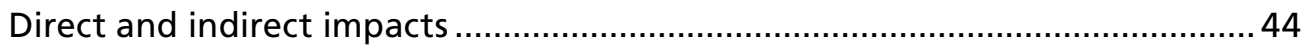

Combination with other vulnerabilities ...................................................... 47

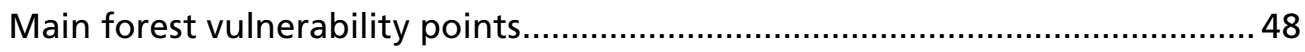

8 Potential impacts of climate change on forest-dependent people, and their specific vulnerabilities ...............................................................51

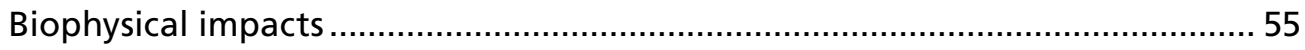

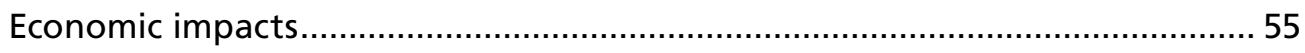

Combination with other vulnerabilities (including those of

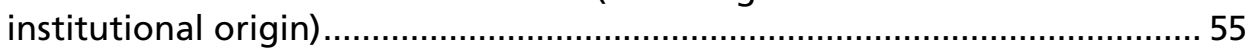

Analysis of the main points of vulnerability of forest-dependent people ........ 56

9 Communicating the results and moving ahead...................................6 63

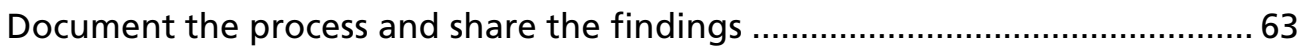

Plan subsequent steps to identify and promote adaptation options ................ 63

10 Good practices and principles for vulnerability assessments.................67

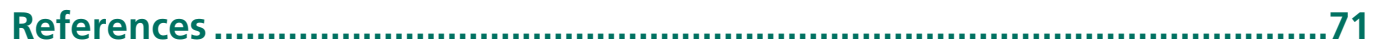




\section{Tables}

1 Key features of the outcome and contextual perspectives ............................ 14

2 Examples of information that can be used for evaluating exposure, sensitivity, impacts and adaptive capacity in a forest vulnerability assessment.

\section{Figures}

1 Components of vulnerability to climate change ............................................ 3

2 Vulnerability and resilience

3 The relationship of adaptation measures to factors that affect the vulnerability and resilience of ecosociological systems.

4 Framework for integrating adaptations identified in vulnerability assessment into forest management planning

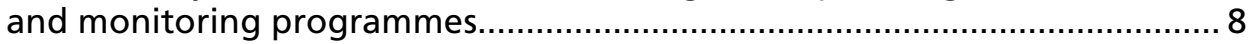

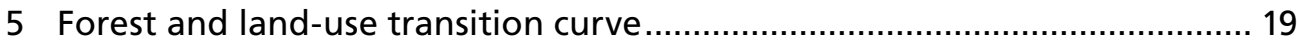

6 Concept pyramid of forest ecosystem services ............................................. 23

7 Cascading impacts of climate change on food security

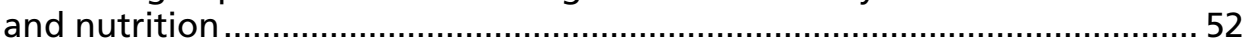

8 Risk matrix for rating disturbances in terms of their likelihood of occurrence and the seriousness of the consequences ............................... 54

9 Computation of the vulnerability from factors that influence forest cover using multifactorial spatial analysis......................................... 58

10 Validity quadrant for ranking potential actions for addressing vulnerability to disturbances

\section{Boxes}

1 Addressing data challenges: the use of proxies ............................................. 13

2 Some well-known approaches to vulnerability assessment ......................... 15

3 Classification of forest functions and services........................................... 22

4 Balancing trade-offs among forest users: an example from Sweden............ 29

5 Diverse forms of forest dependence .......................................................... 33

6 Climate change effects on wildfire risk......................................................... 43

7 Climate change effects on pest risks ......................................................... 44

8 Methods and tools for assessing the vulnerability of forests and

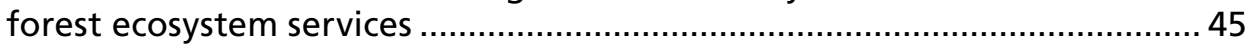

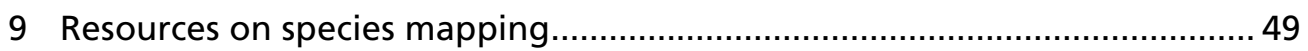

10 Role of forests in reducing human vulnerability ........................................... 53

11 Participatory methods and tools for assessing impacts of climate change on the vulnerabilities of forest-dependent people ............. 53

12 Vulnerability assessment of Mediterranean forests...................................... 56 
13 CRiSTAL Forests: a tool for screening community-based risk ....................... 59

14 Good practice and lessons learned in assessing climate change

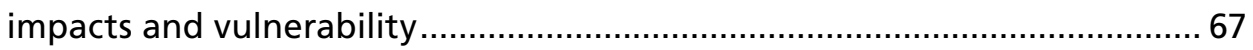

15 Principles for effective vulnerability assessments ...................................... 69 


\section{Foreword}

Negative impacts of climate change on forests, which are already apparent in many places, threaten the delivery of crucial wood and non-wood goods and environmental services on which an estimated 1.6 billion people fully or partly depend. While some of the problems associated with climate change are emerging gradually, immediate action is needed to build resilience into forests and people's livelihoods. Forests and people constitute an integrated socio-ecological system. Assessing the vulnerability of this system to climate change makes it possible to pinpoint the risks and the most vulnerable areas and people. Vulnerability assessment is thus a necessary first step in identifying measures for adaptation and targeting them for specific contexts.

This publication has been developed to provide practical technical guidance for forest vulnerability assessment in the context of climate change, as requested by the Committee on Forestry (COFO), FAO's global statutory body for forestry, at its twenty-third session in July 2016. It describes the elements that should be considered in assessing the vulnerability of forest ecosystems and forest-dependent people for different time horizons, and outlines a structured approach for conducting these assessments. The aim is to guide practitioners in conducting a step-by-step analysis and to facilitate the choice and use of appropriate tools and methods, also taking gender dimensions into account.

The framework builds on the wide range of methods described in $A$ review of existing approaches and methods to assess climate change vulnerability of forests and forest-dependent people (FAO Forestry Working Paper No. 5), published in 2018. Furthermore, it capitalizes on the existing body of knowledge related to forest management and climate change adaptation, and in particular on the experience of FAO and the CGIAR Research Program on Forests, Trees and Agroforestry (FTA). The framework has been developed through a multi-stakeholder process involving technical experts and key stakeholders from civil society organizations, non-governmental organizations, the private sector and international organizations.

By including summarized background information for readers with differing amounts of experience in forestry, climate change and assessment practices, the publication is designed to provide useful support to any practitioner conducting a vulnerability assessment with a forest- and tree-related component.

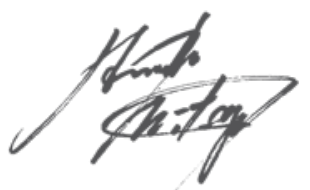

Hiroto Mitsugi

Assistant Director-General FAO Forestry Department

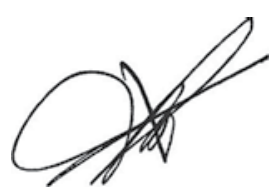
Robert Nasi
Director General CIFOR 


\section{Acknowledgements}

The contributions of the following researchers from the CGIAR Research Program on Forests, Trees and Agroforestry (FTA) are acknowledged: Houria Djoudi, Christopher Martius, Daniel Murdiyarso, Pablo Pacheco, Bimbika Sijaparti Basnett, Center for International Forestry Research (CIFOR); Yves Laumonier and Bruno Locatelli, French Agricultural Research Centre for International Development (CIRAD)/CIFOR; Lasisa A. Duguma, Aster Gebrekirstos,Ramni Jamnadass, Roeland Kindt, Beria Leimona, Peter Minang, Catherine Muthuri, Fergus Sinclair and Meine van Noordwijk, World Agroforestry (ICRAF); Marlene Elias and Chris Kettle, Bioversity International; Eduardo Somarriba, Tropical Agricultural Research and Higher Education Center (CATIE); Thanglong Trinh, International Network for Bamboo and Rattan (INBAR); and Herman Savenije (Tropenbos International).

The following FAO specialists also provided valuable contributions: Nora Berrahmouni, Kristin Devalue, Nicolas Picard, Marieke Sandker, Shiroma Sathyapala and Mette Wilkie, Forestry Policy and Resources Division; Rima Al-Azar, Climate and Environment Division; Neil Marsland, Ulrich Nyamsi and Sylvie Wabbes Candotti, Emergency and Rehabilitation Division; Ilaria Sisto, Social Policies and Rural Institutions Division; Daniela Kalikoski, Rural Poverty Reduction Programme Management Team; and Steve Colombo, consultant.

The contributions of the following peer reviewers are much appreciated: Susan Braatz, FAO retiree; Rodney Keenan, School of Ecosystem and Forest Sciences, University of Melbourne, Australia; Ferenc Lakatos, Forest Invasive Species Network for Europe and Central Asia; David Rhodes, New Zealand Forest Owners Association; Keiko Saito, World Bank; Jagmohan Sharma, Centre for Sustainable Technologies, Indian Institute of Science; and Chris Swanston, Northern Institute of Applied Climate Science, United States of America. 


\section{Acronyms}

CIFOR Center for International Forestry Research

FAO Food and Agriculture Organization of the United Nations

FTA CGIAR Research Program on Forests, Trees and Agroforestry

ICRAF World Agroforestry

IISD International Institute for Sustainable Development

IPCC Intergovernmental Panel on Climate Change

IUCN International Union for Conservation of Nature

IUFRO International Union of Forest Research Organizations

NGO non-governmental organization

REDD+ Reducing Emissions from Deforestation and Forest Degradation, plus conservation of forest carbon stocks, sustainable management of forests and enhancement of forest carbon stocks

UNFCCC United Nations Framework Convention on Climate Change 


\section{Executive summary}

Negative impacts of climate change on forests are already apparent in many places, threatening the delivery of a range of crucial goods (wood and non-wood) and environmental services from forests, on which an estimated 1.6 billion people fully or partly depend. While some of the problems associated with climate change are emerging gradually, immediate action is needed to build resilience into forests and people's livelihoods. Assessing the vulnerability of forests and forest-dependent people enables practitioners to identify the risks posed by climate change and to develop adaptation options targeted at the most vulnerable areas and people.

The vulnerability of a system is a function of its exposure to change, its sensitivity to such change, and its capacity to adapt to it. Vulnerability is a complex concept having many interacting dimensions (environmental, economic, social, political and geographic). A vulnerability assessment should answer the question "what (or who) is vulnerable to what". In theory, assessment of vulnerability to climate change should take into account both the evolution of the system and the pressures and risks with which it will be confronted.

Over the past few decades, methods of vulnerability assessment have been developed and documented in a wide range of development-related fields, addressing, for example, natural hazards, food security, poverty and sustainable livelihoods. The framework presented in this publication builds on the wide range of available methods to provide a single common approach that can be used in a broad range of forest situations. The aim is to guide practitioners in conducting a step-by-step analysis and to facilitate the use of appropriate tools and methods. The publication will be useful for any actors and institutions that conduct vulnerability assessments with a forest- and tree-related component, including forest owners, managers and administrators in the private and public sectors and in community forestry organizations, as well as land-use planners. The framework is structured according to the following steps.

\section{Defining the objectives, scope and means}

The first step of a vulnerability assessment is to define clear objectives, considering the main forest functions and the concerned populations. This phase includes identifying the project team, the geographic location, the scale and time frame of the assessment, and the means, resources and competencies required. Based on these characteristics, it is then possible to decide on the approach and methods for carrying out the assessment - quantitative or qualitative, top-down or bottom-up, or a mix of these. Processes for engaging with stakeholders are also considered. 


\section{Describing the situation and state of the forests and trees}

As forests are diverse, it is important to understand the actual or potential changes of the forests and trees in a specific landscape over time, as these changes will often influence the forests' and trees' vulnerability to climate change and other stresses as well as their capacity to contribute to human well-being. Therefore the assessment begins with analysis of the biophysical situation, the biological composition of the forest, the current state of the forest, and the forest's functions and services. The assessment should also consider other trends and potential vulnerabilities besides those associated with climate change, in order to envisage how vulnerabilities might interact and evolve in the future.

\section{Legal status, institutions and governance}

It is important to evaluate the institutions and rules that govern a specific forest and the forms of governance, ownership, tenure and management, as these can have a considerable impact - positive or negative - on the vulnerability and adaptive capacity of both the forest and the people that depend on it. The effectiveness of forest governance depends to a large degree on the level of involvement of forest stakeholders.

Gathering information on laws, rules and institutions is relatively easy, but implementation of the legislation is equally important and can only be understood from direct exchange with local stakeholders. Of particular importance are the duration, stability and protection of tenure rights. It is also important to take into account any non-written customary rules that may govern access to the forest and its resources; and to consider prospective evolution in governance and institutions.

\section{Describing the forest-dependent people}

To understand the potential impacts of climate change on people, it is necessary to evaluate the number and characteristics of forest-dependent people and the nature of their dependence on the forest, including the socio-economic contribution of the forest. To explore the vulnerabilities of forest-dependent people, the assessment should investigate their exposure and sensitivity to the consequences of climate change impacts on forests, as well as their adaptive capacity (which mainly depends on factors beyond the forest, including institutional factors and access rights). It may also be relevant to address whether and how the forest is linked with other agricultural systems for the livelihoods and communities in question.

The assessment needs to take gender dimensions and intersecting social variables into account. Women and men have different roles in relation to forests, as well as different vulnerabilities and adaptive capacities. The analysis should consider access to and control over productive resources and services and employment opportunities for women and men, as well as their participation in decision-making and local institutions.

\section{Climate change and climate-related risks in the region where the forest is located}

The assessment should include an analysis of historical and current climate-related events and risks. It should consider climate change projections, taking into account the general 
circulation models used to project future climates; the scenarios of future emissions of greenhouse gases; and the time period(s) of the evaluation. In some cases, it may also be necessary to consider projections of hydrological changes.

\section{Potential impacts of climate change on forests and trees, and their specific vulnerabilities}

The next step is to evaluate the ways in which climate may affect the structure or function of forests. A range of sources and types of information can be used, including expert opinion (from published literature, consultation of subject matter experts or traditional local knowledge), retrospective analysis, forest condition and life traits, climatic niche models and physiological models. Baseline forest conditions and historical forest responses to climate and extreme weather may be available from published forest statistics and technical literature.

Impacts on forests and trees may be direct or indirect. Direct impacts include consequences of weather changes or events such as alteration in temperature patterns, heat waves, droughts, frost and windthrow. Indirect impacts include effects on production or ecosystem functioning caused by changes in non-tree species such as pollinators, pests, disease vectors and invasive species. Impacts from human activities, such as land-use conversion and unsustainable land-use practices, should also be considered along with impacts from climate change, as the vulnerabilities are likely to interact.

\section{Potential impacts of climate change on forest-dependent people, and their specific vulnerabilities}

At this stage, an integrated approach can be used to draw conclusions about some of the main points of vulnerability of forest-dependent people to climate change, highlighting the pathways through which impacts translate from forest to people, and thus the critical points for intervention. Methods for pulling together the information of the various vulnerability components can be grouped in three broad categories: modelling based, indicator based or stakeholder based. Most vulnerability assessments will combine various methods.

\section{Communicating the results and moving ahead}

In addition to documenting the process and sharing the findings with stakeholders, the final stage of the assessment should emphasize planning of subsequent steps to identify and promote adaptation options. The publication concludes with a summary of good practices and principles for conducting vulnerability assessments. 



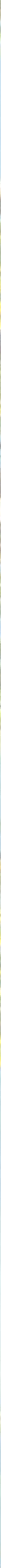




\section{Introduction}

The fact of the Earth's changing climate is undeniable. The global average temperature for the period 2016-2035 is projected to be 0.3 to $0.7^{\circ} \mathrm{C}$ higher than that of the period 1986-2005 (Kirtman et al., 2013). Extreme high-temperature episodes will be more frequent over most land areas (IPCC, 2014b). The contrast in precipitation between wet and dry regions and between wet and dry seasons will increase. Average precipitation is likely to increase in high and middle latitudes, and the frequency and intensity of heavy precipitation are also likely to increase on average. Globally, maximum wind speed and rates of precipitation from tropical cyclones are also expected to increase in the long term.

Negative impacts of climate change on forests are already apparent in many places. These changes threaten the delivery of a range of crucial goods (wood and non-wood) and environmental services, which will have far-reaching social and economic consequences for the estimated 1.6 billion people who depend fully or partly on forests, and particularly for the forest-dependent poor (Braatz, 2012).

While some of the problems associated with climate change are emerging gradually, immediate action is needed to build resilience into forests and people's livelihoods. Assessing the vulnerability of forests and forest-dependent people to climate change is an indispensable first step. Identifying the risks posed by climate change and pinpointing the most vulnerable areas and people make it possible to identify measures for adaptation and to target adaptation options for specific contexts.

Vulnerability is a complex concept having many dimensions (environmental, economic, social, political and geographic) whose interactions make it difficult to clarify precise cause-and-effect relationships. Vulnerability is bound to specific locations and contexts. Impacts of climate change, and vulnerabilities to them, vary across regions, social groups and systems (e.g. natural, social, economic, socio-ecological).

Over the past few decades, methods of vulnerability assessment have been developed and documented in a wide range of development-related fields, addressing, for example, natural hazards, food security and poverty, sustainable livelihoods and related fields. Several conceptual models have been developed to provide environmental managers with a framework for understanding vulnerability to natural disasters and how to reduce it, also taking into account the different needs and priorities of men and women, boys and girls.

Vulnerability assessments of forests and forest-dependent people may have diverse purposes and uses. They may be focused on the environmental value of a forest, on how to conserve its biodiversity or on its contribution to livelihoods. They address tree-based systems that differ widely in terms of size, composition, situation and dynamics. Assessments may be limited to present vulnerabilities (sometimes called contextual vulnerabilities) or may estimate future vulnerabilities, accounting for the dynamics and developments with which climate change will interact. This diversity 
of objectives, situations and time horizons, as well as the range of resources that can be devoted to an assessment, have given rise to diverse methodologies. Some are general, while others focus on biophysical, economic and/or social dimensions or are tailored to specific cases.

In this context, the Committee on Forestry (COFO), FAO's global statutory body for forestry, requested at its twenty-third session in July 2016 that FAO "further develop technical guidance for forest vulnerability assessment in the context of climate change, as appropriate". The main purpose of this publication is thus to identify and describe the elements that should be considered in assessing the vulnerability of forest ecosystems and forest-dependent people for different time horizons, and to outline a structured approach for conducting these assessments, taking gender dimensions into account.

The present framework builds on a wide range of methods to provide a single common approach that can be used in a broad range of situations. The aim is to guide practitioners in conducting a step-by-step analysis, to ensure that no critical point is missed and to facilitate the choice and use of appropriate tools and methods. A common framework may also facilitate comparisons, upscaling of results and outscaling in different contexts, making it possible to fill some data gaps.

The framework methodology is aimed at practitioners (including forest owners, managers and administrators in the private and public sectors and in community forestry organizations), land-use planners and other actors and institutions that conduct vulnerability assessments with a forest- and tree-related component. Some general background information is provided, often in text boxes, as it is recognized that such a broad audience may include readers with varying experience in forestry, climate change or assessment practices.

The framework uses the existing body of knowledge related to forest management, climate change adaptation and vulnerability assessments. It builds on a previously published literature review on existing methods for assessing the climate change vulnerability of forests and forest-dependent people (FAO, 2018a) and the experience of FAO and the CGIAR Research Program on Forests, Trees and Agroforestry (FTA). The framework has been developed through a multi-stakeholder process involving technical experts and key stakeholders from civil society organizations, non-governmental organizations (NGOs), the private sector and international organizations.

\section{VULNERABILITY, RISK AND RESILIENCE}

The Intergovernmental Panel on Climate Change (IPCC, 2014b) defines vulnerability as "the propensity or predisposition to be adversely affected", explaining further that vulnerability "encompasses a variety of concepts and elements including sensitivity or susceptibility to harm and lack of capacity to cope and adapt". It is a function of a system's exposure to change, its sensitivity to such change and its capacity to adapt to it (Figure 1). These components of vulnerability are defined as follows:

- Exposure is the presence of people, ecosystems, infrastructure or a species in an area expected to be exposed to changes in climate or to extreme weather, either under present conditions or in the future. 


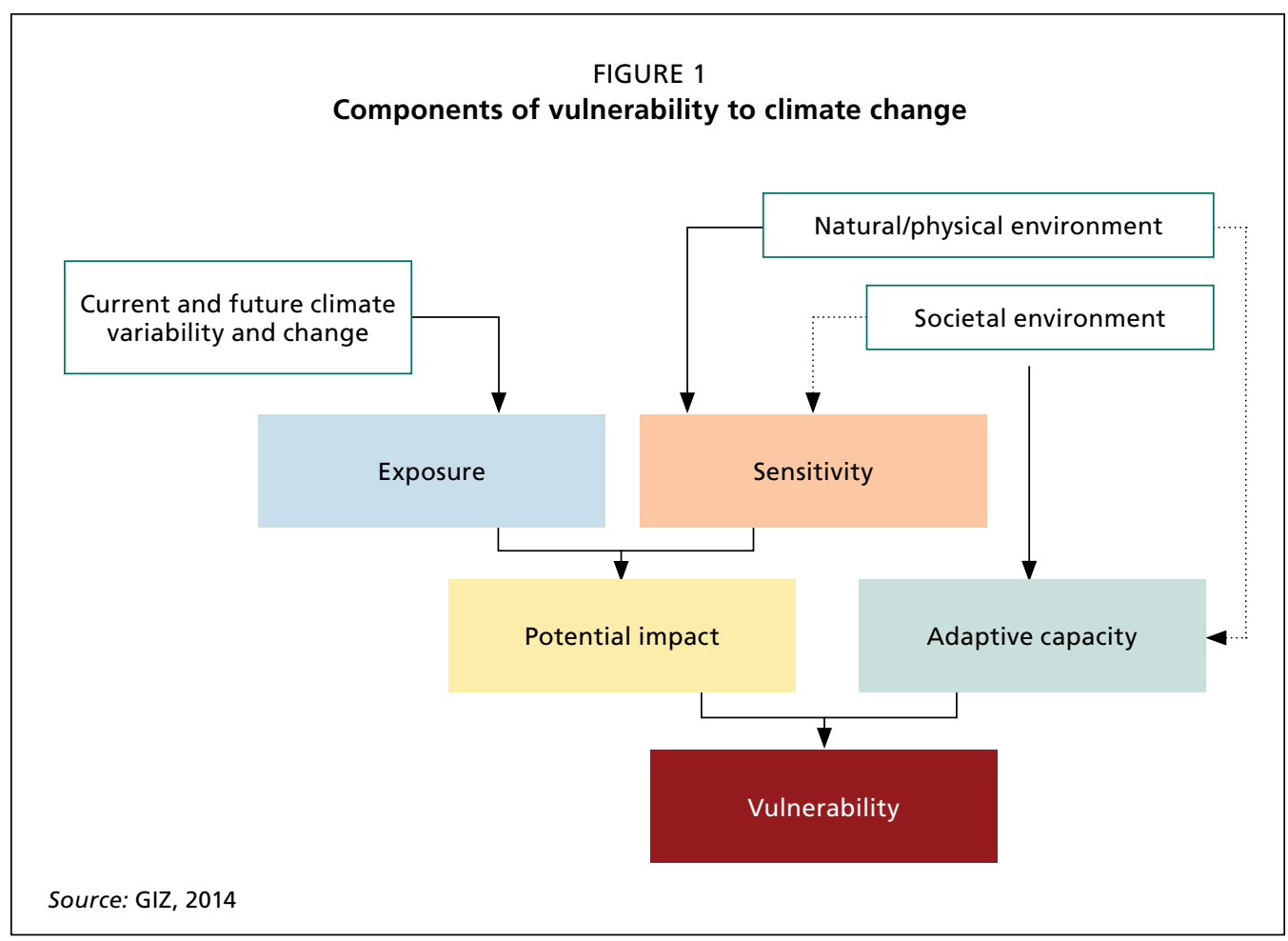

- Sensitivity is the magnitude of the direct or indirect effects of climate or extreme weather, either adverse or beneficial, relative to the climatic event.

- Adaptive capacity is the ability of a system or a species to respond to climate change or a climatic event in a way that reduces harmful impacts.

IPCC (2014b) defines risk as a combination of the likelihood or probability that an event will happen and the consequences if that event were to happen. Exposure, sensitivity and adaptive capacity are thus not only components of the vulnerability of the system; they also contribute to determining risk. In other words, risk only exists in relation to a system where it might occur.

\section{Resilience}

The scientific concept of resilience was initially developed to explain how ecosystems respond to stress (Holling, 1973). The resilience concept has since been applied to projecting how systems may respond to climate change. In this context, IPCC (2014b) defines resilience as: "the capacity of social, economic, and environmental systems to cope with a hazardous event or trend or disturbance, responding or reorganizing in ways that maintain their essential function, identity, and structure, while also maintaining the capacity for adaptation, learning, and transformation".

Thus as defined by IPCC, both vulnerability and resilience are aspects of how a system may be affected by climate change (Figure 2). Vulnerability refers to the harm climate 


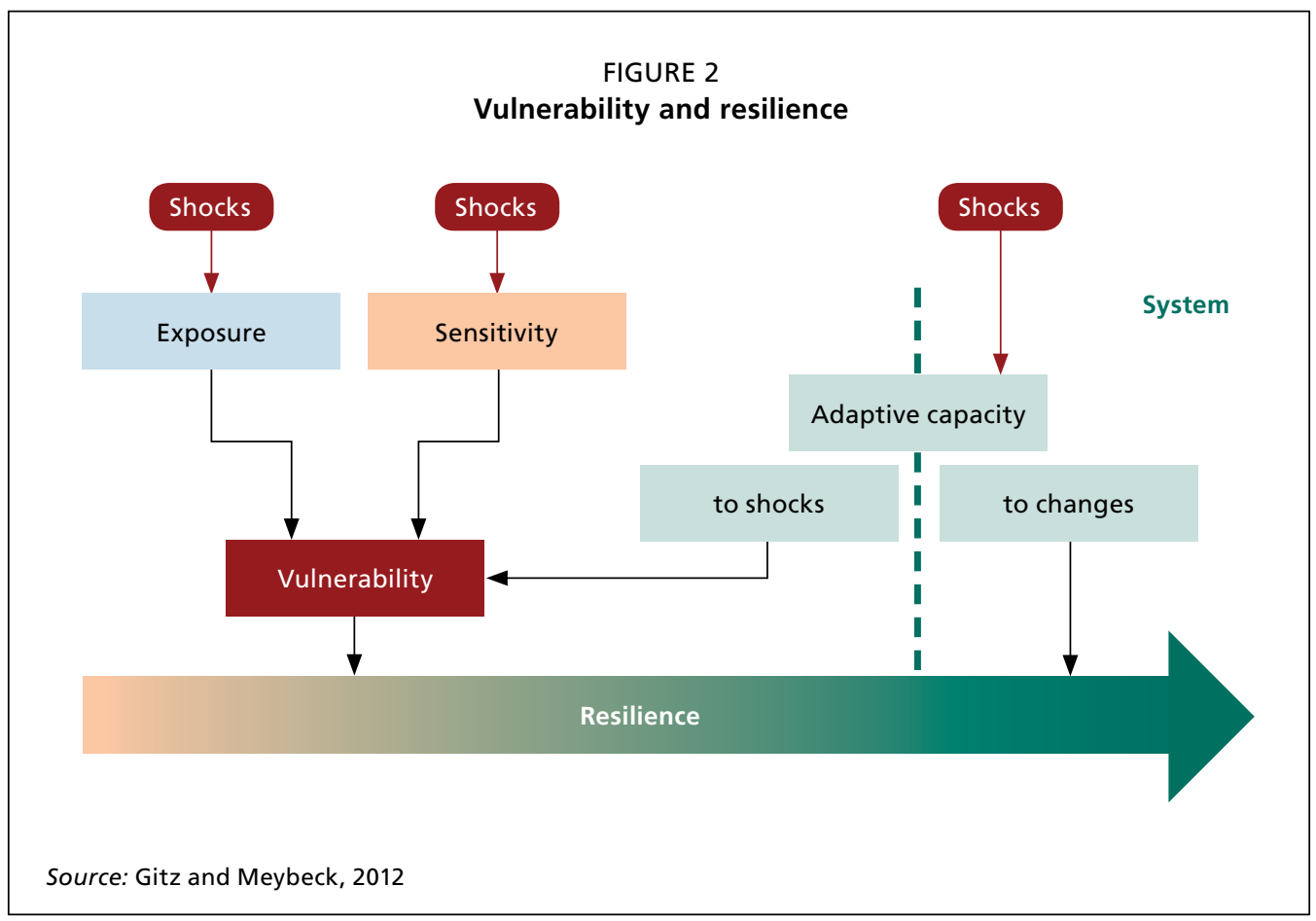

change may cause to the system, while resilience refers to the system's ability to carry on despite exposure to climate change (Brugère and De Young, 2015). Although these concepts are closely linked, they are not opposites, as a system can be both vulnerable and resilient, if it has the capacity to recover from and adapt to damage caused by climate change (Buckle, Marsh and Smale, 2001; Gallopín, 2006).

\section{WHAT IS A VULNERABILITY ASSESSMENT?}

A vulnerability assessment should answer the question "what (or who) is vulnerable to what?" (Gitz and Meybeck, 2012). The first "what" (or who) to be identified describes the social or ecological system that is to be evaluated and which aspects of that system may be at risk. Describing "what is vulnerable" can be done by answering the following general questions (Brugère and De Young, 2015), disaggregating data by sex and age:

- Which people and activities and/or species and processes are vulnerable?

- Where are the vulnerable people and systems located?

- Who or what will experience the greatest consequences (economic or social) because of their vulnerability?

- Where and for whom might climate change result in opportunities and benefits? The second "what" describes the aspects of climate that create risk.

Clarifying both parts of "what is vulnerable to what" is essential to determine the scope and focus of a vulnerability assessment. Within that scope, the vulnerability assessment will evaluate the system's potential exposure to the climatic risk that was 
identified, the sensitivity of the system to that climatic risk, and the system's capacity to adapt to the climate risk (Füssell and Klein, 2006).

In theory, assessment of vulnerability to climate change should take into account both the evolution of the system and the pressures and risks with which it will be confronted. This raises complex methodological issues.

The climate changes themselves may be relatively easy to predict (albeit with a level of known uncertainty) using projection models based on historical meteorological information. It is much more difficult to project the future vulnerability of a complex system such as a forest and the people that depend on it, given the number of parameters that must be taken into account. Some of these parameters change slowly, such as the optimal conditions for a species or even for a particular type of ecosystem. However, all parameters of vulnerability that are driven by human activity, institutions, economy, social organization and even forest management can change dramatically in 30 years. Most of these changes are difficult to model or predict with accuracy. Indeed, one of the main purposes of a vulnerability assessment is to orient these changes in order to reduce vulnerability.

The vulnerability of a system to a specific risk can be determined by one factor or, more often, several combined. Forest fires provide a good example. Drought increases the risk of forest fires. The vulnerability of the forest will depend on the amount of dead biomass, which in turn depends on the way the forest is managed, the amount of dead trees resulting from previous droughts and/or pests, the spatial organization of the forest (e.g. the presence of buffer strips and fire breaks), which could facilitate or constrain the spread of the fire, and the openness of the forest to human activities. Finally, its vulnerability will depend on the means of preventing and monitoring fires and addressing them at an early stage. The importance of potential impacts is determined by a combination of biophysical, economic and institutional factors which can either augment or limit one another. Landscape, community and institutions can all buffer the consequences of hazards, thus helping to reduce the vulnerability of households. Analysis of such combinations is particularly important in determining areas of action; it can lead to the identification of links among different vulnerabilities and risks, and can also shed light on some broad contextual factors that may cause vulnerability to most risks. For instance, forest degradation and deforestation increase the vulnerability of a forest to many of the impacts of climate change and are often perceived as greater and more immediate threats to tropical forests than climate change (Guariguata, Locatelli and Haupt, 2012).

\section{MOVING FROM VULNERABILITY ASSESSMENT TO ADAPTIVE MEASURES}

If adaptive capacity is the ability of a system or species to adjust in response to the challenges or benefits brought about by climate change, then adaptation refers to the specific changes that are implemented to reduce impacts on human or biological systems or to take advantage of beneficial opportunities (IPCC, 2014b). While mitigation is the best way to reduce climate change impacts, adaptation is necessary when mitigation options have been exhausted. Adaptation includes not just the measures that will be taken, but also the decision-making process for identifying vulnerabilities and setting priorities for adaptation (Nelson, Adger and Brown, 2007). 
Adaptation may occur through incremental change or may result in the transformational change of a system (IPCC, 2014b). Incremental adaptations are intended to preserve the essential nature and benefits provided by a system in spite of climate change, allowing a "system to better cope with, manage or adjust to some changing condition, stress, hazard, risk or opportunity" (Smit and Wandel, 2006). Incremental adaptations promote a system's resilience, as resilience reflects the capacity of a system to respond to climate change while maintaining the system's essential function and structure (IPCC, 2014b). In contrast, transformational adaptation alters a natural or human system's basic characteristics and occurs when conditions become so severe that the existing system can no longer be supported (Park et al., 2012). Transformational adaptation aims to produce a new system that has higher resilience and lower vulnerability than the system that it replaces. The major difference between incremental and transformational adaptation can be stated in terms of their goals: incremental adaptation aims to maintain the services provided by an existing system, and transformational adaptation seeks to create a new system with its associated services. The distinction between incremental and transformational adaptations may not always be sharp (Nelson, Adger and Brown, 2007).

A vulnerability assessment can point to adaptations that reduce the risk of damage to social or ecological systems. Identifying which aspects of a system are sensitive to climate change is the first step in developing adaptations to reduce those sensitivities. Similarly, when a vulnerability assessment reveals that a system lacks adequate adaptive capacity, then adaptations can be carried out to increase this capacity (GIZ, 2014). Actions that increase adaptive capacity may also increase the range of options available for adaptation, so that the adaptation process may be cyclical rather than static (Figure 3). In cases where a vulnerability assessment has revealed that a system is highly exposed to climatic stress,

FIGURE 3

The relationship of adaptation measures to factors that affect

the vulnerability and resilience of ecosociological systems

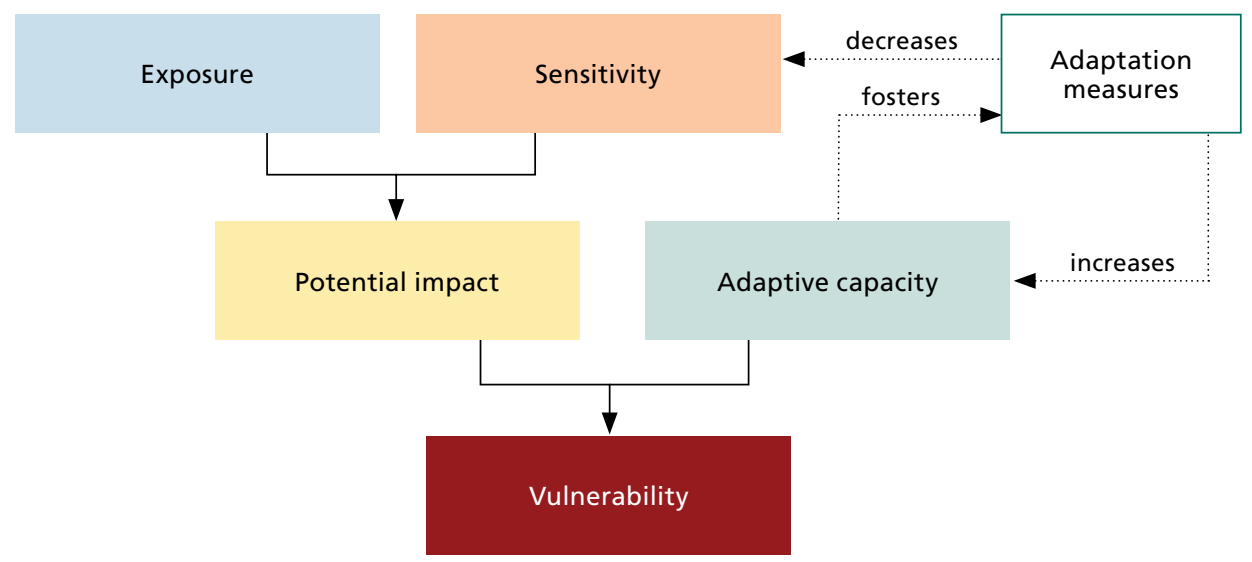


vulnerability may be reduced by implementing adaptations that reduce sensitivity to the identified stress. Examples include restoring mangroves to protect fields from sea-level rise or planting more drought-resistant species or varieties.

As a general principle, adaptation to climate change should support the goals of conservation and sustainable management of forests (Ogden and Innes, 2007), as embodied in the United Nations Sustainable Development Goals. Incorporating adaptation into sustainable forest management helps to ensure that adaptation aligns with other forest management objectives and that the economic, social and environmental values of forests are taken into consideration (FAO, 2013). Sustainable forest management is the primary vehicle for implementing adaptations to reduce the vulnerability of forests. Indirectly, adapting forests to climate change can also reduce the vulnerability of forest-dependent people to climate change.

Integrating vulnerability assessments into the process that forest managers use for forest management planning will facilitate adaptation efforts. Vulnerability assessments and monitoring provide forest managers and community members with important tools to evaluate what is at risk and can point them towards adaptation measures relevant to their forests and communities (Guariguata, Locatelli and Haupt, 2012). As vulnerability is subject to change over time, a vulnerability assessment of a forest or a community is not a conclusion, but rather a point on a continuum of vulnerability and adaptation over time. Together, vulnerability assessments and monitoring are part of a cyclical process for adaptive management that considers the risks posed by climate change and measures to adapt to those risks. Incorporating climate change into forest management and community development in this manner is important to support the long-term ecological sustainability of forests and to provide for the needs of forest-dependent people. However, integrating climate change adaptation into forest management can present challenges if doing so conflicts with use of the forest by communities that depend on it - for example, if adaptation measures emphasizing forest protection interfere with subsistence uses (Mimura et al., 2014).

FAO (2013) has developed a framework process for integrating adaptation into forest management plans and implementing adaptation into forestry practices (Figure 4), in which vulnerability assessment is seen as part of the adaptive management cycle. Forest monitoring and evaluation provide information on forest responses to climate, which supports the vulnerability assessments. The vulnerability assessment process is used to identify areas where adaptation is needed to reduce impacts. Adaptation options are then evaluated based on cost-benefit analysis, the prevailing policies, financial and technical incentives, and the availability of support for implementing adaptations. Forest management plans are then amended to incorporate adaptation measures, leading to the next round of forest monitoring and evaluation.

Although forest vulnerability assessments may identify vulnerabilities that will arise in the future, the measures to address these vulnerabilities may require action in the present. Adaptation measures that require changes in tree species have long lead times because of the slow growth of trees. If a vulnerability assessment indicates a long-term risk of drought, for example, it can take decades to shift forest tree species composition in favour of more drought-tolerant species. 
FIGURE 4

Framework for integrating adaptations identified in vulnerability assessment into forest management planning and monitoring programmes

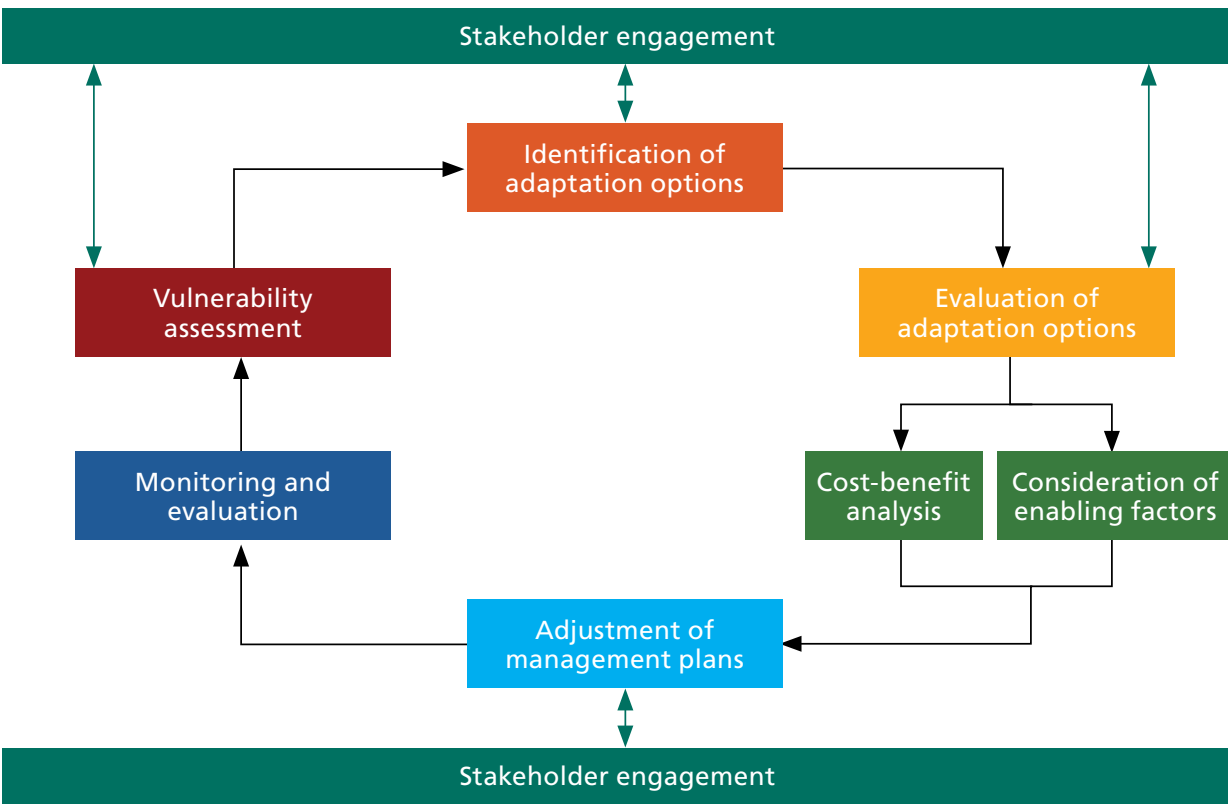

Source: Adapted from FAO, 2013, with additions from Schipper et al., 2010

Adaptations intended to address future climate risks involve greater uncertainty. Projections of future climate are approximate, and the responses of socio-ecological systems to future climate are difficult to predict precisely, as many ecological processes are imperfectly understood. Programmes to monitor forest condition can identify emergent problems caused by current climate change so that they can be addressed through silviculture and management planning (Spittlehouse and Stewart, 2003). Ideally, monitoring to identify impacts of current climate change will be complemented by vulnerability assessments that consider current and potential future impacts (Yousefpour et al., 2012).

Adaptive management is particularly relevant in environments where the future is uncertain (Robledo and Forner, 2005). Adaptive management involves a systematic process for continually adjusting and improving management practices by monitoring, analysing and learning from the outcomes (Seppälä, Buck and Katila, 2009). This process of observation, analysis, planning, implementing, monitoring and taking corrective action for further improvement is in itself a valuable adaptation tactic, particularly where the speed, direction and impacts of climate change are difficult to predict. Setting up systems for forest management conducive to adaptive management can help to keep improvements in resilience in step with climate changes. 


\section{USING THE FRAMEWORK METHODOLOGY}

The framework methodology presented in this publication is designed for assessing the vulnerability of forests and forest-dependent people on widely varying scales and in different contexts, for different purposes and with varying availability of data and resources. The intention is to ensure proper consideration of all relevant issues and of all the various elements and relations that constitute the socio-ecological system.

The framework is organized in a progressive and modular way. Following the exploratory phase, in which objectives, scope and resources are defined, the assessment starts with analyses of the situation of the forest and trees, its legal status and governance and its functions for people. These analyses are focused on compiling an adequate picture of the forest and the people depending on it. The objective is to have a clear understanding of the system, of the relations between the different elements and of the underlying vulnerabilities of both forests and people. The analyses rely on desk studies, consultation of experts and in some cases (depending on time and resources available) complementary studies. The findings from these can be submitted to a participatory exercise that could, in particular, help to define livelihoods and people's vulnerabilities. The results of the consultation may indicate the need for additional studies. As appropriate and depending on the time horizon of the assessment, these analyses include non-climate-related factors and changes.

Next comes analysis of the climate-related risks and vulnerabilities of the forest and trees, followed by consideration of how these translate into vulnerabilities for forestdependent people (considering their other vulnerabilities as well as their capacities). The assessment concludes with analysis of the links among the critical points identified, in order to highlight the main points of vulnerability, as well as to identify, if possible, those that could be most easily addressed and how best to do so.

The framework could broadly represent a skeleton of the outline of the final assessment document. In practice, however, the implementation of the assessment will often be determined by contextual factors, and in particular by collection of information, availability of data and resources, with iterations between desk and field studies and vice versa. This will render the report writing non-linear. 
(1)

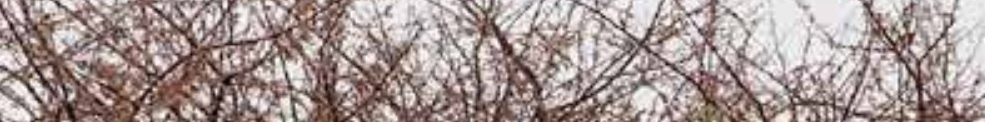

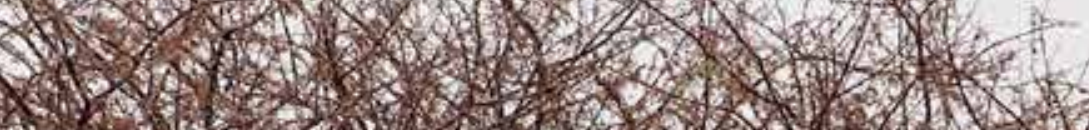

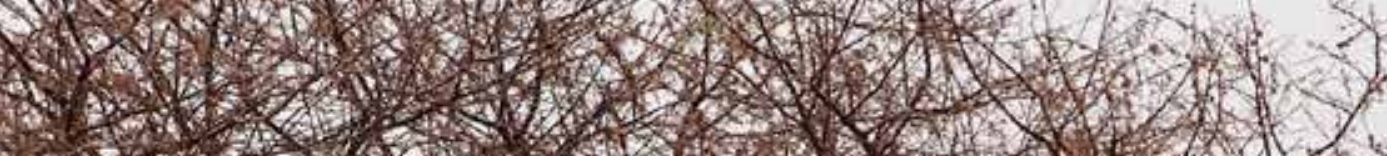

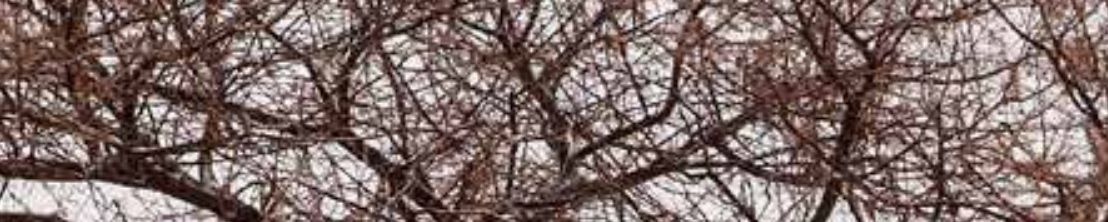

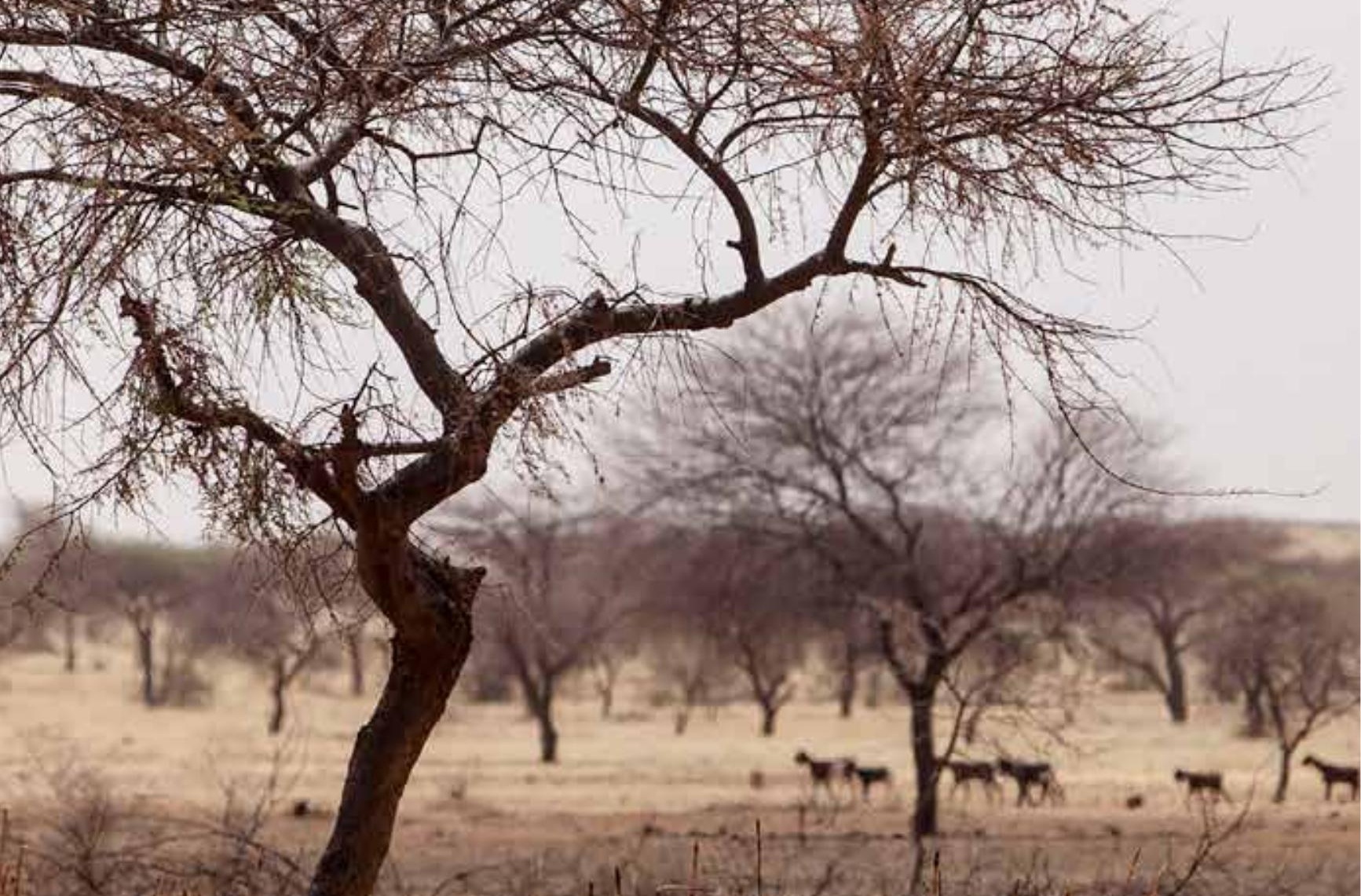

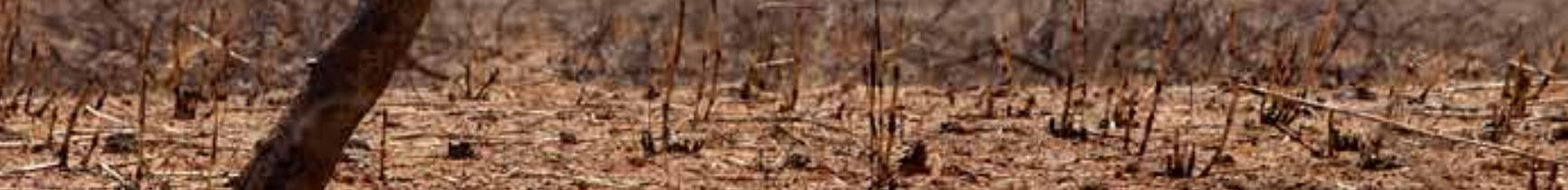

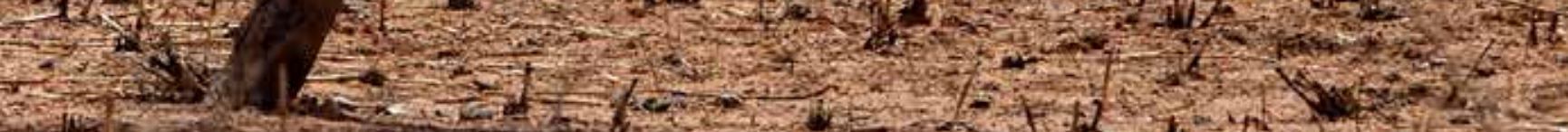

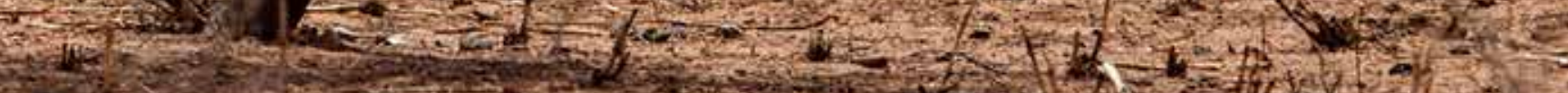

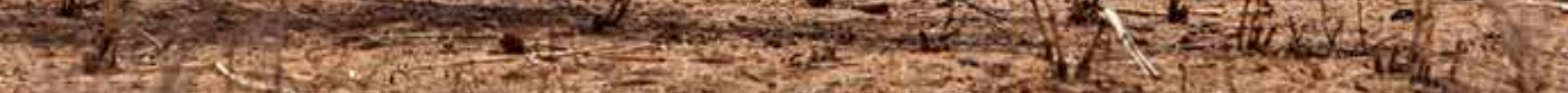

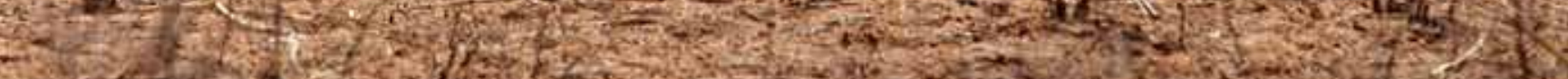

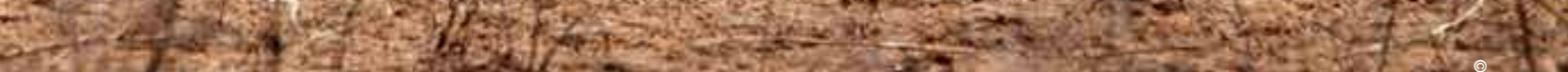

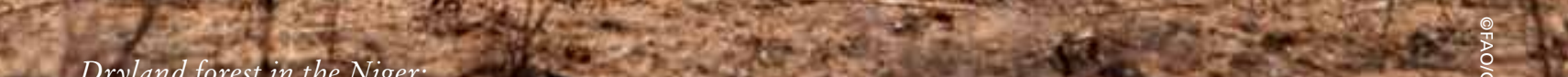
4.0.0. 1.

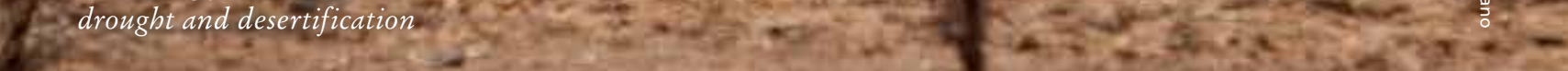




\section{Defining the objectives, scope and means}

The first (exploratory) phase of a vulnerability assessment is to consider its objective; spatial, temporal and thematic scope; and the resources needed and available, including human and financial resources, technical competencies and data. The preliminary priority interests should be determined, setting the context within which the assessment will be conducted and helping to define the appropriate means for carrying it out. Once the boundaries of the project area are determined, this phase requires the collection of some preliminary information on forests and forest-dependent people within the area.

The initial appraisals may be modified in the course of the assessment, as preliminary findings may result in the emergence of new priorities, which may call for additional studies and new resources.

\section{IDENTIFYING THE PROJECT TEAM}

The initial composition of the project team should be designed to include a collective skill set appropriate for the assessment. Buy-in should be obtained from the project team's organization(s) and from those organizations that will be asked to provide input or human and financial resources to the assessment. If need be, the project team can be revised at the end of the scoping phase (see below).

\section{DEFINING CLEAR OBJECTIVES}

The project team should develop an initial statement of objectives for the vulnerability assessment. The initial scope and objectives are likely to be defined by the organization mandating the assessment, and any modifications to the original objectives should be agreed with the organization. The reasons for modification should be clearly documented, as they may be relevant to the assessment itself.

The target audience for the results should be confirmed, and the objectives of the vulnerability assessment should be reviewed to evaluate whether the project, as envisioned, addresses that audience's concerns.

\section{SCOPING}

The scope includes the geographic area, the main forest functions and the concerned populations to be evaluated, as well as the time frame the assessment will consider (current or future vulnerability). Even at this early stage, it is useful to have some preliminary idea of what the most critical areas of interest could be, in order to prioritize the use of resources. Which aspects of climate change can constitute risks? Warmer temperatures? Reduced precipitation? Exposure to extreme events such as droughts, 
heavy rainfall, high winds or frost? These areas of interest may be modified in the course of the assessment.

The project team should conduct an initial brainstorming of the impacts that are potentially important for the vulnerability assessment (i.e. refine the main objectives of the assessment and identify what is vulnerable). Are the concerns primarily about ecological risks (e.g. species, ecosystems, ecological processes) or are they more focused on risks to vulnerable people (e.g. subsistence uses of forests, livelihoods that depend on forests)? Or are the needs related to both forests and people? Does climate change create risks via direct cause and effect, or through multiple pathways? For example, high temperatures can have direct impacts on a system but can also have indirect effects by causing drought.

\section{Geographic location(s) and scale}

Is the vulnerability assessment to address concerns for local small-scale forests ranging in size from several hundred to a few thousand hectares, or for a local community? Is it to cover multiple local forests and communities? Or is it a regional assessment covering thousands of hectares of forest or large numbers of people in many communities across a region?

\section{Time frame}

Is the chief concern vulnerability to current climate and extreme weather, or vulnerability in the near-term future, or both? When assessing vulnerability to climate change, the objective is generally to assess vulnerability to future conditions and hazards. Predicting vulnerabilities more than 30 years into the future is generally not considered useful for adaptation planning (GIZ, 2014); however, there may be circumstances that support an assessment of vulnerabilities beyond that time frame. For example, decisions on land-use planning or on which species and varieties of trees to plant or favour in a forest management plan might require a longer time horizon of 50 or even 100 years, even with uncertainty.

\section{MEANS AND RESOURCES}

The information, financial and human resources, and time needed and available for conducting a vulnerability assessment depend on factors such as the area of the forest and its economic importance. In terms of human resources, additional support may be needed if the project team's technical skill set does not cover all the skills that are needed.

Information needed in the assessment will cover the current state of the forest, the services the forest provides to forest-dependent people, and the human, financial and institutional resources available to the community to avoid or reduce the impacts of climate change. It is important to determine early in the preparation of the assessment what information is available, whether critical information is missing and how such gaps can be filled, for example by collecting data or by using proxies (Box 1). This exercise will help to concentrate efforts on the most important aspects, keeping in mind that these may change in the course of the assessment. 


\section{BOX 1 \\ Addressing data challenges: the use of proxies}

Lack of data, or lack of confidence in them, is perhaps the largest constraint to the rigour and reliability of vulnerability assessments (Brugère and De Young, 2015), particularly where quantitative methodologies are used. For example, gender-disaggregated data are frequently unavailable. Resources may be insufficient for gathering all the needed information.

These shortcomings can be partially overcome through mixed approaches, cross-referencing or alternative means of information collection. Where data are lacking, it may be necessary to use proxies, at least for some types of information. Proxies may include:

- available data that are correlated to the unavailable data;

- data and information gathered on a broader scale;

- data and information available for a comparable case.

Where proxies are used, it is important to highlight the specificities of the forest considered and their influence on the applicability of the information to the specific case.

The validity of proxies can either be tested on a sample or validated through expert consultation and/or participatory approaches.

A preliminary analysis of the current status of the forest and forest-dependent people can be carried out to help to identify information gaps that the assessment should address. It is also beneficial to investigate other ongoing activities that the project may be able to support. For example, is a forest management plan being prepared to which the vulnerability assessment could provide valuable information?

\section{DEFINING THE APPROACH}

The initial scoping exercise provides information that will enable the project team to identify approaches that could be used to carry out the vulnerability assessment, for instance modelling or participatory workshops. The project team should also begin to engage with expected participants in the assessment, such as members of local communities, technical experts or representatives of forest industry, government or NGOs.

In defining the approach, the project team should establish an outline of the major steps in the assessment; decide who will have responsibility for which steps; identify institutions with which the team should coordinate activities; and establish timelines for each step in the project.

\section{Contextual versus outcome assessment}

Using the results of the scoping exercise, the vulnerability assessment can be classified according to whether it considers vulnerability in relation to a given change - the so-called "outcome" approach - or focuses on the characteristics of the system that 
may affect its vulnerability to current or future changes - the "contextual" approach (Table 1).

- A contextual assessment usually evaluates the vulnerability of communities or ecosystems to current climate. It considers climate and social factors, with the ultimate aim of making conditions better for people, or improving forest sustainability, in the present. Contextual assessments often address complex multifaceted problems concerning current socio-ecological and climate-related issues.

- An outcome assessment usually evaluates the biophysical impacts of future longterm climate change on a biological system or human infrastructure. Biophysical impacts on systems are evaluated using a combination of current climate and future climate change scenarios. Outcome assessments are often carried out using biophysical approaches, examining cause-and-effect responses to present and future climate or extreme weather.

The outcome approach is more effective for considering future events than the contextual approach, which allows a more complete consideration of the present situation. The two approaches are nevertheless complementary, even if they are difficult to integrate in a common framework.

One of the benefits of classifying a vulnerability assessment in this way is that it can help to clarify the resources needed to carry out the vulnerability assessment and the types of approaches that will be used to obtain data and information. The decision about whether to conduct a contextual or outcome assessment will depend to some extent on where adaptation efforts will eventually be needed. If the emphasis is on forest-dependent people with limited resources to carry out adaptations, a contextual assessment with a focus on improving their present-day situation is often advisable. In contrast, an outcome assessment is often more suitable for assessment of forests, as it provides information about current and future vulnerabilities, supporting forest adaptations that have long lead times for implementation.

TABLE 1

Key features of the outcome and contextual perspectives

\begin{tabular}{lll}
\hline Perspectives & Outcome vulnerability & Contextual vulnerability \\
\hline Root problem & Climate change & Social vulnerability \\
\hline Policy context & $\begin{array}{l}\text { Climate change mitigation, } \\
\text { compensation, technical adaptation }\end{array}$ & Social adaptation \\
\hline $\begin{array}{l}\text { Relationship between vulnerability } \\
\text { and adaptive capacity }\end{array}$ & $\begin{array}{l}\text { Adaptive capacity determines } \\
\text { vulnerability }\end{array}$ & $\begin{array}{l}\text { Vulnerability determines } \\
\text { adaptive capacity }\end{array}$ \\
\hline Starting point of analysis & Future climate hazards (scenarios) & $\begin{array}{l}\text { Current vulnerability to } \\
\text { climate change }\end{array}$ \\
\hline Dominant discipline & Natural sciences & Social sciences \\
\hline Meaning of vulnerability & $\begin{array}{l}\text { Expected net damage for a given } \\
\text { level of global climate change }\end{array}$ & $\begin{array}{l}\text { Susceptibility to climate } \\
\text { change and variability } \\
\text { as determined by socio- } \\
\text { economic factors }\end{array}$ \\
\hline
\end{tabular}

Source: O'Brien et al., 2004, 2007 
In many cases, a vulnerability assessment of a forest and the people that depend on it will combine (often implicitly) an outcome perspective - what will happen in the event of such a hazard in the future - with a contextual analysis of the system as it stands, or as it will be if modified by some known or predictable trends. The assessment will thus mainly identify present vulnerabilities to present and future risks. This approach enables decision-makers and all actors to see clearly what could happen if appropriate measures are not taken, and it is a good way to engage them to take such measures, as it first addresses present risks. Addressing present risks often offers opportunities for no-regret options and is often the best way to prepare for future risks, especially given their uncertainty, by building resilience and sustainable livelihoods.

\section{Identifying general methods}

Several methods have been developed to assess vulnerability of ecosystems and communities (see some particularly relevant examples in Box 2). They differ in focus, conceptual and disciplinary background, data and resource needs, scale and temporal horizon. Most vulnerability assessments will need to combine various methods.

Vulnerability assessment methodologies are often categorized as quantitative or qualitative or as top-down or bottom-up (Brugère and De Young, 2015; GIZ, 2014). Topdown methods - those based on the handling of data by scientists with no direct inputs from beneficiaries (e.g. statistical analysis, modelling, downscaling) - are often used to

\section{BOX 2}

\section{Some well-known approaches to vulnerability assessment}

The sustainable livelihoods framework (Scoones, 1998; DFID, 1999) was developed to guide interventions aimed at reducing poverty and promoting sustainable livelihoods. In this perspective, vulnerability is influenced by governance processes, with consequences for the natural, human, financial and social capital that sustains livelihoods. This framework is particularly useful for considering vulnerability at household level and examining how the entitlements on which livelihoods depend can be improved by social relations, institutions and organizations (HLPE, 2013).

The institutional analysis and development framework (Ostrom, 2011) identifies the characteristics that are key to organizing social interactions and decision-making processes: institutions and rules, characteristics of the community, and attributes of the physical environment within which the community acts. This framework improves understanding of how the community can adapt to external stressors, for example by modifying its relations with its physical environment.

The resilience approach involves broad consideration of how a system reacts to changes, integrating very different factors, including environmental and social. It can thus be particularly useful for grounding an analysis intended to lead to integrated approaches, such as ecosystem-based adaptation. 
describe and assess the vulnerability of biophysical systems. Bottom-up approaches - those that rely on iterative and participatory processes with the beneficiaries - are of particular use to describe, understand and assess the vulnerabilities of socio-economic systems. Often a vulnerability assessment will combine top-down and bottom-up approaches, including stakeholder engagement, action research and social learning. It may start, for instance, with a literature review and/or an expert consultation and then use preliminary findings to inform a participatory workshop, which can identify priority issues that merit more data collection or a study such as a modelling exercise. The findings would then again be discussed in a participatory workshop (Miller et al., 2010).

A variety of approaches can be used to obtain input, depending on the nature of the participant group. Subject matter experts may be successfully engaged using written surveys. Facilitated workshops may be more effective for engaging local citizens, representatives from government and NGOs and forest-sector workers.

Data obtained from various sources (quantitative and qualitative, with different levels of certainty) can be combined through various means. The vulnerability sourcebook (GIZ, 2014) provides guidelines for normalizing indicator data measured on different scales and in different units. A common way of combining information from different sources is to use participatory methods to identify critical points and priorities. Diverse data can also be combined using scorecards or mapping of issues.

If participatory exchanges will be used, it is necessary to define who should be involved and the exercises that will be carried out to obtain feedback from participants. See Ampomah and Devisscher (2013) for examples of some participatory exercises that can be modified to address questions specific to forest-dependent people.

\section{Implementation plan}

A plan should be prepared for implementing the assessment. To make it possible to present the findings from desk and scientific studies during the participatory exercises, the plan should call for launching long-term studies first, keeping in mind that a need for complementary studies may emerge during the analysis.

Depending on the circumstances, the plan could include one or several participatory exercises. If there are several, it would be better to include the same participants, which might be difficult. In any case the plan should include presentation and discussion of the final results with the participants.

\section{ENGAGING WITH STAKEHOLDERS}

In addition to seeking agreement from the parties that will be involved in the vulnerability assessment, the project team needs to ensure that the assessment is approached in a manner that respects the cultural identity, values and practices of the participants. Infield and Mugisha (2010) and UNESCO (2011) describe some of the challenges and approaches to ensuring that a vulnerability assessment is undertaken in a culturally appropriate manner.

The implementation of adaptation measures can be facilitated if vulnerability assessments are integrated into the existing frameworks used for forest management 
or for community development (see Figure 4, page 8). Such integration can be helped by obtaining input to vulnerability assessments from commercial enterprises that use forests; from NGOs concerned with forest issues; from governments at local, regional and national levels; from groups that represent local interests; and individually from people who use forests and trees outside forests for subsistence purposes. While obtaining such broad-ranging input can be a formidable undertaking, the vulnerability assessment will usually be more effective if it has been formulated with participation from concerned parties, and adaptation options produced from it will be more likely to gain broad acceptance.

It is important to consider at the planning stage of a vulnerability assessment that the process used to frame "Who is vulnerable to what?" will affect the adaptation options that eventually emerge. Thus, representatives from forest communities, local government, NGOs and forest-related industries should be consulted during the framing phase of a vulnerability assessment to tap into their knowledge about their communities' exposure, sensitivities and adaptive capacity, and to ensure that the ensuing adaptation strategies account for the needs of those communities (Smit and Wandel, 2006). A participatory approach to identifying adaptation measures can help in identifying and weighing trade-offs between measures for reducing impacts of future climate change risks and measures addressing present-day climate impacts that are already affecting people (Nelson, Adger and Brown, 2007).

Individuals who rely on forests for subsistence uses are often among the most susceptible to harmful impacts from climate change. They are also often disempowered, with little influence on decisions about forest management, about how forest vulnerability assessments should be conducted and about the adaptation measures that should be implemented. One of the greatest responsibilities of the vulnerability assessment team, therefore, is to see that the needs and rights of forest-dependent people are accounted for when a vulnerability assessment is carried out and adaptation measures are being identified.

People who depend on forests for subsistence uses often do so because of their underlying poverty and lack of other options. Poverty is not only a root cause of forest dependence, but also a factor that in general increases vulnerability to climate change (Rochester et al., 2016). In developing countries, poverty makes responding to climate change especially difficult, as human and financial resources for implementing adaptations will often be lacking (Schipper et al., 2010). Therefore, assessments of the vulnerability of rural communities in developing countries will often identify contributing factors that are tied to poverty (Butler et al., 2016). For the same reason, some adaptation measures will inevitably involve efforts to alleviate poverty. In many cases, issues of forest landownership and community access and rights to forest resources will be closely linked to the poverty-vulnerability cycle (Brockhaus, Djoudi and Locatelli, 2013; Sunderlin, Angelsen and Wunder, 2003). 



\section{Describing the situation and state of the forests and trees}

Most assessments will consider forests and tree systems in a broad sense, to include naturally regenerated forests (with and without evidence of human activities); planted forests; other wooded land; and other land with tree cover, including groups of trees and scattered trees in agricultural landscapes, agroforestry systems and urban areas ("trees outside forests").

Forests are extremely diverse, depending on both the geographic situation (latitude, elevation, topography, slope, temperature, rainfall patterns, soil composition) and human activities. It is important to understand actual or potential changes of forests and trees in the landscape over time, as these changes will often influence their vulnerability to climate change and other stresses, as well as their capacity to contribute to human well-being.

Historically, countries have experienced phases of decreasing and then increasing forest area, with changes in both type and amount of tree cover in landscapes. The forest and land-use transition curve (Figure 5) illustrates the link between various management regimes and the "evolution" of forest and tree cover loss and recovery (Mather and Needle, 1998). The movement of a country or region along this transition curve has tended to follow demographic change and economic development.

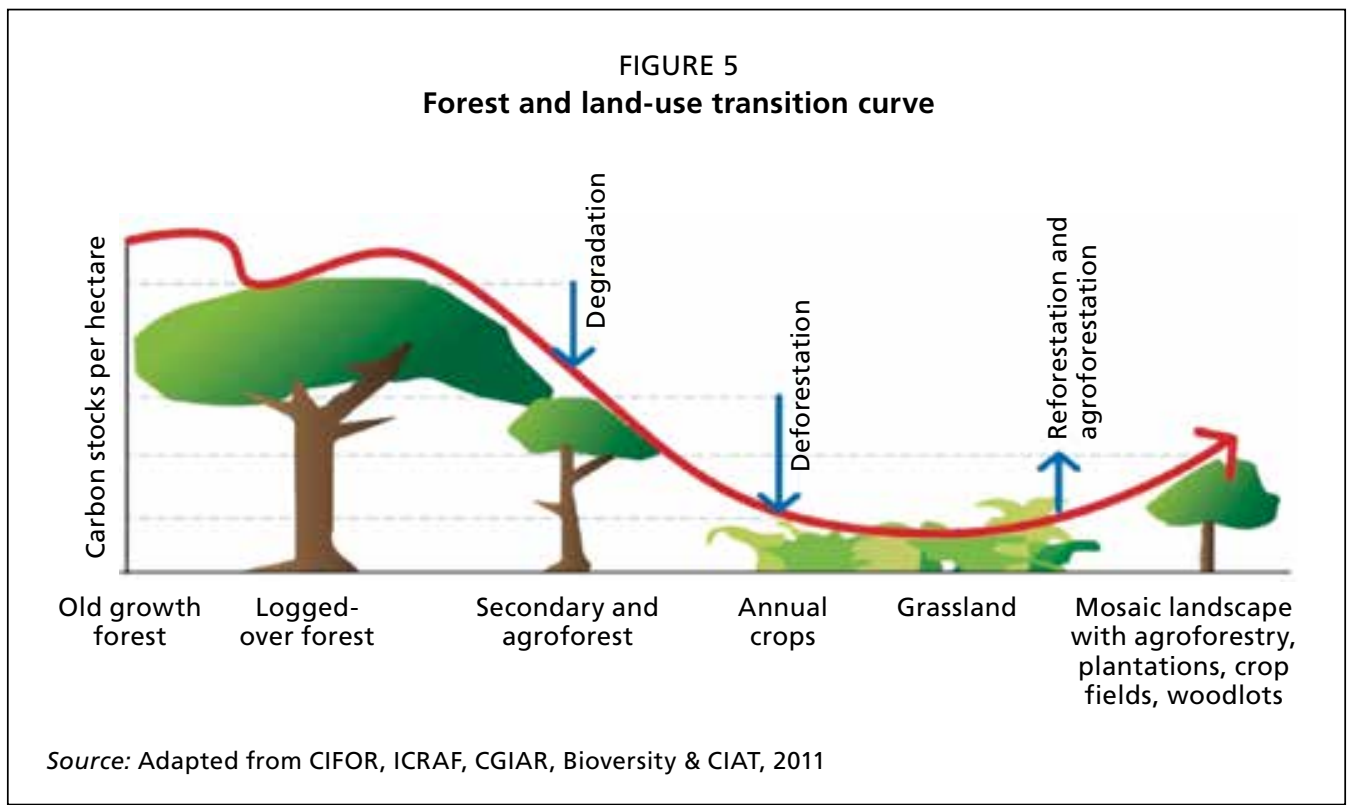


In many areas of the world, forests and tree systems are evolving rapidly, influenced by many factors at the local and global levels, including increasing demands on land and forests, abandonment of some agricultural areas and environmental concerns. These factors can profoundly modify their vulnerability to climate change, especially in the medium-term perspective.

\section{BIOPHYSICAL SITUATION}

The situation of a forest (or trees outside forests) within the landscape determines in large part its exposure to climate change risks and to other risks, including deforestation and degradation; its contribution to human well-being; and its adaptive capacity.

Geophysical factors need to be considered. Altitude (average and distribution) influences both exposure to climate change and adaptive capacity, as an altitude gradient can offer possibilities for species to move more easily to cooler areas. Slope influences water circulation and erosion, which can be intensified by increased precipitation. Proximity to important waterways should be noted, for their relevance to the forest's water regulation services downstream. In coastal areas, proximity to the sea determines potential impacts of sea-level rise (including indirect effects through salinization of the water table). Mangrove ecosystems, in particular, face numerous threats and are sensitive to climate change impacts, particularly to sea-level rise (see Ellison [2012] for a specific methodology for assessing the vulnerability of mangroves).

Urban forests also deserve consideration, as they will be particularly important to reduce the heat-island effect in cities (and are accordingly promoted in many national adaptation plans) but are themselves particularly vulnerable. FAO's Guidelines on urban and peri-urban forestry (Salbitano et al., 2016) can support such analysis.

Proximity and/or linkage to other comparable forests should be noted, as this can facilitate the movement of animal species and seed dispersal and thus increase adaptive capacity on the one hand, or facilitate the spread of pests and diseases on the other (particularly in the case of monospecific plantations), which would be a vulnerability factor.

\section{BIOLOGICAL COMPOSITION OF THE FOREST}

The composition, diversity and distribution of species within a forest are major factors in its sensitivity to climate change and its value for humans. A simple characterization of the forest, in terms of ecosystem, forest type and structure and/or major species of interest, can help in refining the main conservation objective(s): conserving a whole ecosystem deemed remarkable, protecting the habitat of endangered species, and/or ensuring that the system is diverse enough to ensure sustainable provision of ecosystem services. Such an approach makes it possible to determine some species of particular interest which can then orient analysis on the potential impacts of climate change.

For planted forests, tree plantations and trees on farms, the composition of species and varieties is related to the expected economic return. Including information on the distribution of species and varieties will make it possible for the analysis of potential climate change impacts to address potential effects on income, and thus on people. 
It is also important to draw attention to those species that, while perhaps marginal in terms of distribution or income generation, could be of interest as substitutes for major species and/or as sources of food and/or income in times of crisis. Such species may become key assets for building adaptive capacity.

The analysis can make use of more detailed descriptions and studies from comparable situations. The availability of information on the composition of the forest is variable and depends on the forest's recognized importance for economic or conservation reasons, on the history of its exploitation and on its legal status. Forests with biodiversity conservation interest have often been the object of study by environmental agencies, academics and/or environmental NGOs. Existing information can be augmented through consultation of experts.

\section{CURRENT STATE OF THE FOREST}

The current state of the forest (or trees outside forests) can be described in terms of the physical conditions and the factors that have affected the forest in the past, leading to the current state. Description of the physical state includes the forest species (including important non-tree species), tree ages and/or size distributions. A more detailed physical description could delineate ecological zones within the forest, indicate the presence of rare species and ecologically unique areas, and identify areas of historical abiotic and biotic disturbance. For large and/or heterogeneous forests, zoning for differentiated management may be useful where it does not already exist.

Forest health and vitality are determined by considering a range of factors such as age, structure, composition, function, vigour, the presence of unusual levels of insects or disease, and resilience to disturbance. It should be recognized that the perception and interpretation of forest health and vitality is influenced by individual and cultural viewpoints, land management objectives, spatial and temporal scales, and the appearance of the forest at a particular point in time.

Biotic disturbances include damaging endemic and invasive insects and other pests. Historical abiotic forest disturbances can be described in terms of the weather and climatic events that produced them (e.g. extreme heat, frost, windthrow, snowfall or drought that damaged or killed trees, precipitation that caused erosion, or forest fires).

Anthropogenic influences on the forest should be described as part of the information on its state. This information might include, for example, areas and species harvested over time, areas of plantation forest established, the occurrence of deforestation and the status of forest management planning. Human activities (roads, for example) can increase vulnerability by increasing the risk of forest degradation, deforestation, wildfire and the spread of pests. On the other hand, they also determine some of the contributions of forests to human well-being.

\section{FOREST FUNCTIONS AND SERVICES}

The initial mandate of the assessment is often driven by a priority concern, which may be considered, at least by its promoters, as the main function of the forest. It could be economic, social or environmental, or a combination of these. If the assessment is part 
of a broader spatial assessment or if it focuses on the vulnerability of forest-dependent people, it may address a broader range of forest functions.

Even if the initial purpose and scope is quite focused, it is nevertheless important to review all potential contributions of the forest to a broader set of objectives (economic, social, environmental, cultural, etc.). Understanding the different functions of the forest and the main goods and other ecosystem services it provides - including specific cultural or religious roles - will clarify how the forest contributes to human wellbeing. Identifying the different functions and their interrelations is a necessary step in understanding how these functions might be modified by climate change or how they might (or might not) be elements of adaptive capacity and therefore key for adaptation. This analysis will also prepare the ground for understanding which priority adaptation measures could be put in place as safeguards for the most essential functions.

The concept of ecosystem services is particularly useful to identify and describe the various contributions of forests, direct and indirect, to human well-being (Box 3). In conducting this analysis, it is important to include all forest functions and services, even those that are linked only to specific groups, are less apparent or are not valued in a narrow economic sense. Some functions, including the provision of food, feed and a large part of energy and raw materials, are the object of informal activities which are not registered in official statistics. Many forest services benefit vulnerable and marginalized people whose voice is not easily heard. These contributions often provide benefits on large spatial scales. Some forest functions, particularly those that relate to buffering shocks, are only recognized in times of crisis, but in the context of climate change they are no less important, especially considering that climate change is likely to increase the risk of crises.

\section{BOX 3 \\ Classification of forest functions and services}

The Millennium Ecosystem Assessment (MA, 2005) divides ecosystem services into four groups: regulating, supporting, provisioning and cultural (Figure 6).

In terms of provisioning services, forests and trees are a source of various goods that are either consumed directly or traded, formally or informally, providing income. It is these contributions that are most commonly considered to underpin the concept of forest dependence. People living in or near forests consume a great variety of animal and plant forest foods, which can represent an important part of the diet and source of nutrients for these populations.

Fuelwood is a major source of energy for cooking and heating, often the only available energy in rural areas in developing countries. It is estimated that almost 2.4 billion people rely on fuelwood for cooking, including three-quarters of African households. Forests and trees also provide materials used for construction, furniture, tools and handicrafts, as well as many substances used in both traditional and western medicine. 
Box 3, continued

Forests and trees also deliver numerous non-provisioning ecosystem services that are essential to agriculture, to communities and to humankind. They play a considerable role in the hydrological cycle, regulating surface and groundwater flows while contributing to water quality. They contribute to rainfall, locally and remotely downwind. They facilitate infiltration and can improve groundwater recharge. Forests and trees can offer important protection against flooding, including far downstream, or in coastal areas (mangroves). Forests and trees, including their root systems, contribute to accumulation of soil, to its protection against water and wind erosion and to nutrient circulation.

Forests are host to over half of the world's known terrestrial plant and animal species (Shvidenko et al., 2005). These include a number of species that provide beneficial services at various spatial scales, including pollinators and natural enemies of pests. Numerous studies have shown the relation between proximity to forest or forest patches and density of wild pollinators, with benefits to the yield and quality of pollinated crops (Garibaldi et al., 2016).

Forests also play a considerable role in climate regulation, at various geographical and temporal scales. Locally they act as windbreaks and provide a cooling effect beneficial for crops, animals and humans, including around urban areas. They contribute to the distribution of precipitation downwind through "rain recycling", including at regional and continental scales. Furthermore, because of their role in the carbon cycle, they play an important part in climate change mitigation at global level.

In addition to these economic and environmental benefits, forests also carry social, cultural and religious values that are of critical importance to various communities and groups, especially indigenous peoples. Forests typically play an important role not only in the livelihoods of these peoples, but also in their cultures, traditions, religions and spiritual beliefs and practices (e.g. Widmark, 2009).

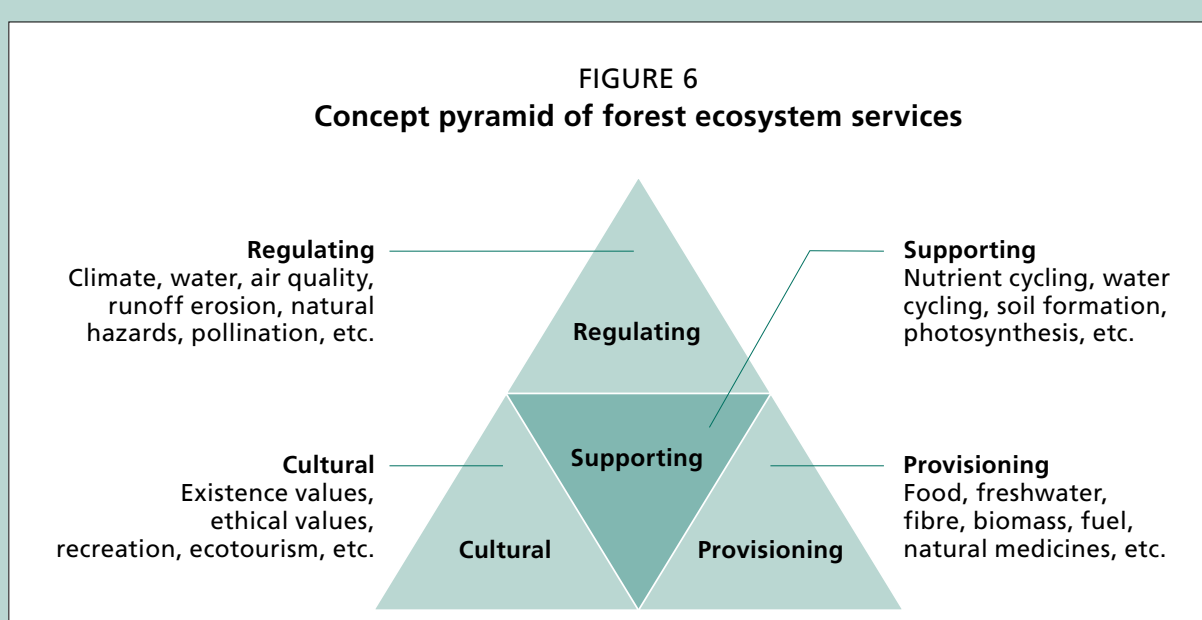




\section{TRENDS AND POTENTIAL VULNERABILITIES UNRELATED TO CLIMATE CHANGE}

As vulnerabilities can be multiple and can interact, it is essential to identify other threats and changes aside from those related to climate change, such as deforestation and forest degradation, and their effects on the forest, particularly when the assessment is conducted with a long-term perspective. Such an analysis should first identify present vulnerabilities; examples might include degradation, presence of invasive species, lack of good governance (see Chapter 4), poor enforcement of existing laws, demographic pressure and overexploitation of non-wood forest products.

The analysis should then envisage how these vulnerabilities might evolve in the future. A first approach is to look at past and ongoing trends of deforestation and forest degradation, and to consider their causes and drivers.

A second approach is to consider the trends (stable, increasing or decreasing) in the human activities that are conducted in or around the forest and their potential impacts. The vulnerability assessment of the Maâmora forest in Morocco (Belghazi and Mounir, 2016) provides a good example. The analysis identified strong anthropogenic pressure from wood collection for all uses, overgrazing and systematic collection of cork oak acorns for food and trade. Livestock (337000 sheep and 91000 cattle) were observed to graze throughout the year, with the grazing level three to four times higher than the carrying capacity of the ecosystem. Grazing in cork oak forests was resulting in compaction of the forest soil and was seen to be a threat to tree seedlings that were already rare because of acorn collection and climate change. By preventing natural regeneration, overgrazing was resulting in forest ageing. The forest was also experiencing uninterrupted development in forest recreation, with up to 30000 visitors and 3000 vehicles per week.

A third approach is to evaluate strategies and plans that could have impact on the forest, whether positive (e.g. projects for conservation or sustainable management) or negative (e.g. new roads and mines). 




\section{Legal status, institutions and governance}

The legal status of a forest may be an indication of its role and recognition. Legal status, existing institutions and management practices, at both national and local levels, can also be a cause of vulnerability for the forest and/or the people that depend on it, and can be harnessed to reduce vulnerability and to increase adaptive capacity.

Gathering information on laws, rules and institutions that apply to a specific forest is relatively easy and constitutes the first step of the analysis. However, implementation of the legislation is equally important and can only be understood from direct exchange with local stakeholders. It is also important to take into account any non-written customary rules that may govern access to the forest and its resources, and to document them in the assessment.

\section{LEGAL STATUS AND INSTITUTIONS GOVERNING THE FOREST}

The institutions and rules that govern a specific forest can play a considerable role in reducing its vulnerability and enhancing its adaptive capacity. They can also fail to do so.

It is useful to start this part of the assessment with a general overview of national laws, policies and measures that apply to forests. This will enable a better understanding of the legal status of the forest in question and will also help to identify potential instruments that could be used to reduce vulnerability and support adaptation measures.

Public instruments that can orient forest management are of various types: laws and regulations, direct or delegated management of public forests, incentives (including taxation regimes) and support to market-based instruments, often in combination. National legislation defines what a forest is and which areas are deemed permanent forest. It defines property and tenure rights, including in some cases restriction of property rights to trees on private land. National legislation can also contain provisions regarding forest governance and management, with various degrees of detail. Increasingly often, these rules might be differentiated according to zoning that defines a specific status.

National laws can contain specific provisions for protected areas or give particular status to certain forests because of their situation or function. Such status generally evokes management rules that influence the vulnerability and adaptive capacity of the forest and the people depending on it. In some countries or for some categories of forest, such rules may be partially or totally delegated to subnational authorities or other specific entities.

\section{GOVERNANCE AND MANAGEMENT}

The type of governance, ownership, tenure and management has an influence on the vulnerability and adaptive capacity not only of the forest, but also of the people that 
depend on it. Both depend on the level of involvement of forest stakeholders in governance.

The degree of proximity of decision-making to the forest and to local actors is one of the main factors that can contribute to adaptive management. Three main forms of non-centralized governance can be identified (Vira, Wildburger and Mansourian, 2015):

- decentralization, i.e. transfer of responsibility to locally elected government;

- deconcentration, i.e. transfer of responsibility to local offices of the national government, as in Senegal (Ribot, 2009);

- devolution or "community management", i.e. transfer of responsibility to local communities, as in Nepal (Pokharel et al., 2008).

Both centralized and non-centralized forms of governance can involve forms of co-management between public entities and communities and/or the private sector.

The details of these arrangements, how they are implemented and how they translate into forest management are of major significance for the vulnerability of forests and forest-dependent people. Non-centralized governance can give greater consideration to stakeholders, depending on the power relations at the decentralized level. Governance arrangements at different levels determine the conditions influencing the participation of communities in forest planning and management, the status of land tenure or rights to use the forest, and the communities' access to human, financial and institutional resources and infrastructure.

A review of forest management plans, where they exist, can be a useful step in assessing how sustainable forest management can lead to reduced vulnerability and contribute to adaptive capacity.

\section{RISK MANAGEMENT}

Policies and institutions addressing risk management deserve specific consideration. The following elements should be highlighted.

\section{Capacity of institutions to enable people to be prepared and to react to changes or events}

The capacity to facilitate preparedness and reaction, which is relevant in any circumstance and for any type of change and risk, depends on the functioning of the institutions themselves. To what degree do the institutions have the liberty to take action? To what extent are they able to adapt management to changing circumstances? This capacity depends, of course, on the legal setting, institutional arrangements and power relations, often unwritten. It depends on a delicate balance among the interests of different actors. It also depends on the competencies of forest managers and forest-dependent people, on their training and their capacity to react and innovate, and on the technical and scientific institutions on which they can rely.

\section{Systems for risk prevention and early action}

What systems are in place for prevention, monitoring and early action to avoid large negative impacts from major risks? A classic example is forest fire. The voluntary guidelines for fire management published by FAO (2006) describe the strategic actions 
needed for forest fire prevention, early detection and early action. Depending on the country, action may be organized by national and/or local authorities.

Another important example is prevention and monitoring of forest pests and diseases (FAO, 2009). Many countries have established systems for pest monitoring and reporting of pest outbreaks and/or make available pest identification tools, guidelines for early action and online databases (e.g. Te Uru Rākau/Forestry New Zealand, 2019). Other useful systems might include monitoring of air pollution and climate change effects.

\section{TENURE AND ACCESS RIGHTS}

Ownership, tenure and access rights serve as incentives for long-term and sustainable management of forests, trees and the resources and ecosystem services they provide. Of particular importance are the duration, stability and protection of such rights.

Tenure and access rights governing forests and trees also affect people's ability to rely on them as a source of goods and income and as a buffer. Many of these rights are customary or informal and can be threatened by the establishment of formal agreements such as concessions to private companies. The most vulnerable people, including women and marginalized groups, often have the fewest rights (whether formal or customary) and the greatest difficulty in having their rights recognized, even though they are often the most dependent on forest resources. In analysing legal arrangements and institutions, particular attention should be devoted to informal access rights, which are often a key element in the livelihood strategies of the most vulnerable. This analysis requires appropriate investigation methods that give due consideration to the voices of women and marginalized groups, such as separate participatory workshops and consultations.

It is often necessary to manage trade-offs between categories of forest users (Box 4) or between measures to protect forests, such as protected areas, and access rights of

\section{BOX 4}

Balancing trade-offs among forest users: an example from Sweden

In northern Sweden, the Sami people have the exclusive right to practise reindeer herding - a right formally recognized by the Swedish Government - on the same land that private forest owners use for commercial timber harvesting. The two uses have come into conflict: Mechanized timber harvesting has a negative effect on lichens, which are vital for winter forage, and trampling by reindeer damages young forest stands.

A co-management system was instituted, in which forest companies were required to consult reindeer herders (organized in small communities) to consider the negative effects of management plans. After research showed that the consultations often took the form of information meetings or dialogues, rather than the intended co-management partnership, the system was revised in 2010. The role of the consultations was clarified, and a conflictresolution mechanism was established.

Sources: Sandström and Widmark, 2007; Bostedt et al., 2015 
indigenous and local populations (Sylvester, Segura and Davidson-Hunt, 2016). Here the quality of governance is crucial.

\section{PROSPECTIVE INSTITUTIONAL AND GOVERNANCE TRENDS AND PLANS}

Given the time frame of the analysis, it is also important to take into account prospective evolution in institutions and laws, such as plans to increase the extent of protected areas. Strategies and broad orientations, such as the nationally determined contributions for addressing climate change, can also indicate elements of future trends (including mitigation measures involving forests and/or plantations, and their impact on the forest) and provide potential arguments to support pleas for adaptation measures and policies. 



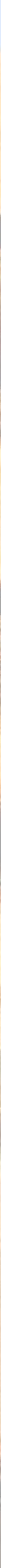




\section{Describing the forest-dependent people}

To understand the potential impacts of climate change on forest-dependent people, it is necessary to analyse the various pathways that connect them to the forest. Forests provide food, energy, materials and numerous other ecosystem services on which people depend to various degrees for their livelihoods, food security and nutrition, and well-being. Moreover, forests are often of particular importance for livelihoods in times of crisis. The sum of all these relations between forests and people defines the notion of forest dependence (Box 5) and makes it possible to analyse how this dependence can be influenced by climate change. Whatever the initial purpose of the vulnerability assessment, even if it is primarily conducted for environmental reasons such as biodiversity conservation, it is essential to identify the categories of people that depend on the forest, their number, and the nature and significance of the dependence. The analysis should also consider access to and control over productive resources and services and employment opportunities for women and men, as well as their participation in decision-making and local institutions.

\section{BOX 5 \\ Diverse forms of forest dependence}

The notion of forest dependence has often been primarily defined by the direct economic contribution to livelihoods of forest products, either directly consumed or sold. In this way, Fisher, Srimongkontip and Veer (1997) distinguish three types of forest-dependent people:

- People who live in and around natural forests, or on the forest frontier, often living as hunter-gatherers or shifting cultivators, and who are heavily dependent on forest resources for their livelihoods, primarily, but not always, on a subsistence basis. Shifting cultivation is a major contributor to their food security. This category often includes indigenous peoples or minority ethnic groups. They are thus usually outside both the political and economic mainstream.

- People who live in proximity to forests, are usually involved in agricultural practices either within or outside the forest, and regularly use forest products (timber, fuelwood, bush foods, medicinal plants, etc.), partly for their own subsistence purposes and partly for income generation. Communities in remote areas that may have fewer opportunities to find off-village employment and fewer resources to purchase foods (Narain, Gupta and van 't Veld, 2008) may be more dependent on forest resources. 
Box 5, continued

For those more involved in agriculture, dietary supplements from forests are often of critical importance to food security and nutrition.

- People who engage in such commercial activities as hunting, collecting minerals or forest industries such as forest management and logging. Such people may be part of a mixed subsistence and cash economy. They depend on the forest mainly as a source of cash income. However, it is important to note that for this group, a relation between the people and the forest can exist even in a highly monetized context. For example, small rural communities in highly industrialized countries such as Australia can be almost totally dependent on wages from commercial logging. In a study of 8000 households in 24 developing countries, the pantropical Poverty and Environment Network (PEN) calculated that on average over one-fifth (22 percent) of rural income was derived from forest resources, often equivalent to, or even outstripping, direct income from agriculture (Angelsen et al., 2014).

For the purpose of vulnerability assessments, however, it is useful to enlarge this perspective to cover additional categories of people:

- People depending economically on agricultural systems that are heavily dependent on the goods and services provided by forests and trees. These would include farmers whose crops depend on wild pollinators for their reproduction, or fishers relying on fish and aquatic species that rely on mangrove forests for their reproductive and growth cycles. This category fosters the inclusion of communities living close to forests for whom forests are the primary source of food and income; people who are dependent on trees outside of forests (e.g. farmers practising agroforestry) for a range of goods and ecosystem services; and communities and people downstream depending on forests for the provision of water.

- People depending on forest services (including recreation and tourism) and on transformation and distribution of forest products as a source of income. This group is distinguished from the third category of Fisher, Srimongkontip and Veer (1997), as these people may have more options.

- Populations, e.g. in urban areas, that depend on forests for the provision of services such as cooling, protection against floods or provision of water (quantity and quality).

- People interested in forests and trees, or in a specific forest, for cultural, religious, environmental, moral or recreational reasons. People in this group are not forest dependent in the strict sense, although in some cases their physical and psychological well-being can rely on forests to a high degree. They nevertheless can provide political and even financial support to actions in favour of forests.

\section{NUMBER AND CHARACTERISTICS OF FOREST-DEPENDENT PEOPLE}

A first step in the analysis is to determine the number of people that are, or can be, dependent on forests and trees for their livelihoods. Demographic statistics can be of help, as can agricultural statistics in some cases. The assessment should estimate: 
- the number of people living in the forest, including indigenous peoples;

- the number of people living in proximity to the forest;

- the number of people depending on the forest economically, for example as foresters or guides;

- the number of people depending economically on the forest in an indirect way, such as farmers depending on pollination of crops in the proximity of a forest;

- the number of people reliant on trees outside forests, including in agroforestry systems, for household use, income or ecosystem services.

Depending on the type of forest or tree system, these figures can be more or less accurate. Data reliability is particularly variable at local level, depending on the national situation and the importance of the informal sector. National-level information can also be useful, including data on timber and other commodities produced by the forest. Available data generally do not cover the whole range of potential contributions of forests and trees to the economy or to household income. In the absence of detailed quantitative data on forest dependence, it may be useful to use people's location in relation to the forest as a proxy. For each figure, the methodology used for calculation should be explained, along with the degree of reliability, if possible.

Particular attention needs to be given to the informal economy and household consumption, as well as to disaggregation by gender and, when appropriate, social groups.

There are usually two categories of beneficiaries of forest trade, consumers and producers, i.e. persons involved in the collection, transformation and distribution of these goods. Many of these activities are informal and not fully included in national statistics. Many of them are also heavily gender differentiated, calling for a thorough analysis by gender.

In addition to people depending economically, directly or indirectly, on forests and trees, a wider range of people may depend on them for other ecosystem services, such as protection against floods and safeguarding downstream water quality. To estimate the size of this group of users, it may be necessary to enlarge the geographic scope of the assessment.

A forest can also have special religious, social or cultural importance. Here again, it is important to try to estimate the number of people that give the forest a particular value and that might be affected by its modification. Data on recreational users of the forest, such as the number of entries into a national park or the number of recreational hunters registered, may be available and will be useful for the assessment.

\section{SOCIO-ECONOMIC CONTRIBUTION OF THE FOREST}

Next, the contribution of forest resources to the livelihoods of dependent people should be estimated, in absolute terms or as a percentage. FAO, CIFOR, IFRI and the World Bank (2016) have prepared guidance and survey modules for conducting socio-economic surveys in forestry, which may be used either to conduct a dedicated survey (resources permitting) or to support participatory studies.

It should be noted that these contributions of the forest are often of an informal nature, may vary over time, are often seasonal and are often particularly important in 
times of crisis or difficulty. They also generally vary depending on gender and social characteristics. Any survey or enquiry should therefore take into account social and gender diversity, with appropriate sampling, and might require conducting separate workshops or enquiries for different social groups or genders.

\section{CHARACTERIZING THE DEPENDENCE}

The analysis should distinguish the roles of forests for food provisioning, forage, fodder for livestock, non-wood forest products and income, as well as for other ecosystem services. It should aim to identify as much as possible those characteristics of the forest that enable it to fulfil its different functions. For instance, identifying the different species that provide timber, food, fodder or other products of importance will make it possible, later in the assessment, to give particular attention to the potential impacts of climate change on these species. This information can also uncover potential risks of overexploitation of some resources, which can constitute an additional source of vulnerability for both the forest and the people depending on it.

The analysis should also identify the specific moments in time when some forest functions are more important, such as the "hunger season" which extends from the moment when crops of the previous harvest have been exhausted to the next harvest. Forests may also have an important role in cases of complete harvest loss, extreme droughts or floods.

These findings will help to quantify the contribution of forests and trees to livelihoods as well as identify potential alternatives to these sources of food or income.

\section{VULNERABILITIES OF FOREST-DEPENDENT PEOPLE}

Vulnerabilities of forest-dependent people depend on their exposure and sensitivity to the consequences of the impacts of climate change on forests, as well as on their adaptive capacity, which mainly depends on factors beyond the forest (including institutional factors and access rights). The analysis should review the main factors that need to be investigated in this respect, taking into account the specificities of each category of forest-dependent people, with particular attention to indigenous peoples and marginalized groups. Points of particular interest include:

- the importance of forest-related resources to overall livelihoods, i.e. to the functioning and economics of the household and the community, and to food security and the other functions described above;

- alternative sources of income and food, their correlation (or lack of correlation) to forest-related fluctuations, and their vulnerability to climate change and other stresses;

- general indicators of vulnerability such as poverty, educational level and institutional factors.

Also relevant is the question of how the forest is linked, or not, with other agricultural systems for the livelihoods and communities in question. For instance, a farm, village or region that depends on monoculture of cocoa or coffee will be vulnerable to a bad harvest or severe price fluctuation of that commodity. In relation to the second bullet 
point above, if agriculture is the source of diversified income, the overall vulnerability of the farm, village or region may be amplified, as agriculture is also likely to be directly affected by climate change impacts. In this case, it would be important to preserve the buffering functions of forests.

The analyses conducted up to this point need to be complemented with participatory approaches, giving due respect to the specificities of social groups.

In some cases, data that could support the analysis of global vulnerability factors could be useful, such as statistics on levels of income, assets and education, as poverty and low levels of education are generally recognized as indicators of overall vulnerability and lower adaptive capacity.

Lack of secure tenure and access rights is an additional factor of vulnerability which may create difficulty for particular groups. Safety nets and social protection schemes, whether institutionalized or resulting from traditional forms of solidarity, can reduce vulnerability at household level. Their efficiency has to be assessed on a case-by-case basis. For instance, traditional community-based systems might be reactive but may be overwhelmed by a shock that affects the whole community, such as a drought.

Retrospective analysis is particularly useful to reveal the actual vulnerabilities of people as well as their agency and capacity to react and adapt.

In addition, as vulnerabilities can multiply, it is essential to identify other threats and changes besides those related to climate change, and to predict how they will affect forest-dependent people, particularly if the assessment has a long-term perspective.

\section{GENDER SPECIFICITIES}

Women and men have different roles in relation to forests, as well as different vulnerabilities and adaptive capacities. The different cultural, domestic and economic roles of women and men in their households and communities influence the sets of knowledge they develop about forest and tree resources and the environment (Bee, 2016). Globally, the collection of forest products tends to be significantly differentiated by gender, with important regional variation (Sunderland et al., 2014). The differences in knowledge and roles contribute to disparity in adaptive capacities and strategies in the face of a changing natural resource base (Djoudi and Brockhaus, 2011). Gender inequalities and norms often limit women's access to and control of resources such as land, capital and technical services; these limitations can hinder their capacity to address the challenges of a changing climate (Brody, Demetriades and Esplen, 2008; Lambrou and Piana, 2006; Rodenberg, 2009).

To avoid omission of important factors of vulnerability, the assessment needs to adopt a gender-sensitive approach that takes intersecting social variables into account. The Guidance note on gender-sensitive vulnerability assessments in agriculture (FAO, 2018b) provides a list of criteria and factors to consider in this regard. 


\section{Climate change and climate-related risks in the region where the forest is located}

In many countries, climate information and projections have been gathered in the process of preparing national adaptation plans (e.g. Australia [CSIRO, 2015] and the United States of America [USDA Forest Service, undated]). Where available, this information should be consulted first to determine its relevance for the assessment. The use of such information is also likely to provide an advantage in promoting the results of the assessment to national authorities. If other hypotheses and parameters are used, the reasons should be explained and justified - for instance, specificities of the situation or the particular sensitivity of the forest to certain parameters.

\section{ANALYSIS OF HISTORICAL AND CURRENT CLIMATE-RELATED EVENTS AND RISKS}

If vulnerability is being estimated for current climatic conditions, then it may be possible to use weather records to determine the historical mean and range in climate values considered important, as well as the occurrence of extreme weather events (Borja-Vega and de la Fuente, 2013; Dasgupta et al., 2014). If information is not available for the precise location, owing to lack of meteorological stations for instance, proxies can be used, such as recordings from a comparable station or averages at a broader scale. However, in these cases care must be taken to account for topographic specificities.

Dendrochronological studies can be helpful, as they give information on the conditions that existing trees have experienced in the past (Gebrekirstos et al., 2014).

This information may be supplemented with (or, if necessary, replaced by) observational reports of climate events (e.g. Bele et al., 2013; Dazé, A mbrose and Ehrhart, 2009; Obeng et al., 2011; Parkins and MacKendrick, 2007). In this case the accuracy of quantitative variables may be lower. On the other hand, such information may facilitate the understanding of links between observed phenomena and concrete impacts on forests and livelihoods.

In the event that both climate records and personal observations by affected people are used, consideration should be given to their relative weighting (Dasgupta et al., 2014).

\section{CLIMATE CHANGE PROJECTIONS}

As mentioned above, it is often easiest to use projections already prepared for countrywide analysis. However, it may be useful to use varied projections and methods, or a range of results, in order to show a range of possible scenarios. This may be done by 
using a Representative Climate Futures approach (Whetton et al., 2012), which involves identifying a small set of possible scenarios, differentiated according to the main variables of interest and their likelihood. For instance, in the range of potential scenarios derived from projections, a hotter, drier, windier or more variable climate may be selected, with identification of its likelihood. This approach enables stakeholders to prepare for contrasting scenarios, including the most likely and the worst case, depending on the variables of interest for the specific system. It can also facilitate the representation and understanding of uncertainty.

Three elements need to be taken into account in projections of future climate: the general circulation models (GCMs) used to project future climates; the scenarios of future emissions of greenhouse gases; and the time period(s) of the evaluation.

Future climate information should preferably be obtained from downscaled climate simulations. An example is the PRECIS regional circulation model, which provides future climate projections at a resolution of about $50 \times 50 \mathrm{~km}$ (Met Office, undated). The Coordinated Regional Climate Downscaling Experiment (CORDEX) (WCRP CORDEX, 2019) covers almost all regions of the world, providing a large amount of high-resolution climate information.

Another useful resource is WorldClim, a set of global climate layers (gridded climate data) with fine spatial resolution (about $1 \times 1 \mathrm{~km}$ ) (WorldClim, 2016). The database includes present, past and future data, which can be used for mapping and spatial modelling.

It is important to document and clearly present the methodological choices made, scenario, model and type of downscaling, so that they can be factored into any comparison.

In coastal areas, climate projections should be complemented by analysis of sea-level rise and potential impacts on water salinity.

In some cases, it may also be necessary to consider projections of hydrological changes, which are increasingly available in a growing number of watersheds (IPCC, 2014a). 

(1)

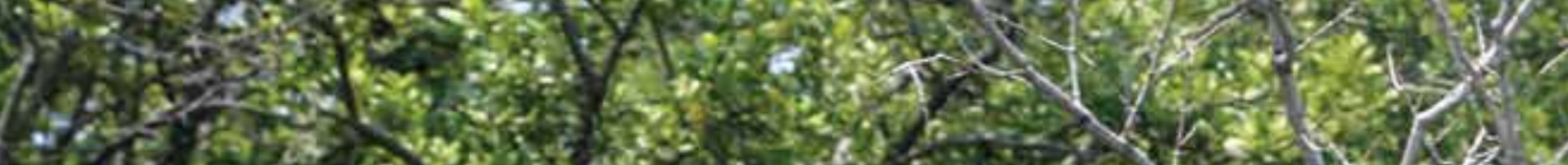

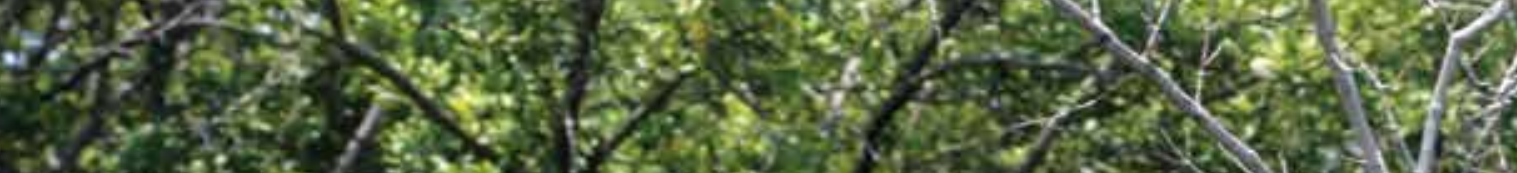

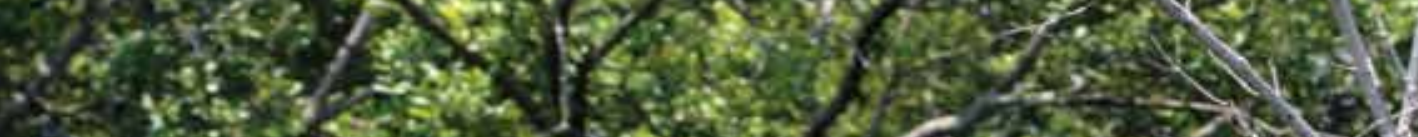
3.5.

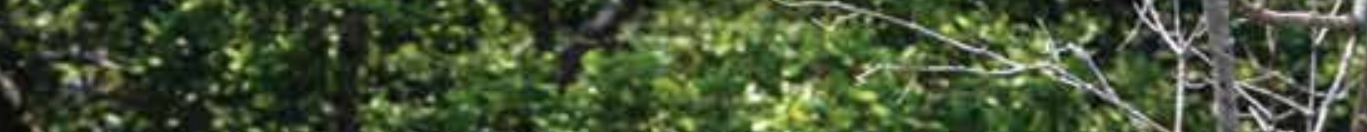

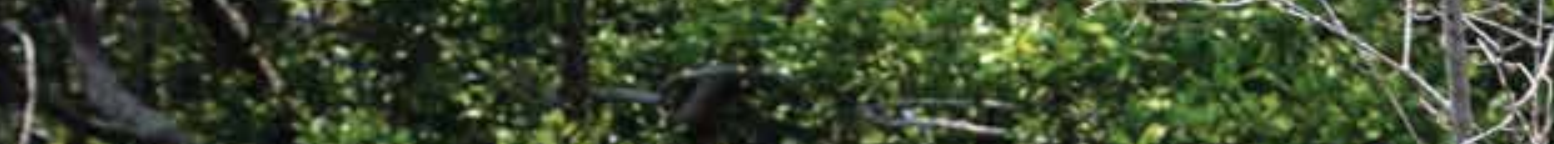
(a) 50.5
A. I3 cist. 35

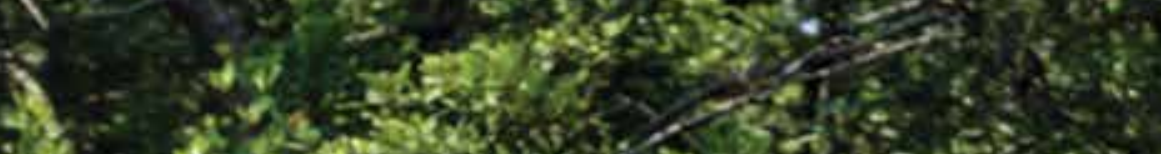
and 1 -

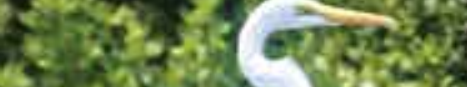

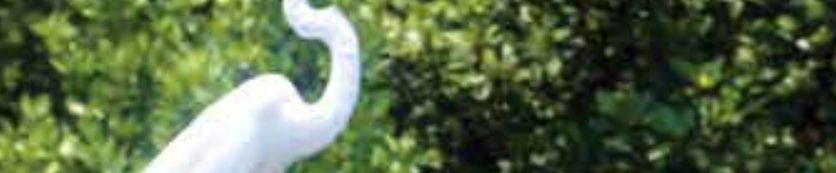
(4) 10.0 8 (3) <.

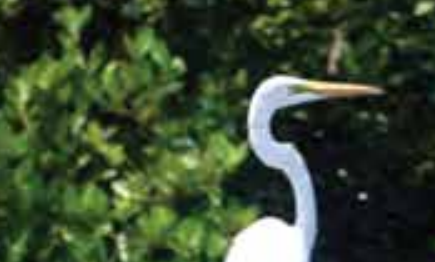

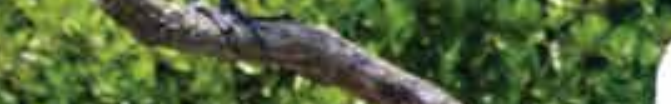

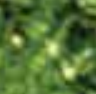
Q6. (2.)

. 2.

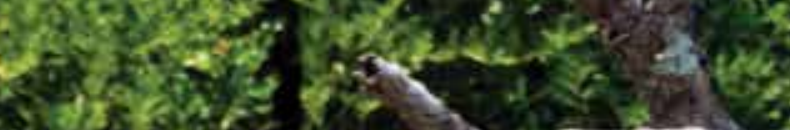

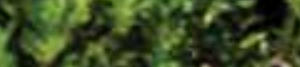

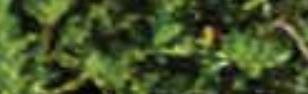

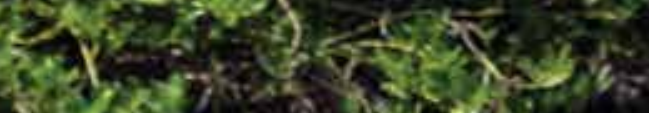

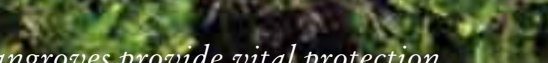
Mangroves provide vital protection. against coastal flooding and habitat for biodiversity, but are particularly

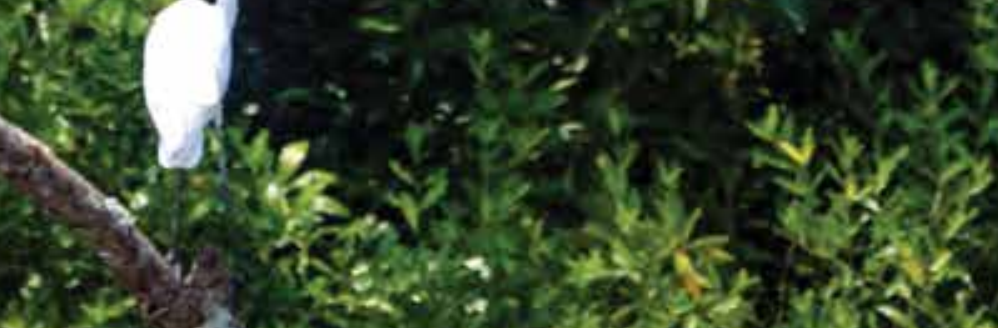
s.

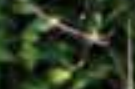

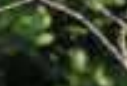
Nivis

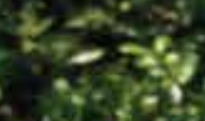

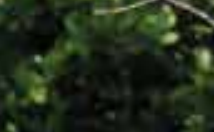
Y)

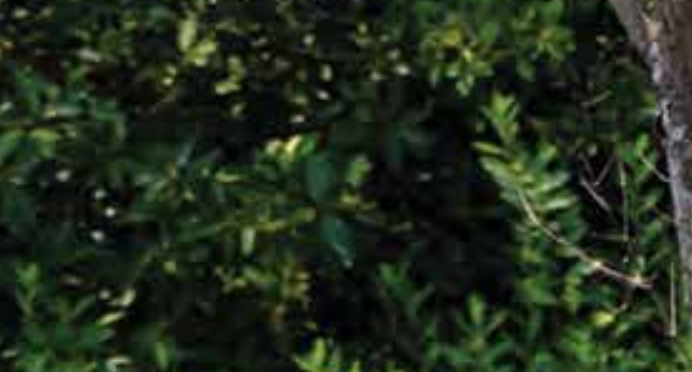

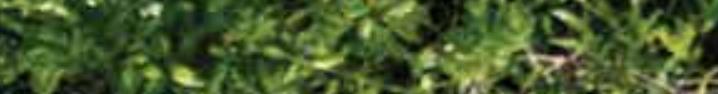

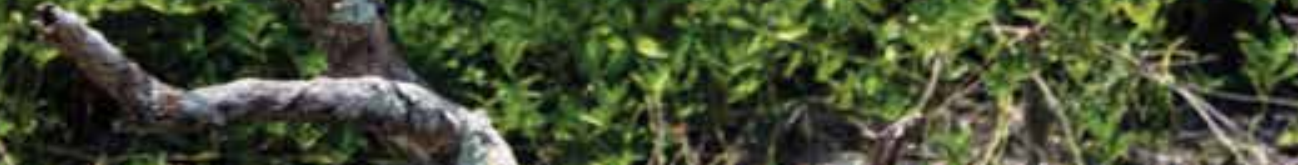

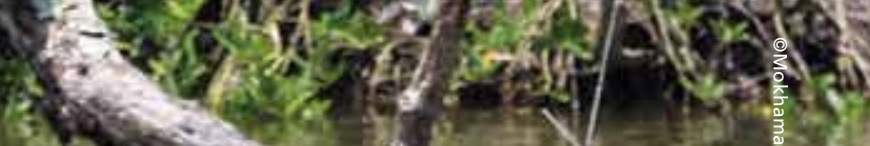




\section{Potential impacts of climate change on forests and trees, and their specific vulnerabilities}

Although it is often difficult to distinguish climate change effects from other stresses, evidence shows that in various places climate change is contributing to decreased productivity and dieback of trees from drought and temperature stress; increased wind and water erosion; increased storm damage; increased frequency of forest fires (Box 6) and pest and disease outbreaks (Box 7); landslides and avalanches; changes in ranges of forest plants and animals; inundation and flood damage; saltwater intrusion and sea-level rise; and damage from coastal storms (Braatz, 2012). Changes in water availability will be a key factor in the survival and growth of many forest species, although the response to prolonged droughts will vary among species and also among varieties of the same species (Lucier et al., 2009).

A forest vulnerability assessment can evaluate the ways in which climate may affect the structure or function of forests. It can provide information about the causes or factors that predispose the system of interest to harm from an external stress. For example, increased fuel load due to prolonged fire suppression in a tropical forest can potentially enhance the vulnerability of such a forest to drought-mediated fire under climate change.

Most forest vulnerability assessments will focus on the forest attributes that are valued by people. The assessment may be oriented towards ranking the relative vulnerability of species to climate change, or towards evaluating the risks of climate change altering unique ecosystems that have ecological or social significance. It could also focus on processes that are important for economic reasons, e.g. growth rates and regeneration

\section{BOX 6 \\ Climate change effects on wildfire risk}

Climate change will increase the risk of frequent and more intense wildfires, especially in areas where it leads to lower precipitation or longer dry periods, as in boreal forests and forests in Mediterranean and subtropical regions, as well as areas where traditional fire-based land-clearing practices are used, as in the Amazon. Moist tropical forests have many species that are vulnerable to drought and fire-induced mortality during extreme dry periods. In the Amazon, there is evidence that forest fire frequency and severity are increasing because of a combination of land-use change and drought (FAO, 2017). 


\section{BOX 7 \\ Climate change effects on pest risks}

Climate change may increase the impact of pests by allowing them to establish in areas where they previously could not. Changes in temperature can result in changes in pest geographic ranges and facilitate overwintering. Some species could therefore extend their geographic range towards the poles and to higher altitudes (Porter et al., 2014; Svobodová et al., 2014).

In North America, the spread of the mountain pine beetle (Dendroctonus ponderosae) in boreal forests has largely been attributed to the absence of consistently low temperatures over long periods, which have allowed an existing outbreak to spread across mountain areas and into colder boreal forests. In Finland's coniferous forests, an increase in infestations of root and bud rots is expected due to a virulent fungus, Heterobasidion parviporum, whose spread is favoured by longer harvesting periods, increased storm damage and a longer spore production season (Burton et al., 2010).

In the tropics, increased warming is expected to accelerate the life cycle of many insect pests, and increased fire damage makes trees more susceptible to insect attacks (Lucier et al., 2009). Higher temperatures may increase the impact of pests by allowing them to appear earlier in the season. Studies also predict an increased number of generations per growing season under climate change for some pests, such as the coffee nematode in Brazil (Ghini et al., 2008) and walnut pests in California (Luedeling et al., 2011).

of commercially important trees and non-wood forest products. In addition, a forest vulnerability assessment could evaluate forest condition through expressions of forest health (tree mortality, dieback or insect and disease incidence).

A range of sources and types of information can be used, including: expert opinion (from published literature, consultation of subject matter experts or local people's traditional knowledge), retrospective analysis, forest condition and life traits, climatic niche models and physiological models (Box 8). Baseline forest conditions and historical forest responses to climate and extreme weather may also be available from published forest statistics and technical literature.

\section{DIRECT AND INDIRECT IMPACTS}

Climate change impacts on forests can be direct or indirect. The direct impacts are those that are immediate consequences of weather changes and events such as increased temperature or altered temperature patterns throughout the year, heat waves, droughts (which may alter water availability for specific species), frost and windthrow.

Indirect impacts are effects on production or perturbations of ecosystem functioning caused by changes in other species such as pollinators, pests, disease vectors and invasive species. Drought, for example, often has indirect consequences such as forest fires and increased pest infestations which in turn create dead biomass that feeds wildfires. In turn, wildfires influence the distribution of species (van Breugel et al., 2016). 


\section{BOX 8 \\ Methods and tools for assessing the vulnerability of forests and forest ecosystem services}

Expert opinion and local knowledge. The perspectives of experts and local people can be obtained from the published literature or through participatory approaches.

Indigenous knowledge can provide information on ecological responses to climate and weather (Mazzocchi, 2006), aspects of biodiversity, ecological processes, sustainable resource use and climate change (Alexander et al., 2011; Berkes, Colding and Folke, 2000). This knowledge tends to be local and multidimensional, expressing a holistic viewpoint rooted in stewardship of the land (Alexander et al., 2011).

Input from experts in relevant fields of knowledge can be obtained individually, in group sessions or through questionnaires (e.g. Daust et al., 2011). This approach can be used, for example, to address current climate conditions or to estimate responses to future climates, often based on past experience. Expert opinion can offer rapid assessment of the risks posed by climate change, but it may introduce biases, depending on which experts take part and their academic backgrounds (PROVIA, 2013). This risk can be addressed by obtaining opinions from a range of experts across a number of fields of study.

Retrospective analysis. Review of published reports can be used to reveal historical climate-species relationships, to assess sensitivity to climate and in some cases to project impacts from future climate conditions. A large amount of information has been published describing changes in ecological systems around the world caused by recent climate change (Parmesan and Yohe, 2003; IPCC, 2014a). Dendrochronological studies can be useful not only to reconstruct past climate, but also to show plant responses to past variations in climate factors (Gebrekirstos et al., 2014). Such results can then be used in models that simulate effects of climate changes on overall and species-specific biomass dynamics and tree species composition (Hiltner et al., 2016).

However, many observational studies fail to provide information on what can be called "dose-response" relationships between climate and an ecological response (by a tree, forest or ecological process) (see examples in Man et al., 2009; Hanna and Kulakowski, 2012). The results are therefore difficult to use in a predictive manner. Retrospective studies also do not take into account the effects of future increases in atmospheric $\mathrm{CO}_{2}$ concentrations on plant development, growth and increased tolerance to soil moisture deficits. For these reasons, many retrospective studies have limited value for predicting responses to future climate.

Life trait evaluation. Forest vulnerability can also be assessed based on the current condition of the forest and the life traits of forest species of concern. This is often accomplished by obtaining expert opinion and extracting information from the published literature. Life trait approaches to vulnerability assessment that have been used for trees and other plant 
Box 8, continued

species (reviewed by Beardmore and Winder, 2011) include the Forest Tree Genetic Risk Assessment System (ForGRAS) (Potter and Crane, 2010) and the NatureServe Climate Change Vulnerability Index (CCVI) (Young et al., 2011). Both methodologies use multiple factors to assess the vulnerability of plant or tree species and express the output using a rating of relative vulnerability among species. Williams et al. (2008) have proposed an integrated framework for assessing species vulnerability to climate change.

One of the challenges in carrying out life trait evaluation is that detailed information for some species may be lacking. More importantly, these methodologies are not readily scaled up from individual species evaluations to a forest-level assessment of vulnerability, given that each species responds uniquely to climate and that the approach does not address the complex interactions among species (e.g. regeneration, competition).

Climatic niche modelling. In this approach, the climate in which a species or an ecosystem is currently found - its climatic niche - is characterized and its location is identified on a map (e.g. Joyce and Rehfeldt, 2013; Wang et al., 2016). The current location of the species is then compared to the future location of the climatic niche. Geographic dissimilarities between the current and future location of the climatic niche (due to climate change) and/ or fragmentation of a species' climatic niche (and by inference, future species distribution) are used to indicate exposure to climate change (Foden and Young, 2016).

One shortcoming of this approach is that the current climatic niche is based on the current presence or absence of a species, which may be unrelated to climate. For example, interspecies competition may exclude a species even if the climate is suitable (Clark et al., 2014). More crucially, dissimilarity between the current and future location of the climatic niche does not indicate whether, or at what point, a species might experience stress because of climate change exposure or be unable to cope with the new climate. Such information would require knowledge about the species' biology (Foden and Young, 2016).

Physiological modelling. Physiological models simulate how trees and forests may respond to climate change, typically by applying mathematical expressions of climatically driven changes in physiological or biochemical processes. Some physiological models are able to simulate the behaviour of multiple species over time frames ranging from decades to centuries. They simulate changes in forest growth and/or development using computer-generated responses to environment that are scaled up from finer-level processes. For example, the effects of temperature on leaf photosynthesis and respiration are scaled up to represent carbon sequestration at the level of trees, stands or even landscapes (see e.g. Sprintsin et al., 2012). Farquhar's biochemical model of $\mathrm{CO}_{2}$ assimilation is one of the most common models of this type (Farquhar, Von Cammerer and Berry, 1980).

Physiological models may be linked with landscape models to take into account landscape functions or changes such as stand-replacing disturbance, regeneration and species migration, 
Box 8, continued

which can affect forest structure over longer time frames. Such linked physiological-landscape models can account for processes such as forest succession and disturbance. They can thus be used to project changes in species composition and forest productivity with longer-term climate change (for examples, see Coops, Hember and Waring, 2010; Duveneck et al., 2014; Koca, Smith and Sykes, 2006).

Climate analogue analysis. In this method, the target ecosystem is compared with another ecosystem at a different location where the climate is similar to the future climate projected for the target location (Luedeling, Muthuri and Kindt, 2013).

Direct impacts are easier to predict, because they can be more easily simulated and/ or modelled. They are now quite well projected for some plant species, particularly staple crops.

Indirect impacts, which can have a major role, particularly in less controlled forest environments, are much more difficult to model, given the high number of interacting parameters and links, many of which are often not yet known. In some cases, to predict impacts it may be useful to refer to a comparable system under the predicted climate or to the effects of climate change on a comparable system (FAO, 2016).

Most tree species have a climatic range within which they grow best, are competitive with other plant species, can adapt to environmental change, and respond to increased insect attacks, disease, and adverse environmental conditions and anthropogenic influences. Some species will adapt better than others to changing conditions, which will lead to changes in the composition of forests rather than in geographic shifts in forest types (Breshears et al., 2008). In general, most tree species will shift poleward and to higher altitudes at a rate faster than natural migration (Rosenzweig et al., 2007; Breshears et al., 2008).

\section{COMBINATION WITH OTHER VULNERABILITIES}

Vulnerability of local populations, to climate change and to other changes, can be a source of additional stress, and thus vulnerability, to a forest. For instance, settlements of displaced people create an additional pressure on forests, particularly through increased demand for fuelwood, which needs to be assessed and addressed to avoid environmental degradation (d'Annunzio et al., 2016).

The impacts of climate change, land-use conversion and unsustainable land-use practices are expected to interact (FAO, 2017). Climate change, deforestation, fragmentation, fire and human pressure place virtually all dry tropical forests, for example, at risk of replacement or degradation (FAO, 2016). 


\section{MAIN FOREST VULNERABILITY POINTS}

At this stage, an integrated approach should be used to draw conclusions about some of the main points of forest vulnerability.

The forest vulnerability assessment uses information on the type of climate exposure that is of concern; the sensitivity of some elements within the forest to climatic factors; projected impacts of climate change; and the capacity of the forest to adapt to climate change (Table 2).

Methods could include integrated modelling, which is more easily applicable to simple situations, such as monospecific plantations. Expert consultation or participatory approaches may be effective for vulnerability mapping. Future potential distribution of species under climate change can be mapped by identifying areas with climatic conditions that are considered favourable for species of interest (Box 9).

TABLE 2

Examples of information that can be used for evaluating exposure, sensitivity, impacts and adaptive capacity in a forest vulnerability assessment

\begin{tabular}{|c|c|c|}
\hline Indicator & Broad-scale information ${ }^{a}$ & Narrow-scale information ${ }^{b}$ \\
\hline Exposure & $\begin{array}{l}\text { Historical average temperature and } \\
\text { precipitation (annual and seasonal) } \\
\text { Likelihood of temperature and } \\
\text { precipitation being outside a defined } \\
\text { range, based on current climate and future } \\
\text { climate scenarios } \\
\text { Temperature and precipitation expressed } \\
\text { together to reflect soil moisture in a } \\
\text { species' or ecosystem's climatic niche }\end{array}$ & $\begin{array}{l}\text { The likelihood that temperature or } \\
\text { precipitation will be outside a known } \\
\text { threshold for selected forest elements } \\
\text { (a species, a process, etc.), based on } \\
\text { current climate and future climate } \\
\text { scenarios }\end{array}$ \\
\hline Sensitivity & $\begin{array}{l}\text { Trends in a species' range, growth or } \\
\text { regeneration, or other expressions of } \\
\text { behaviour that are correlated with } \\
\text { historical climate } \\
\text { Modelled alteration of future species } \\
\text { composition where climate drives change }\end{array}$ & $\begin{array}{l}\text { Historical examples, expert opinion or } \\
\text { traditional knowledge on thresholds } \\
\text { of a climatic factor (e.g. temperature, } \\
\text { precipitation) that causes harmful } \\
\text { effects } \\
\text { Modelled effects of climatic factors on } \\
\text { specific ecological processes }\end{array}$ \\
\hline Impacts & $\begin{array}{l}\text { Changes in species health or forest } \\
\text { composition following a climatic event } \\
\text { Changes in the occurrence of stand- } \\
\text { replacing disturbances (e.g. fire), damaging } \\
\text { insects and disease }\end{array}$ & $\begin{array}{l}\text { Changes in responses of specific } \\
\text { ecological processes } \\
\text { Tree damage or mortality following a } \\
\text { climatic event }\end{array}$ \\
\hline Adaptive capacity & $\begin{array}{l}\text { Presence of attributes that mitigate } \\
\text { harmful effects of climatic events on a } \\
\text { forest (e.g. greater species functional } \\
\text { diversity, which increases the likelihood } \\
\text { that some species will be adapted to } \\
\text { climate conditions) }\end{array}$ & $\begin{array}{l}\text { Species life traits that reflect tolerance } \\
\text { of the effects of climatic events (e.g. the } \\
\text { ability to photosynthesize over a wider } \\
\text { range of environmental conditions) }\end{array}$ \\
\hline
\end{tabular}

Source: FAO, 2018a

a Broad-scale information refers to general features considered at larger levels of organization (e.g. regions, landscapes or watersheds).

b Narrow-scale information refers to more specific features considered at smaller levels of organization (e.g. forest stands or species within them). 


\section{BOX 9}

\section{Resources on species mapping}

An increasing number of studies model potential impacts of climate change for species of interest in a determined area. Examples include assessment of food tree species in Burkina Faso (Gaisberger et al., 2017), projection of banana and coffee production zones in Nepal (Ranjitkar et al., 2016b), and support to agroforestry species selection in Yunnan Province, China (Ranjitkar et al., 2016a).

The ForeCASTS (Forecasts of Climate Associated Shifts in Tree Species) tool (USDA Climate Hubs, undated) uses projections of future climate to produce maps that depict future suitable habitat ranges for North American tree species in the United States and globally.

Suitability of key Central American agroforestry species under future climates: an atlas (de Sousa et al., 2017) presents current and future suitability maps for 54 species that are commonly used as shade in agroforestry systems in Central America. The 54 species that were selected include 24 species of fruit trees, 24 timber trees and six species used to improve soil conditions. 
$x^{m}-y^{2}$

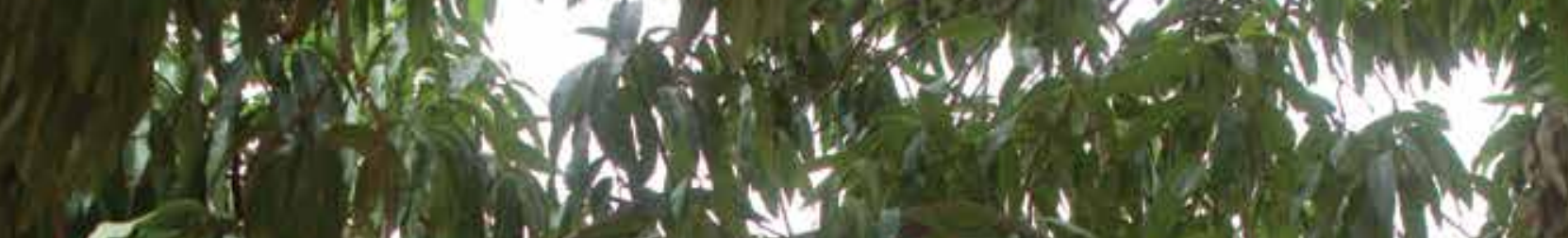

$+p^{2}$,

(8)

Af. $4: 24$

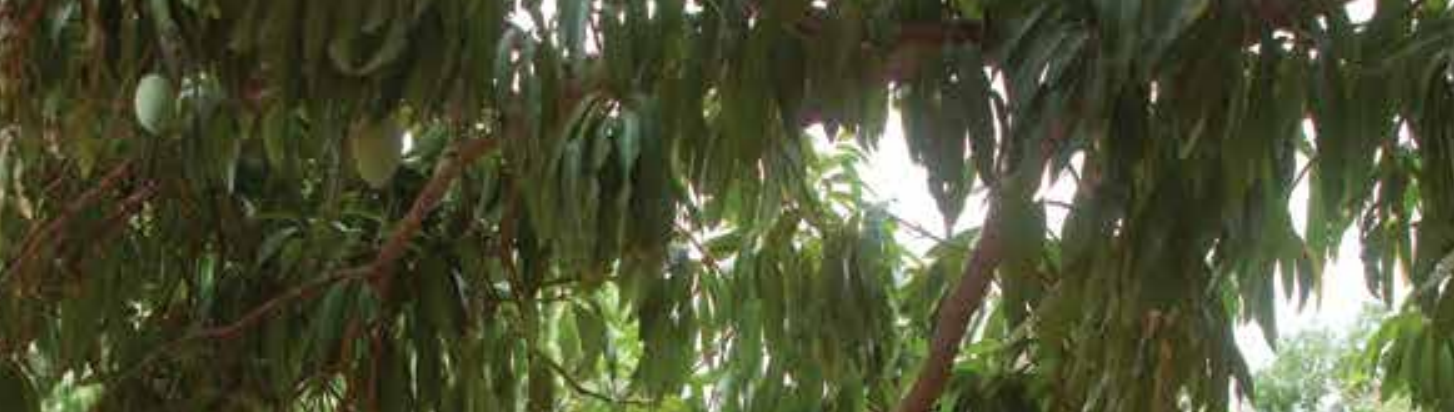

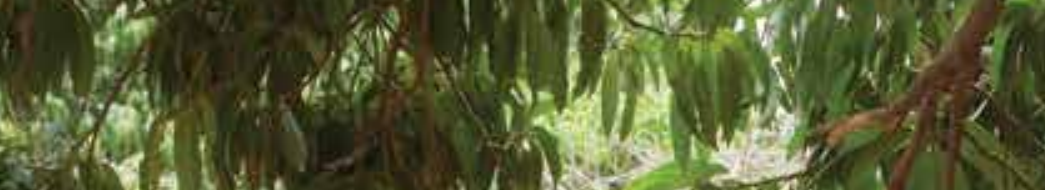

rale

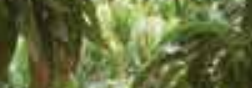

ine

b.

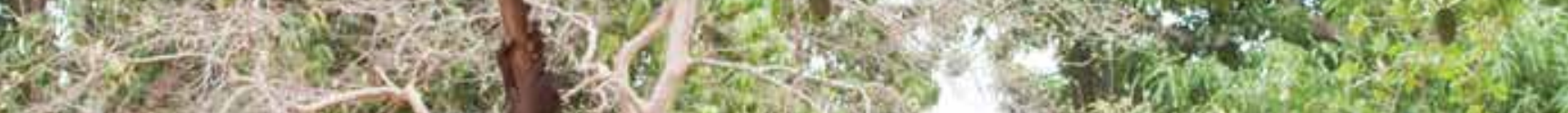

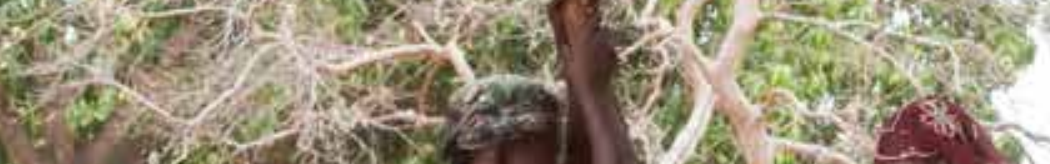

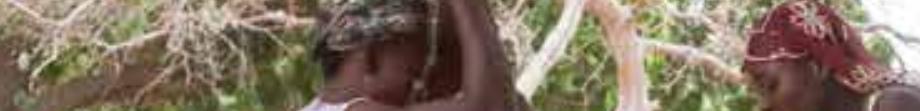
1.

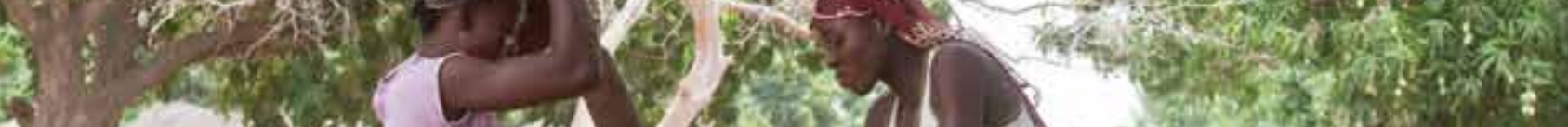

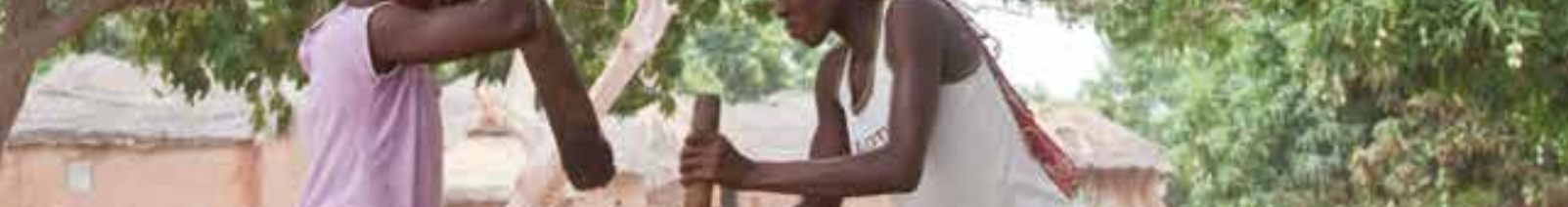
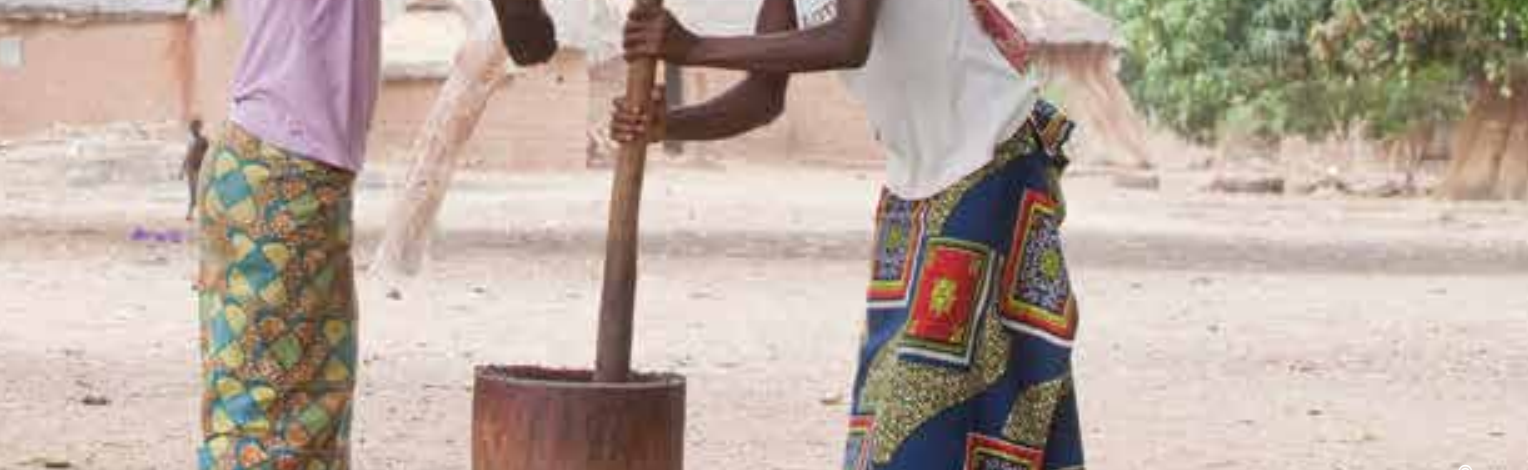


\section{Potential impacts of climate change on forest-dependent people, and their specific vulnerabilities}

For forest-dependent people, the social and economic consequences of the impact of climate change on forest goods and services will largely be influenced by the type and level of forest dependence, other sources of income (many of which are also likely to be vulnerable to climate change) and other sources of vulnerability. All categories of forestdependent people are likely to be affected. Reduced productivity of species of interest, or of a whole forested area, will reduce food availability and diversity as well as income.

These impacts are magnified by the fact that climate change will also affect agriculture, the main other source of food and income for rural communities. Changes in heat and precipitation will modify ecosystems, with consequences for ecosystem services and thus for agricultural production and food security, in what IPCC (2014a) refers to as the "cascading impacts of climate change ... from physical climate through to intermediate systems and then to people" (Figure 7). Populations that depend on forests and trees for the sustainability of their farming systems will particularly suffer the reduced capacity of forests and trees outside forests to provide ecosystem services, such as water regulation, at a time when these services are especially needed. Changes in the quantity, quality and price of agricultural production will affect not only the income of farm households, but also the purchasing power of non-farm households.

Climate change will also have impacts for populations that benefit from forests' role in microclimate regulation, urban and peri-urban cooling and protecting against floods. The ability of forests and trees to buffer shocks may also be compromised, at a time when forest and tree resources would be particularly needed to compensate for crop failures, which are expected to become more common (Box 10).

An assessment of the vulnerability of forest-dependent people requires information on their exposure, sensitivity, impacts and adaptive capacity. Methods to be used for this part of the evaluation generally combine findings generated in the previous stages of the analysis with expert consultations, participatory approaches and vulnerability mapping (Box 11). Demographics, economic conditions and a variety of social statistics can be used as proxies for sensitivity and adaptive capacity. Such information may be available from published statistics and subject-matter experts. Information about exposure to climate change can be extrapolated from information on the types and frequency of past climate impacts. Often, the consideration of future climate change impacts will be evaluated as if the change were occurring in the socio-economic system as it is today. 
FIGURE 7

Cascading impacts of climate change on food security and nutrition

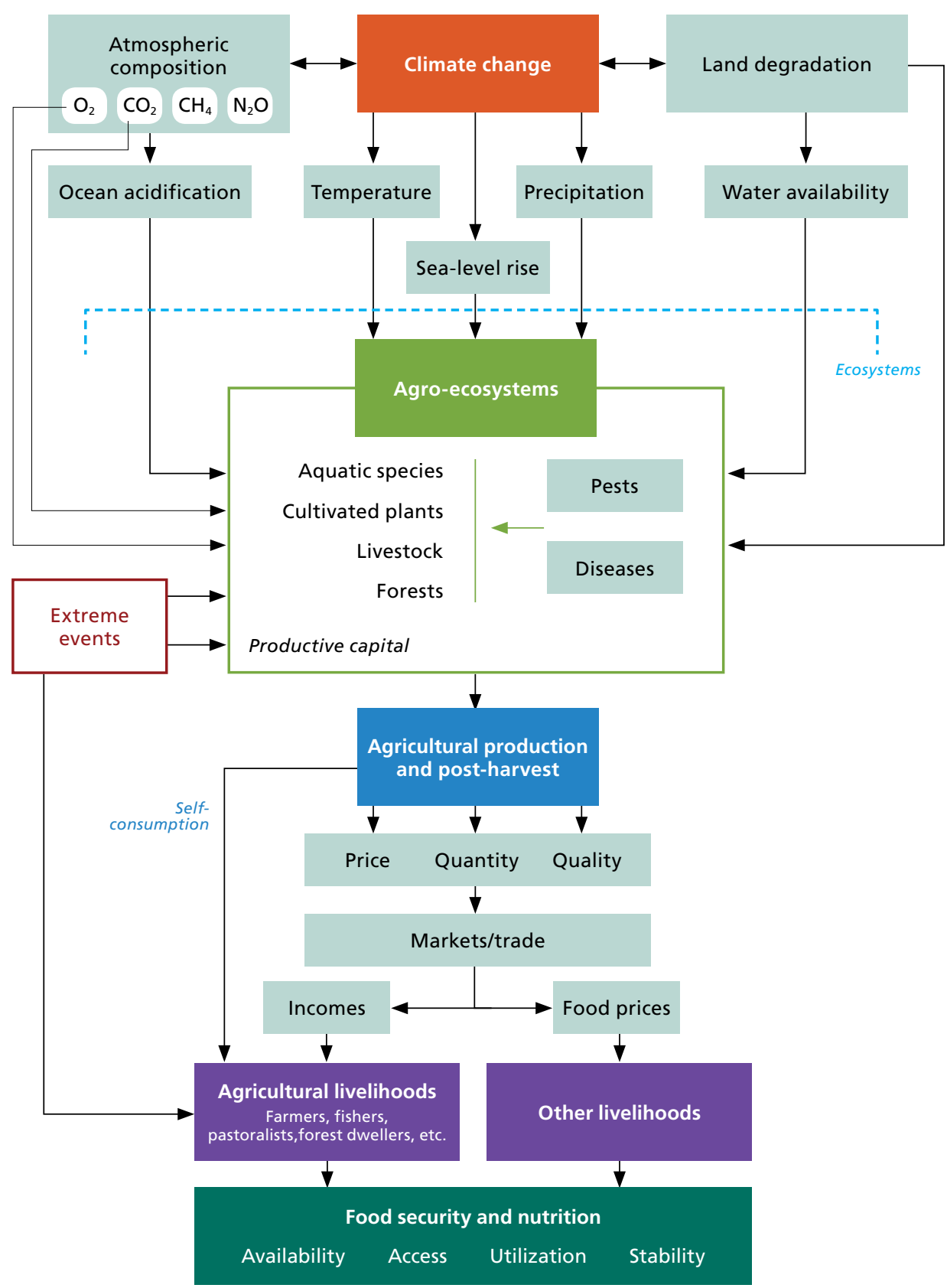




\section{BOX 10 \\ Role of forests in reducing human vulnerability}

Forests and trees often play a key part in the resilience of landscapes, communities and households. This function, particularly evident in times of crisis, may become even more important with climate change, but may also be perturbed by climate change.

Ecosystem services provided by forests and trees are particularly important to reduce the impacts of climate variability and weather-related shocks such as floods, droughts, wind and heat waves. In agroforestry systems, trees can contribute to microclimate regulation, increasing the productivity and resilience of the food production system (Pramova et al., 2012). In a landscape, forested areas between cultivated areas can also act as barriers to the propagation of some pests and diseases.

Trees contribute to a diversification of sources of food and income that can help to buffer economic shocks of any origin. More diversified systems are also likely to offer more resilience to increased volatility of food supply and prices (Vira, Wildburger and Mansourian, 2015).

In many communities, forest foods are used as a safety net during the lean or hungry season or when crops fail (Shackleton and Shackleton, 2004). In semi-arid regions, such as the Sahel, trees and shrubs provide fodder for livestock during the dry season (Franzel et al., 2014).

Forests and trees are used as a safety net to address occasional income needs, particularly in times of conflict, natural disaster or economic crisis. The most vulnerable men and women can find a source of income and employment through the collection and sale of fuelwood and non-wood forest products (Angelsen and Wunder, 2003).

\section{BOX 11}

\section{Participatory methods and tools for assessing impacts of climate change on the vulnerabilities of forest-dependent people}

Participatory approaches enable the vulnerability assessment to take into account the views and experiences of different groups of people that work in, live in, use or value the forest. They can facilitate the combination of diverse data sets and types of information and help to fill knowledge gaps with qualitative data, expert opinion or experiential knowledge.

Participatory action research (reviewed by Rowe and Frewer, 2005), in which the assessment team and local stakeholders share learning and exchange information in a way intended to benefit both parties, has been a popular approach for community vulnerability assessment (e.g. Ampomah and Devisscher, 2013; Bele et al., 2013; Devisscher et al., 2013; Djoudi, Brockhaus and Locatelli, 2013; Locatelli et al., 2008; Obeng et al., 2011; Pavageau, Butterfield and Tiani, 2013; Somda et al., 2014; Tiani et al., 2015). 
Box 11, continued

In participatory exercises (Tiani et al., 2015; Turnbull and Turvill, 2012), the discussion should focus on the community's exposure to climate change; the features, locations or activities (including forest-based subsistence uses and employment activities) that are most sensitive, as perceived by participants based on past impacts; the observed impacts; and the ability of the community to adapt. Separating the participants by gender can provide a wider range of views on the topics and uncover gender-linked vulnerabilities.

Participants can use a risk matrix to rate disturbances in terms of their likelihood of occurrence and the seriousness of the consequences (Figure 8). The level of risk attached to each disturbance type is ranked from highest to lowest, with high impact-highly likely disturbances the greatest risk, followed by high impact-unlikely disturbances and low impact-highly likely disturbances. Low impact-unlikely disturbances pose the lowest risk. Community members can then rank the attributes of the forest and the community for high-impact disturbance types that are highly likely to occur. Each of the disturbances in the high impact-highly likely category can be ranked based on the risk to community interests.

To investigate their current adaptive capacity, forest-dependent people can be asked to identify actions taken to respond to disturbances in the past. Potential measures that were not taken, and the reasons why they were not, should be identified to determine impediments to adaptation.

FIGURE 8

Risk matrix for rating disturbances in terms of their likelihood of occurrence and the seriousness of the consequences

\begin{tabular}{l|l|l}
\hline & High impact & Low impact \\
Likelihood & & \\
\hline Highly unlikely & & \\
\hline Unlikely & & \\
& & \\
\hline
\end{tabular}

Climate change affects men and women in different ways. Women are often more exposed to climate risks, as they tend to be more dependent on natural resources for their livelihoods, have fewer endowments and entitlements to help them to absorb shocks and may not equally benefit from available technologies and practices. For this reason, 
it is important to assess the specific sources of vulnerability for women and girls, their role in the management and conservation of natural resources and their potential as agents of change.

It is extremely important that an evaluation of the potential impacts on the most vulnerable communities be included in the assessment, i.e. women and youth, indigenous and marginalized peoples and communities that depend on threatened resources.

\section{BIOPHYSICAL IMPACTS}

Forest-dependent people may experience direct impact from changes to the forest, such as increased risk of forest fires and floods and impacts on water availability and quality. Depending on the situation of the forest, some of these impacts, particularly on water regulation, can be felt far from the forest itself.

In many countries, forest fires represent a major risk for populations living close to forests. In addition to the direct risks of wildfire, there is also a risk that high-intensity precipitation in the years following wildfire can result in particularly destructive debris flows in burned areas. Landslides are also a risk in some mountain regions.

\section{ECONOMIC IMPACTS}

Economic impacts on a single species, domesticated or not, can be fairly easily assessed. For timber production or other tree-based commodities, simple estimations of the economic consequences of decreased yields can be prepared. The biomass production of a specific forest under modified conditions can also be modelled, from which the economic production of wood can be derived.

These results can be used to estimate the potential impacts on the livelihoods of dependent people, not only those directly involved in harvesting, but also those along the value chain. In some cases, the impact on a single production cycle may result in significant reduction of income, which will have consequences for the livelihoods of dependent people.

Effects on species of interest for tourism or recreational hunting can be estimated in a similar way, starting from the number of people interested in the species or activity.

The effects of the changed composition of a forest may be more difficult to quantify precisely, in part because they generally affect a wide range of goods and services, many of which are not economically quantifiable.

The impacts of climate change on a forest may necessitate remedial interventions, such as the restriction of access to protect the forest or specific species or to reduce fire risks. These measures will in turn affect forest-dependent people and should therefore be included in the analysis.

\section{COMBINATION WITH OTHER VULNERABILITIES (INCLUDING THOSE OF INSTITUTIONAL ORIGIN)}

The assessment needs to consider the importance of forest resources in the overall income of various groups of forest-dependent people. It should also consider alternative sources of income and how they may be affected by climate change. As mentioned above, the impacts of climate change on agriculture, which is usually the other main source of 
income for forest-dependent people, is particularly relevant. These impacts have to be considered in relation to the specific vulnerabilities identified earlier in the assessment. The impacts of historic events, even of a different nature, and the way they were managed may provide useful insight into the adaptive capacity of the population or community.

Especially for groups that are vulnerable to food insecurity and nutritional deficiencies, it may be useful to assess the impacts of climate change in relation to the four dimensions of food security and nutrition (availability, access, utilization and stability), given the multiple roles of forests in providing income, nutritious foods and fuel for cooking as well as in supporting agriculture (HLPE, 2017).

The role of forests and trees in reducing the vulnerability of ecosystems and people to climate change (discussed above in Box 10) should also be considered here.

\section{ANALYSIS OF THE MAIN POINTS OF VULNERABILITY OF FOREST-DEPENDENT PEOPLE}

At this stage, an integrated approach can be used to draw conclusions about some of the main points of vulnerability of forest-dependent people to climate change, highlighting the pathways through which impacts translate from forest to people, and thus the critical points for intervention.

The analysis often presents a challenge because it involves drawing together information from different sources, both quantitative and qualitative, with different levels of accuracy and certainty.

Methods for drawing together the information on the vulnerability components can be grouped into three broad categories: modelling based, indicator based (see example in Box 12) or stakeholder based. Most vulnerability assessments will combine various methods. The selection of an approach will depend on the purpose of the assessment. If the assessment is intended to guide new policy development, thus requiring broad perspectives, then obtaining expert opinion may be the preferred approach. However, if the goal of the assessment is to discern how local factors that vary from one social group to another affect vulnerability, or to provide information to help local people to develop their own strategies for adapting to climate change, then some form of participatory approach is preferable. Box 13 describes a useful tool for combining the information collected from communities and other local experts using participatory methods together with information from desk-based reviews (e.g. scientific information on climate change projections).

\section{BOX 12}

\section{Vulnerability assessment of Mediterranean forests}

A methodology for assessing the vulnerability of Mediterranean forests to climate change was designed in the regional project "Maximize the production of goods and services of Mediterranean forest ecosystems in the context of global changes", funded by the French 
Facility for Global Environment (FFEM) and implemented between 2012 and 2016 in five pilot sites in Algeria, Lebanon, Morocco, Tunisia and Turkey (Picard and Garavaglia, 2017). The methodology relied on satellite images, IPCC climate scenarios and multifactorial spatial analysis $(G I Z, 2013)$ to analyse the factors that influence the current forest cover and future changes and to map them according to different climate scenarios.

Landsat and Spot satellite images were used to produce maps of forest cover at different dates. Five categories of factors that influenced forest cover were collected as spatial layers in a geographic information system (GIS):

- biophysical factors: terrain slope, aspect, soil depth, soil type;

- climatic factors: annual rainfall, water availability index, rainfall seasonality, air temperature, continentality index, Emberger's thermic variant, altitude;

- forest ageing factors: tree age or diameter classes;

- socio-economic factors: population density, livestock density, policy enforcement index;

- fire factors: vegetation type, distance to roads, power lines and residential areas.

The data were analysed using thresholding, weighting and integration to assign a vulnerability index for each factor, and the weighted sum of the five indices was used to define a single synthetic vulnerability index (Figure 9). Using the spatial information on the factors in the GIS, the synthetic vulnerability index was mapped across each study site. The current vulnerability was mapped using the current value of the factors. Projected estimates of the factors were used to predict the future vulnerability in 2020 and 2050.

The results indicated that the direct impacts of climate change on forests (such as drought or temperature-induced forest dieback, decrease of productivity or shifts in species composition [richness and diversity]) and the indirect impacts (such as increased risk of forest fires or increased sensitivity to pests and pathogens) interact with other factors such as human activities, land abandonment or land-use intensification. As a consequence, it is difficult to disentangle the effects of climate change alone from the other drivers that influence forests. The impacts of climate change on forests will threaten the delivery of a range of crucial goods and services such as timber, fuelwood, prevention of soil erosion, water quality, recreation, hunting, fodder, and non-wood forest products (mushrooms, honey, aromatic and medicinal plants, pine nuts, acorns, resin), from which a large number of people derive their income.

The analysis conducted on the pilot sites shows that the vulnerability of Mediterranean forests to climate change is exacerbated by human activities, mostly overgrazing and fuelwood collection and, to a lesser extent, tourism (particularly at sites closer to cities). The vulnerability to climate change could be reduced by implementing sustainable adaptive management options in forest policies. Adaptation options for Mediterranean forests include reducing their vulnerability and strengthening their adaptive capacity by managing forest biodiversity; maintaining forest health and vitality; improving fire suppression and prevention; and adjusting forest management practices (FAO and Plan Bleu, 2013). 
Box 12, continued

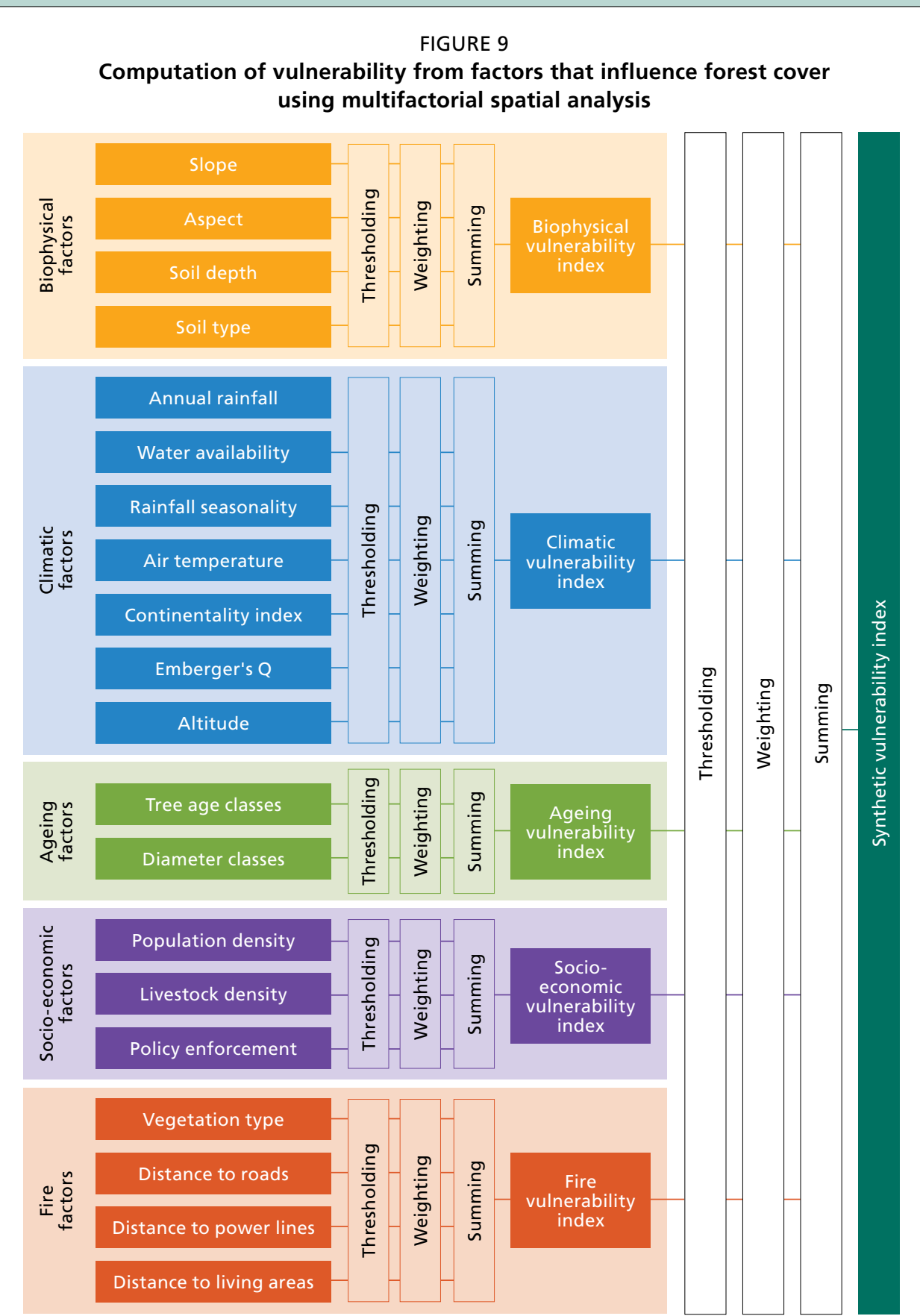

Source: Picard and Garavaglia, 2017 
The assessment may reveal that the main causes of vulnerability are not climate related but require intervention to reduce the impacts of climate change on forest-dependent people. Particular attention needs to be given to people's adaptive capacity, including their collective agency and potential to develop alternative livelihood strategies.

\section{BOX 13 \\ CRiSTAL Forests: a tool for screening community-based risk}

CRiSTAL, the Community-Based Risk Screening Tool for Adaptation and Livelihoods, is a tool to help project planners and managers to integrate climate adaptation into community-level projects (IISD, 2019). It helps users to identify the livelihood resources most important to climate adaptation and uses these as a basis for designing adaptation strategies. While it does not take users through all the steps of a vulnerability assessment (i.e. the collection and analysis of information to identify who and/or what is most vulnerable in a project area and why), it is a tool for gathering and analysing information on local livelihoods and climate in order to understand which livelihood resources should be targeted in project activities so that communities are better able to manage climate risk and adapt to climate change. It helps to identify and prioritize climate risks that projects might address, and also assesses the contribution of development projects to climate adaptation by looking at their influence on critical ecosystem services. By organizing information in a simple and logical format, this tool can facilitate the combination of diverse data sets and types of information and help to fill knowledge gaps with qualitative data, expert opinion or experiential knowledge.

Several specialized versions of the tool are available, including CRiSTAL Parks for protected areas and CRisTAL Forests (IISD et al., 2013), developed with CIFOR. CRiSTAL Forests uses the concept of ecosystem services to analyse the relationship between forests and people's livelihoods, how these linkages transmit climate impacts from ecosystems to livelihoods, and how ecosystem services support local response strategies to climate impacts.

CRISTAL Forests is organized in two modules and five steps:

- Understand the livelihoods, ecosystems and climate context

Step 1. Describe livelihoods, forests and ecosystems services

Step 2. Analyse climate risk

- Evaluate the implications for the project

Step 3. Revise existing project activities

Step 4. Design new project activities

Step 5. Assess potential for mitigation and REDD+

Consultations are central to the CRISTAL process. While some scientific information is required to analyse climate risk (Step 2), the remaining information can be collected through community consultations and discussions with other project stakeholders, for example through site visits, informal meetings and/or organized workshops using participatory rural appraisal tools (e.g. resource mapping, vulnerability matrix) with different social and gender groups. 
Box 13 , continued

CRiSTAL Forests users are encouraged to complement and triangulate the information collected at community level with additional information collected through meetings with researchers, academics, NGOs and government representatives.

Applying CRiSTAL leads to three main outputs: a list of livelihood resources that are most affected by climate hazards and most important for responding to climate impacts; proposed adjustments to existing projects and new activities to support climate adaptation; and a list of desired adaptation outcomes and important influencing factors to be monitored.

Results in West Africa. CIFOR has tested the CRiSTAL Forests tool in more than 60 workshops in West Africa. The results reveal a great diversity of contributions of forests to income and livelihoods, varying by ethnic groups and gender. The buffering role of forest resources is well recognized. However, human activities are also the main source of vulnerability for forests. Forest ecosystem services have enabled people to cope with stress, including climaterelated stress, at least in the short term. However, such short-term use of the forest, often characterized by overexploitation and lack of appropriate measures for regeneration, is likely to jeopardize forest resources in the long term and thus to increase future vulnerabilities. For instance, in many areas of Burkina Faso, the shea tree populations - an important source of income, particularly for women - are ageing as a result of a lack of regeneration measures, often due to the weakening of traditional collective actions.

In the study area, the contribution of forests in reducing future vulnerability will depend on their management and on higher-level commitment to support adaptation efforts at the local level. Even though forests are a key resource for local livelihoods, major efforts are still needed to integrate them into adaptation frameworks at the subnational level, as well as into national action programmes for adaptation. 



\section{Communicating the results and moving ahead}

The analysis and results should be shared with the stakeholders that were consulted at other stages of the assessment, in order to get their feedback, to give them the opportunity to discuss the results and also to orient them towards the next step: the design and implementation of adaptation measures. When forest-dependent people have taken part in the study, their participation at this stage can empower them to make changes to reduce their vulnerability.

This is also the moment to check whether the initial objectives of the assessment have been fulfilled.

\section{DOCUMENT THE PROCESS AND SHARE THE FINDINGS}

The team should prepare and distribute a report describing the results of the assessment. Key sections of the report typically include an executive summary, a description of the methods, the findings and a list of next steps. The report should also describe the actions identified during the assessment that might be implemented to reduce vulnerability.

The methods should be sufficiently detailed so that other project teams can replicate them independently.

The findings should be expressed in the general format of "who (or what) is vulnerable to what?", with emphasis on describing the exposure, sensitivity and adaptive capacity of the forest and forest-dependent people. This form of organization makes it possible to identify the main points of vulnerability, as well as, if possible, those that could be most easily addressed and how. The results should be evaluated in light of whether the assessment adequately addressed the objectives originally established for the project. If not, follow-up activities should be identified that can fill the gaps.

The report can follow the outline of the framework presented in this publication, to show how climate change translates into impacts on forests and forest-dependent people, given their vulnerabilities.

The report can reinforce the results in participants' minds, and may provide an added impetus for finding the resources needed to implement changes that reduce vulnerability.

\section{PLAN SUBSEQUENT STEPS TO IDENTIFY AND PROMOTE ADAPTATION OPTIONS}

The assessment should be followed by the design of adaptation pathways. Indeed, the very process of bringing together stakeholders and raising awareness of vulnerabilities can be the first step leading to improvements. 
Adaptation options identified during the study can be assessed with stakeholders using a validity matrix, which plots the effectiveness of an action for reducing vulnerability against the sustainability of the action in the long term (Figure 10). Adaptation actions that address vulnerabilities with a high aggregate ranking are entered into the matrix. This straightforward process can identify adaptation options that are both highly effective and highly sustainable.

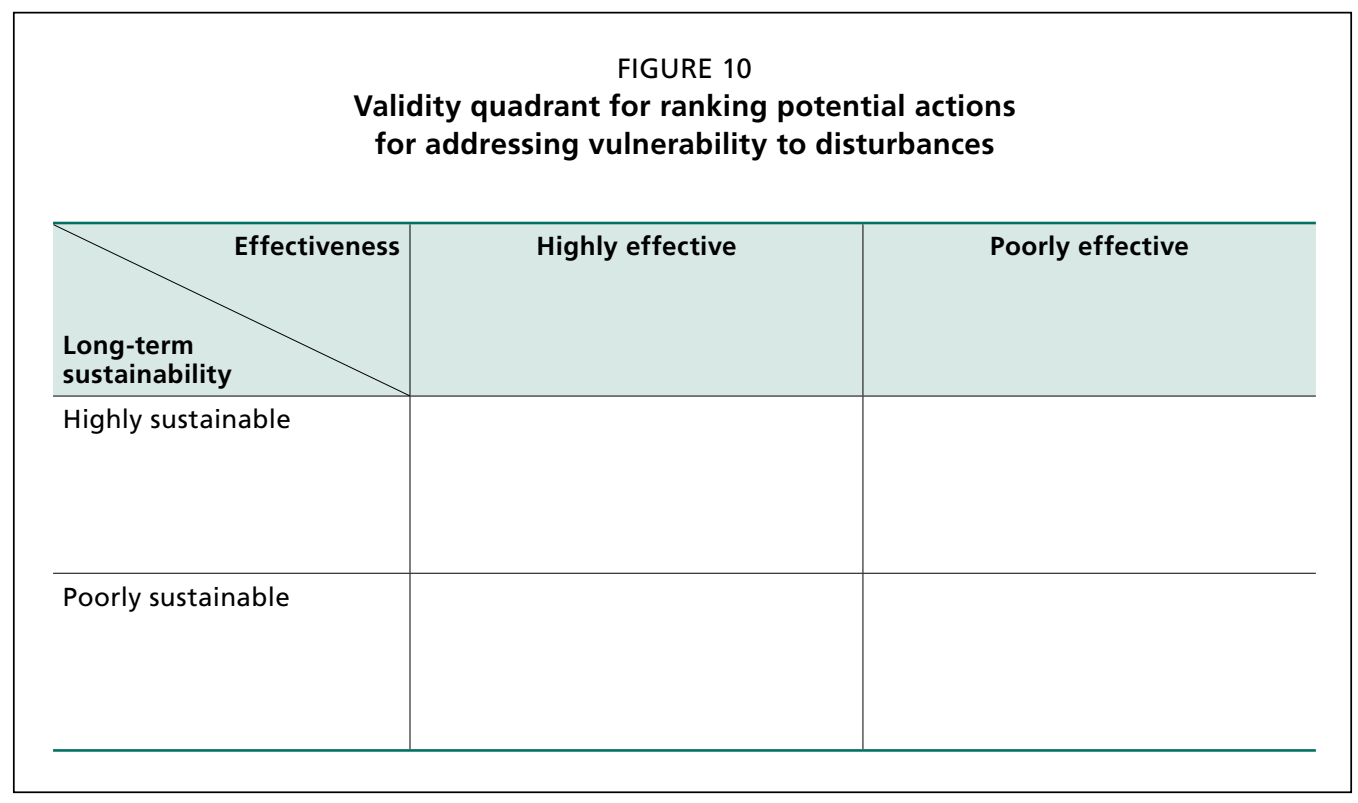





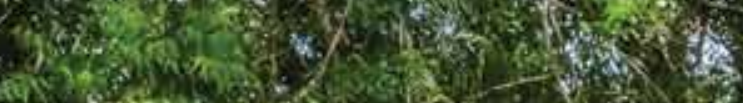

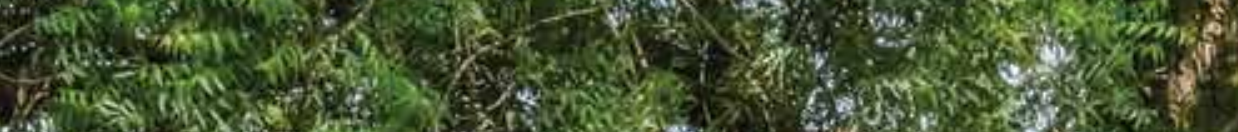
51.

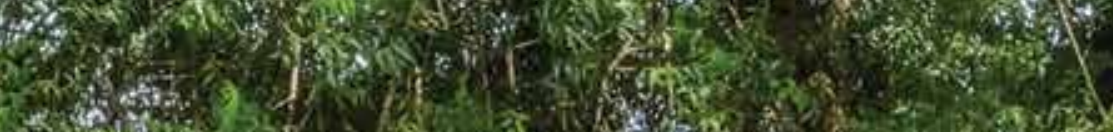

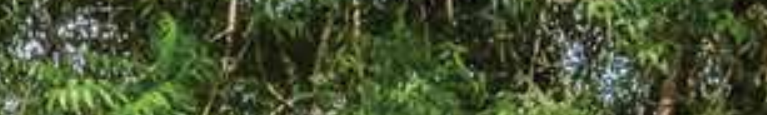

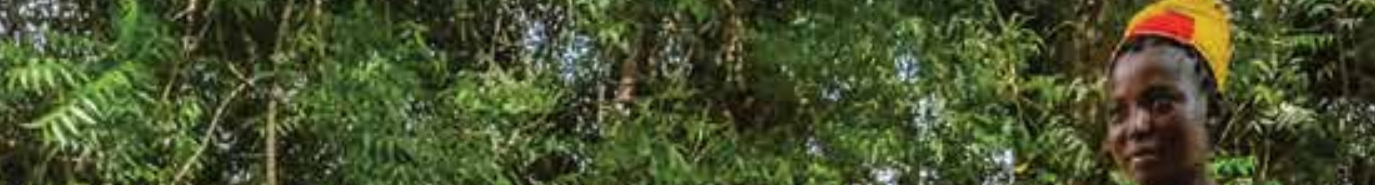

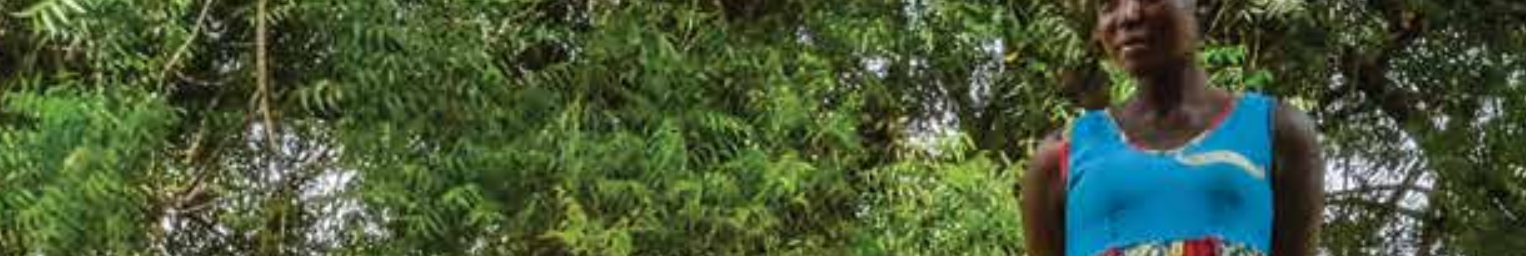

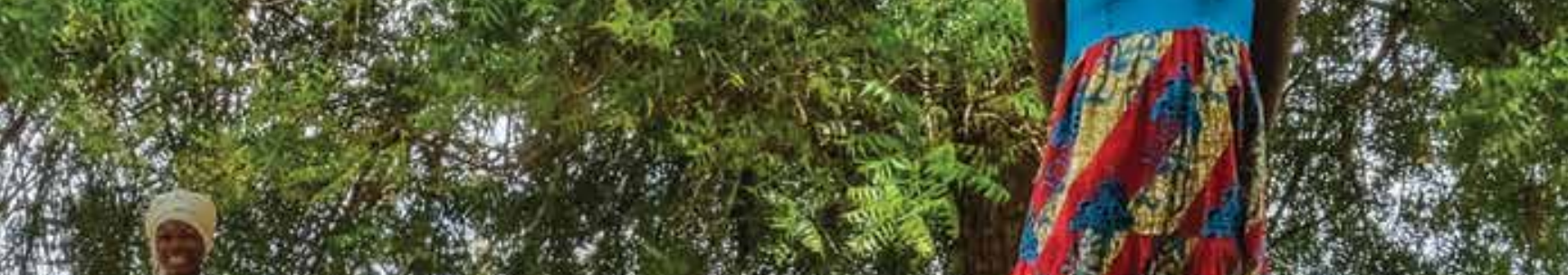

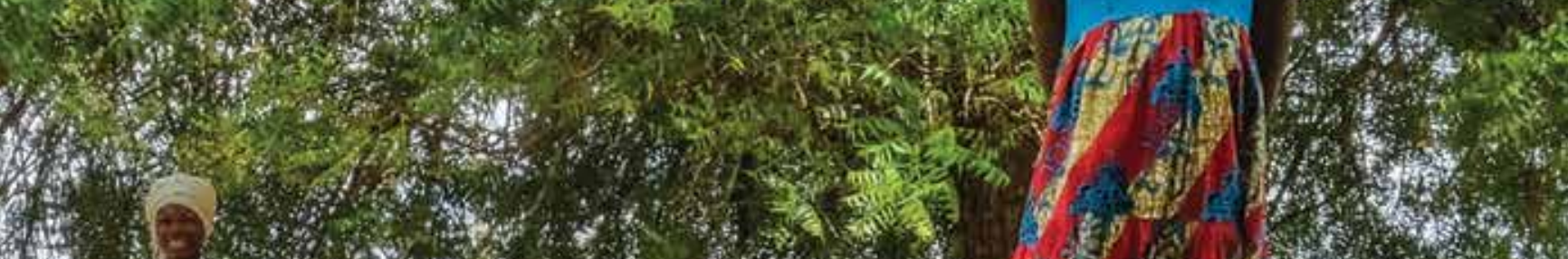

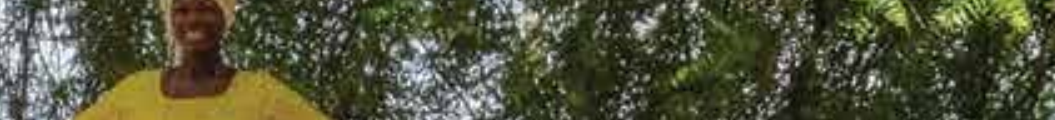

(1)

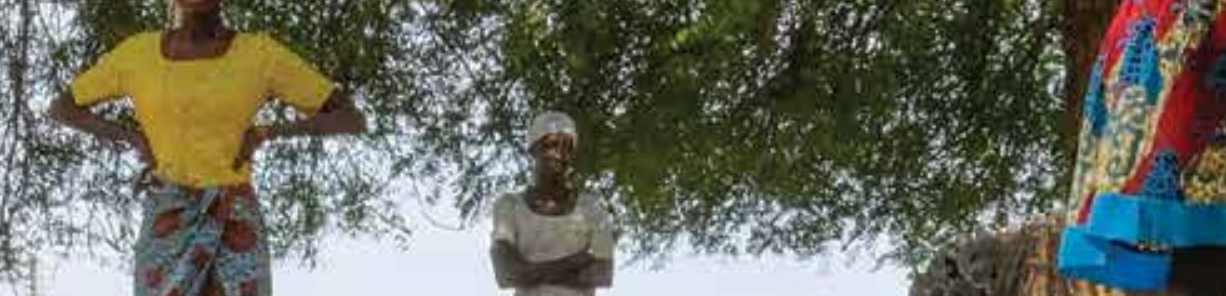
.

Hos.

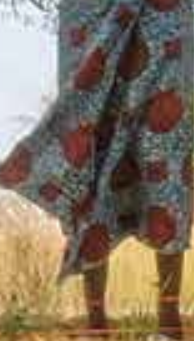

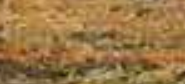

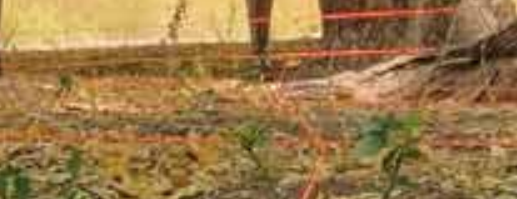

nes.

rind 5 ? -3.5.

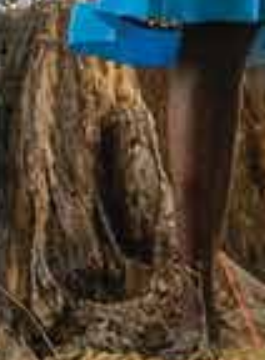

(4) 5 \% (f) ons. (3) tiv. arom

Sise Thes

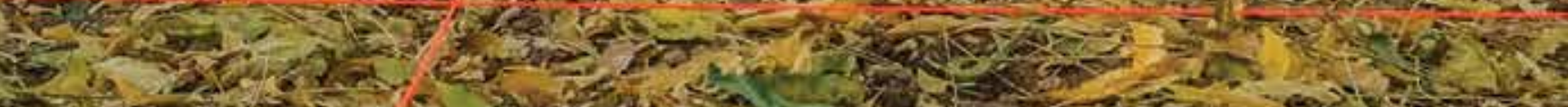

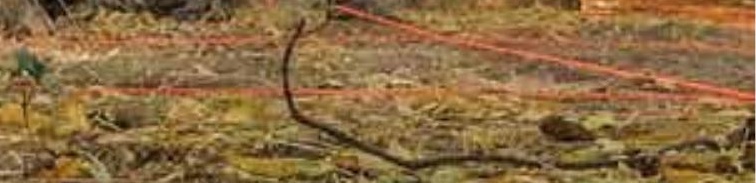
Rein

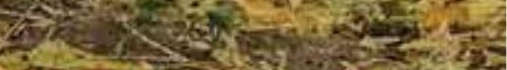

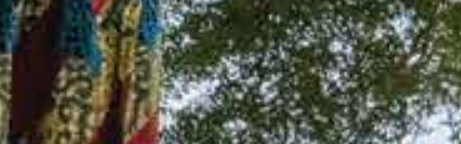

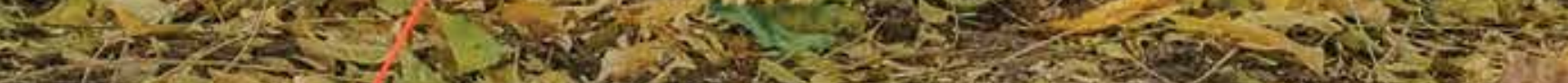

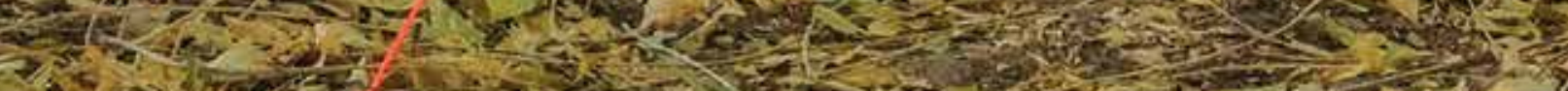
45 thest.

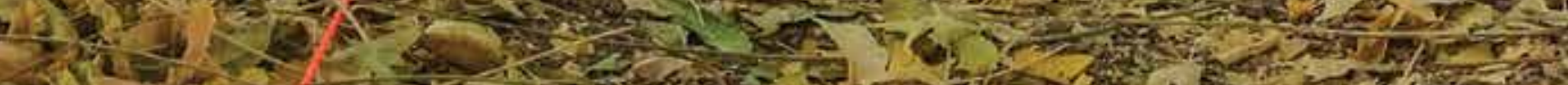

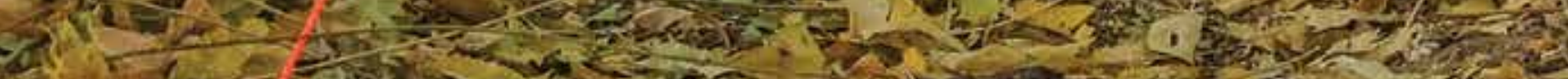

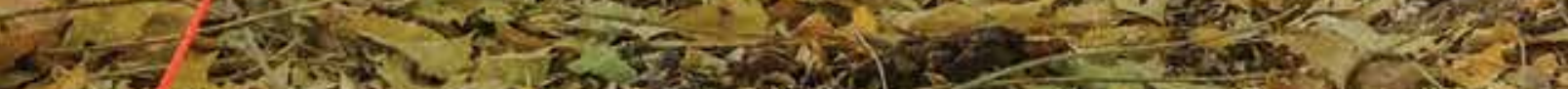

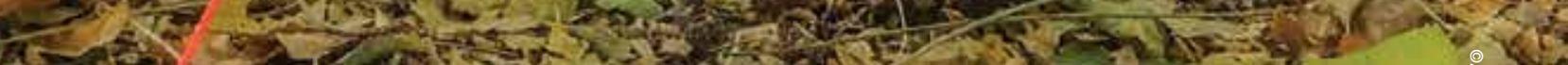

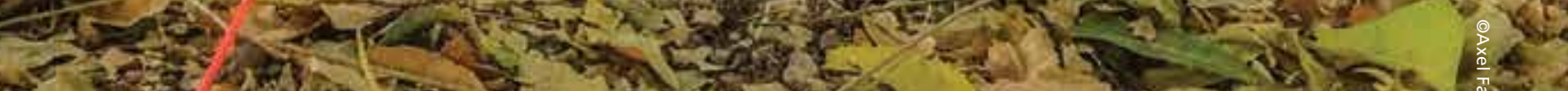

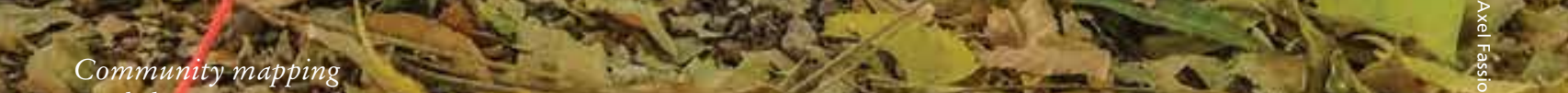

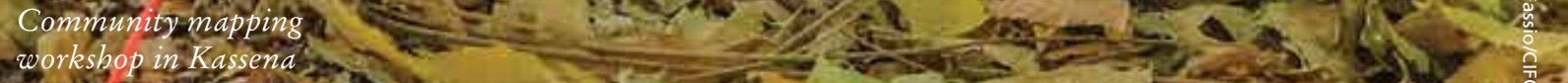

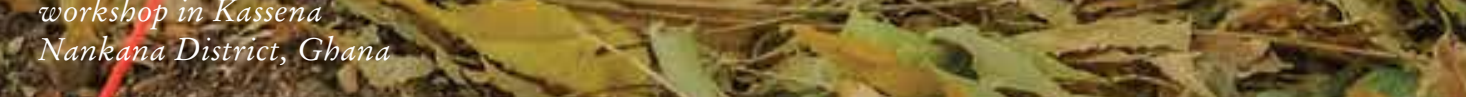




\section{Good practices and principles for vulnerability assessments}

Various authors and organizations have highlighted principles that should guide the preparation and rolling out of a vulnerability assessment. Brugère and De Young (2015) point out that vulnerability analyses should be consistent with the principles of sustainability science (Turner et al., 2003); that they need to focus on people in order to identify "winners" and "losers" from changes and to frame actions targeted at the groups at risk of losing; and that gender, equity and social justice are of critical importance in reducing vulnerability and should thus be incorporated in assessments. Based on these considerations, Brugère and De Young (2015) recommend that assessments should:

- call on varied, flexible and multidisciplinary inputs while integrating local knowledge;

- be specific to a place and its related context, while paying attention to scale issues and interactions;

- recognize multiple and interacting drivers of change (and thus of potential vulnerability);

- account for differential adaptive capacities;

- be based on both prospective and historical information;

- incorporate a significant range of parameters in building quantitative and qualitative pictures of the processes and outcomes of vulnerability.

From the work conducted under the Nairobi Work Programme, the United Nations Framework Convention on Climate Change (UNFCCC, 2011) has highlighted some good practices and lessons learned in assessing climate change impacts and vulnerability (Box 14). Building on these practices and lessons, Brugère and De Young (2015) outline the principles for effective vulnerability assessments presented in Box 15.

BOX 14

Good practices and lessons learned in assessing climate change impacts and vulnerability

Scope. Up-front efforts to engage all relevant stakeholders, analyse the natural and social contexts, and determine the focus and expected outputs of the assessment will prove time well spent.

Selection of methods and tools. The selection of assessment approaches, methods and tools needs to be guided by the purpose of the assessment, the availability of resources and time, and pragmatism. 
Box 14 , continued

Qualitative versus quantitative. Both qualitative and quantitative analyses are helpful. This is particularly important when traditional knowledge and inputs from indigenous communities are incorporated into the assessment process.

Present versus future. Detailed analyses on current trends in climatic patterns, socio-economic trends and adaptation responses could provide many insights into how changes in the future may affect the natural and social systems, and which adaptation options may help to reduce vulnerability. This is particularly important to bear in mind if analyses on future impacts and vulnerability are impeded by uncertainties associated with, among others, climatic and socio-economic scenarios.

Stakeholders. Key stakeholders need to be involved throughout the entire assessment process - they can provide important inputs, as well as validate the interim results.

Collaboration. Inputs from a wide range of disciplines (e.g. science, social science, engineering and economics) are often required. Effective collaboration among experts and stakeholders from different disciplines/sectors is important to ensure the credibility of the assessment results.

Transparency. For the results of assessments to be used effectively and appropriately in adaptation decision planning, it is important to be transparent about the underlying assumptions and caveats of the assessment process and its results.

Disaggregation. Vulnerability and adaptation options will differ by gender, age and demographic groups, and assessments need to allow for such differences.

Source: Brugère and De Young, 2015, adapted from UNFCCC, 2011 


\section{BOX 15}

\section{Principles for effective vulnerability assessments}

- Acknowledge that climate change is typically one among many risks and drivers of change (and may be an amplifier of existing changes) and that its compounded effects may be difficult to single out from these other drivers, or to quantify and predict clearly.

- Base the assessment on an established and agreed-upon framework.

- Use an approach that relies on established and robust methodologies (to ensure accountability and replicability), while allowing for the uniqueness inherent in each context.

- Consider combining and reconciling the strengths of top-down and bottom-up approaches.

- Use the best available information (evidence-based, objective data and models), but also include perceptions or subjective information from stakeholders.

- Ensure that the process is transparent, acknowledging limitations and uncertainties as well as disciplinary biases.

- Be aware of winners and losers, who may need to be identified for different time frames and/or geographic scales.

- Acknowledge the benefits and limitations of working at any particular scale, and recognize that the findings of the vulnerability assessment may be limited to a predetermined scale, as deemed relevant.

- Account for the different needs of end users, and use communication channels relevant to the context.

- Adopt an iterative, participatory and multi-stakeholder process. 


\section{References}

Alexander, C., Bynum, N., Johnson, E., King, U., Mustonen, T., Neofotis, P., Oettlé, N., Rosenzweig, C., Sakakibara, C., Shadrin, V., Vicarelli, M., Waterhouse, J. \& Weeks, B. 2011. Linking indigenous and scientific knowledge of climate change. BioScience, 61(6): 477-484.

Ampomah, G. \& Devisscher, T. 2013. Adaptation toolkit: guidebook for researchers and adaptation practitioners working with local communities. Dakar, Senegal, Energie, Environnement, et Développement (ENDA).

Angelsen, A. \& Wunder, S. 2003. Exploring the forest-poverty link: key concepts, issues and research implications. CIFOR Occasional Paper No. 40, Bogor, Indonesia, CIFOR.

Angelsen, A., Jagger, P., Babigumira, R., Belcher, B., Hogarth, N.J., Bauch, S., Börner, J., Smith-Hall, C. \& Wunder, S. 2014. Environmental income and rural livelihoods: a global-comparative analysis. World Development, 64(1): S12-S28.

Bee, B.A. 2016. Power, perception and adaptation: exploring gender and social-environmental risk perception in northern Guanajuato, Mexico. Geoforum, 69: 71-80

Bele, M.Y., Tiani, A.M., Somorin, O.A. \& Sonwa, D.J. 2013. Exploring vulnerability and adaptation to climate change of communities in the forest zone of Cameroon. Climatic Change, 119(3-4): 875-889.

Beardmore, T. \& Winder, R. 2011. Review of science-based assessments of species vulnerability: contributions to decision-making for assisted migration. The Forestry Chronicle, 87(6): 745-754.

Belghazi, B. \& Mounir, F. 2016. Analyse de vulnérabilité des écosystèmes forestiers méditerranéens au changement climatique: forêt de la Maâmora (Maroc). Rome, FAO \& Valbonne, France, Plan Bleu pour l'Environnement et le Développement en Méditerranée.

Berkes, F., Colding, J. \& Folke, C. 2000. Rediscovery of traditional ecological knowledge as adaptive management. Ecological Applications, 10(5): 1251-1262.

Borja-Vega, C. \& de la Fuente, A. 2013. Municipal vulnerability to climate change and climate related events in Mexico. Washington, DC, World Bank.

Bostedt, G., Widmark, C., Andersson, M. \& Sandström, C. 2015. Measuring transaction costs for pastoralists in multiple land use situations: reindeer husbandry in northern Sweden. Land Economics, 91(4): 704-722.

Braatz, S. 2012. Building resilience for adaptation to climate change through sustainable forest management. In A. Meybeck, J. Lankoski, S. Redfern, N. Azzu \& V. Gitz, eds. Building resilience for adaptation to climate change in the agriculture sector, pp. 117-127. Proceedings of a joint FAO/OECD workshop, 23-24 April 2012. Rome, FAO.

Breshears, D.D., Huxman, T.E., Adams, H.D., Zou, C.B. \& Davison, J.E. 2008. Vegetation synchronously leans upslope as climate warms. Proceedings of the National Academy of Sciences of the United States of America, 105: 11591-11592. 
Brockhaus, M., Djoudi, H. \& Locatelli, B. 2013. Envisioning the future and learning from the past: adapting to a changing environment in northern Mali. Environmental Science E Policy, 25: 94-106.

Brody, A., Demetriades, J. \& Esplen, E. 2008. Gender and climate change: mapping the linkages - a scoping study on knowledge and gaps. Brighton, UK, Institute of Development Studies.

Brugère, C. \& De Young, C. 2015. Assessing climate change vulnerability in fisheries and aquaculture: available methodologies and their relevance for the sector. FAO Fisheries and Aquaculture Technical Paper No. 597. Rome, FAO.

Buckle, P., Marsh, G. \& Smale, S. 2001. Assessing resilience and vulnerability: principles, strategies and actions. Canberra, Emergency Management Australia.

Burton, P.J., Bergeron, Y., Bogdansky, B.E.C., Juday, G.P., Kuuluvainen, T., McAfee, B.J., Ogden, A., Teplyakov, V.K., Alfaro, R.I., Francis, D.A., Gauthier, S. \& Hantula, J. 2010. Sustainability of boreal forests and forestry in a changing environment. In G. Mery, P. Katila, G. Galloway, R. Alfaro, M. Kanninen, M. Lobovikov \& J. Varjo, eds. Forests and society - responding to global drivers of change, pp. 249-282. IUFRO World Series Vol. 25. Vienna, International Union of Forest Research Organizations.

Butler, J.R.A., Suadnya, W., Yanuartati, Y., Meharg, S., Wise, R.M., Sutaryono, Y. \& Duggan, K. 2016. Priming adaptation pathways through adaptive co-management: design and evaluation for developing countries. Climate Risk Management, 12: 1-16.

CIFOR, ICRAF, CGIAR, Bioversity \& CIAT (International Center for Tropical Agriculture). 2011. CGIAR Research Program 6 proposal - Forests, Trees and Agroforestry: Livelihoods, Landscapes and Governance. Bogor, Indonesia, CIFOR.

Clark, J.S., Gelfand, A.E., Woodall, C.W. \& Zhu, K. 2014. More than the sum of the parts: forest climate response from joint species distribution models. Ecological Applications, 24(5): 990-999.

Coops, N.C., Hember, R.A., Waring, R.H. 2010. Assessing the impact of current and projected climates on Douglas-fir productivity in British Columbia, Canada, using a process-based model (3-PG). Canadian Journal of Forest Research, 40(3): 511-524.

CSIRO (Commonwealth Scientific and Industrial Research Organisation). 2015. Climate change in Australia - Projections for Australia's NRM regions [online]. [Cited 6 March 2019]. www.climatechangeinaustralia.gov.au/en/climate-projections

d'Annunzio, R., Gianvenuti, A., Henry, M. \& Thulstrup, A. 2016. Manual for assessing woodfuel supply and demand in displacement settings. Rome, FAO \& Office of the United Nations High Commissioner for Refugees (UNHCR).

Dasgupta, S., Hossain, M., Huq, M. \& Wheeler, D. 2014. Climate change, soil salinity, and the economics of high-yield rice production in coastal Bangladesh. World Bank Policy Research Working Paper No. 7140. Washington, DC, World Bank.

Daust, D., Morgan, D., Holt, R., Utzig, G., Zielke, K., Nelson, H. \& Change, P.C. 2011. Comparison of regional vulnerability assessments. In D. Morgan \& D. Daust, eds. A climate change vulnerability assessment for British Columbia's managed forests. Government of British Columbia, Canada. 
Dazé, A., Ambrose, K. \& Ehrhart, C. 2009. Climate vulnerability and capacity analysis bandbook. Care International.

de Sousa, K., van Zonneveld, M., Imbach, P., Casanoves, F., Kindt, R. \& Ordonez, J.C. 2017. Suitability of key Central American agroforestry species under future climates: an atlas. ICRAF Occasional Paper No. 26. Turrialba, Costa Rica, ICRAF.

Devisscher, T., Bharwani, S., Tiani, A.M., Pavageau, C., Kwack, N.E. \& Taylor, R. 2013. Current vulnerability in the Tri-National de la Sangha landscape, Cameroon. Working Paper No. 107. Bogor, Indonesia, CIFOR.

DFID (Department for International Development, UK). 1999. Sustainable Livelihoods Guidance Sheets. London. Available at: www.livelihoodscentre.org/intro

Djoudi, H. \& Brockhaus, M. 2011. Is adaptation to climate change gender neutral? Lessons from communities dependent on livestock and forests in northern Mali. International Forestry Review, 13(2): 123-135.

Djoudi, H., Brockhaus, M. \& Locatelli, B. 2013. Once there was a lake: vulnerability to environmental changes in northern Mali. Regional Environmental Change, 13(3): 493-508.

Duveneck, M.J., Scheller, R.M., White, M.A., Handler, S.D. \& Ravenscroft, C. 2014. Climate change effects on northern Great Lake (USA) forests: a case for preserving diversity. Ecosphere, 5(2): 1-26.

Ellison, J.C. 2012. Climate change vulnerability assessment and adaptation planning for mangrove systems. Washington, DC, World Wildlife Fund (WWF).

FAO. 2006. Fire management: voluntary guidelines - principles and strategic actions. Fire Management Working Paper No. 17. Rome.

FAO. 2009. Global review of forest pests and diseases. FAO Forestry Paper No. 156. Rome.

FAO. 2013. Climate change guidelines for forest managers. Rome.

FAO. 2016. Climate change and food security: risks and responses. Rome.

FAO. 2017. Climate-smart forestry. In Climate Smart Agriculture Sourcebook, digital edition [online]. [Cited 12 July 2019]. www.fao.org/climate-smart-agriculture-sourcebook/ production-resources/module-b3-forestry/chapter-b3-1

FAO. 2018a. A review of existing approaches and methods to assess climate change vulnerability of forests and forest-dependent people. Forestry Working Paper No. 5. Rome.

FAO. 2018b. Guidance note on gender-sensitive vulnerability assessments in agriculture. Rome.

FAO, CIFOR, IFRI (International Forestry Resources and Institutions Research Network) \& World Bank. 2016. National socioeconomic surveys in forestry: guidance and survey modules for measuring the multiple roles of forests in bousebold welfare and liveliboods, by R.K. Bakkegaard, A. Agrawal, I. Animon, N. Hogarth, D. Miller, L. Persha, E. Rametsteiner, S. Wunder \& A. Zezza. FAO Forestry Paper No. 179. Rome.

FAO \& Plan Bleu. 2013. State of Mediterranean Forests 2013. Rome.

Farquhar, G.D., Von Cammerer, S. \& Berry, J.A. 1980. A biochemical model of photosynthetic $\mathrm{CO}_{2}$ assimilation in leaves of C3 species. Planta, 149: 78-90.

Fisher, R.J., Srimongkontip, S. \& Veer, C. 1997. People and forests in Asia and the Pacific: situation and prospects. FAO/RAPA Working Paper APFSOS/WP/27. Bangkok, FAO Regional Office for Asia and the Pacific. 
Foden, W.B. \& Young, B.E. 2016. IUCN SSC Guidelines for Assessing Species' Vulnerability to Climate Change, Version 1.0. Occasional Paper of the IUCN Species Survival Commission No. 59. Cambridge, UK \& Gland, Switzerland, International Union for Conservation of Nature (IUCN) Species Survival Commission.

Franzel, S., Carsan, S., Lukuyu, B., Sinja, J. \& Wambugu, C. 2014. Fodder trees for improving livestock productivity and smallholder livelihoods in Africa. Current Opinion in Environmental Sustainability, 6: 98-103.

Füssel, H.M. \& Klein, R.J. 2006. Climate change vulnerability assessments: an evolution of conceptual thinking. Climatic Change, 75(3): 301-329.

Gaisberger, H., Kindt, R., Loo, J., Schmidt, M., Bognounou, F., Da, S.S., Diallo, O.B., Ganaba, S., Gnoumou, A., Lompo, D., Lykke, A.M., Mbayngone, E., Nacoulma, B.M.I., Ouedraogo, M., Ouédraogo, O. Parkouda, C., Porembski, S., Savadogo, P., Thiombiano, A., Zerbo, G. \& Vinceti, B. 2017. Spatially explicit multi-threat assessment of food tree species in Burkina Faso: a fine-scale approach. PLOS ONE, 12(9): e0184457.

Gallopín, G.C. 2006. Linkages between vulnerability, resilience, and adaptive capacity. Global Environmental Change, 16(3): 293-303.

Garibaldi, L.A., Carvalheiro, L.G., Vaissière, B.E., Gemmill-Herren, B., Hipólito, J., Freitas, B.M., Ngo, H.T., Azzu, N., Sáez, A., Åström, J., An, J., Blochtein, B., Buchori, D., Chamorro García, F.J., da Silva, F.O., Devkota, K., de Fátima Ribeiro, M., Freitas, L., Gaglianone, M.C., Goss, M., Irshad, M., Kasina, M., Pacheco Filho, A.J.S., Piedade Kiill, L.H., Kwapong, P., Nates Parra, G., Pires, C., Pires, V., Rawal, R.S., Rizali, A., Saraiva, A.M., Veldtman, R., Viana, B.F., Witter, S. \& Zhang, H. 2016. Mutually beneficial pollinator diversity and crop yield outcomes in small and large farms. Science, 351(6271): 388-391.

Gebrekirstos, A., Bräuning, A., Sass-Klassen, U. \& Mbow, C. 2014. Opportunities and applications of dendrochronology in Africa. Current Opinion in Environmental Sustainability, 6: 48-53.

Ghini, R., Hamada, E., Pedro, M.J. Jr., Marengo, J.A. \& do Valle Gonçalves, R.R. 2008. Risk analysis of climate change on coffee nematodes and leaf miner in Brazil. Pesquisa Agropecuária Brasileira, 43: 187-194.

Gitz, V. \& Meybeck, A. 2012. Risks, vulnerabilities and resilience in a context of climate change. In A. Meybeck, J. Lankoski, S. Redfern, N. Azzu \& V. Gitz, eds. Building resilience for adaptation to climate change in the agriculture sector, pp. 19-36. Proceedings of a Joint FAO/OECD Workshop, 23-24 April 2012. Rome, FAO.

GIZ (German Agency for International Cooperation). 2013. Guide méthodologique: approche spatiale multifactorielle d'analyse de la vulnérabilité des écosystèmes face au changement climatique - cas de la subéraie en Tunisie. Tunis.

GIZ. 2014. The vulnerability sourcebook: concept and guidelines for standardised vulnerability assessments, by K. Fritzsche, S. Schneiderbauer, P, Bubeck, S. Kienberger, M. Buth, M. Zebisch \& W. Kahlenborn. Bonn \& Eschborn, Germany.

Guariguata, M.R., Locatelli, B. \& Haupt, F. 2012. Adapting tropical production forests to global climate change: risk perceptions and actions. International Forestry Review, 14(1): 27-38. 
Hanna, P. \& Kulakowski, D. 2012. The influences of climate on aspen dieback. Forest Ecology and Management, 274: 91-98.

Hiltner, U., Bräuning, A., Gebrekirstos, A., Huth, A. \& Fischer, R. 2016. Impacts of precipitation variability on the dynamics of a dry tropical montane forest. Ecological modelling, 320: 92-101.

HLPE (High Level Panel of Experts on Food Security and Nutrition of the Committee on World Food Security). 2013. Investing in smallholder agriculture for food security. Rome. HLPE. 2017. Sustainable forestry for food security and nutrition. Rome.

Holling, C.S. 1973. Resilience and stability of ecological systems. Annual Review of Ecology and Systematics, 4(1): 1-23.

IISD (International Institute for Sustainable Development). 2019. CRiSTAL Communitybased Risk Screening Tool - Adaptation and Livelihoods [online]. [Cited 4 April 2019]. www.iisd.org/cristaltool

IISD, CIFOR, IUCN, SEI (Stockholm Environment Institute) \& Helvetas. 2013. CRiSTAL Forests user's manual: Community-based Risk Screening Tool-Adaptation and Liveliboods. Focus on Forests and Ecosystems. Winnipeg, Canada, IISD.

Infield, M. \& Mugisha, A. 2010. Integrating cultural, spiritual and etbical dimensions into conservation practice in a rapidly changing world. MacArthur Foundation Conservation White Paper Series. Chicago, USA, MacArthur Foundation.

IPCC (Intergovernmental Panel on Climate Change). 2014a. Climate change 2014: synthesis report. Contribution of Working Groups I, II and III to the Fifth Assessment Report of the Intergovernmental Panel on Climate Change, ed. R.K. Pachauri \& L.A. Meyer. Geneva, Switzerland.

IPCC. 2014b. Annex II: Glossary. In V.R. Barros, C.B. Field, D.J. Dokken, M.D. Mastrandrea, K.J. Mach, T.E. Bilir, M. Chatterjee, K.L. Ebi, Y.O. Estrada, R.C. Genova, B. Girma, E.S. Kissel, A.N. Levy, S. MacCracken, P.R. Mastrandrea \& L.L. White, eds. Climate change 2014: impacts, adaptation, and vulnerability, Part B, Regional aspects, pp. 1757-1776. Contribution of Working Group II to the Fifth Assessment Report of the Intergovernmental Panel on Climate Change. Cambridge, UK \& New York, USA, Cambridge University Press.

Joyce, D.G. \& Rehfeldt, G.E. 2013. Climatic niche, ecological genetics, and impact of climate change on eastern white pine (Pinus strobus L.): guidelines for land managers. Forest Ecology and Management, 295: 173-192.

Kirtman, B., Power, S.B., Adedoyin, J.A., Boer, G.J., Bojariu, R., Camilloni, I., Doblas-Reyes, F.J., Fiore, A.M., Kimoto, M., Meehl, G.A., Prather, M., Sarr, A., Schär, C., Sutton, R., van Oldenborgh, G.J., Vecchi, G. \& Wang, H.J. 2013. Near-term climate change: projections and predictability. In T.F. Stocker, D. Qin, G.-K. Plattner, M. Tignor, S.K. Allen, J. Boschung, A. Nauels, Y. Xia, V. Bex \& P.M. Midgley, eds. Climate change 2013: the physical science basis. Contribution of Working Group I to the Fifth Assessment Report of the Intergovernmental Panel on Climate Change. Cambridge, UK, $\&$ New York, USA, Cambridge University Press.

Koca, D., Smith, B. \& Sykes, M.T. 2006. Modelling regional climate change effects on potential natural ecosystems in Sweden. Climatic Change, 78(2-4): 381-406. 
Lambrou, Y. \& Piana, G. 2006. Gender: the missing component of the response to climate change. Rome, FAO.

Locatelli, B., Herawati, H., Brockhaus, M., Idinoba, M. \& Kanninen, M. 2008. Methods and tools for assessing the vulnerability of forests and people to climate change: an introduction. CIFOR Working Paper No. 43. Bogor, Indonesia, CIFOR.

Lucier, A., Ayres, M., Karnosky, D., Thompson, I., Loehle, C., Percy, K. \& Sohngen, B. 2009. Forest responses and vulnerabilities to recent climate change. In R. Seppala, A. Buck $\&$ P. Katila, eds. Adaptation of forests and people to climate change - a global assessment report, pp. 29-52. IUFRO World Series No. 22. Helsinki, IUFRO.

Luedeling, E., Muthuri, C. \& Kindt, R. 2013. Ecosystem vulnerability to climate change: a literature review. Working Paper No. 162. Nairobi, ICRAF.

Luedeling, E., Steinmann, K.P., Zhang, M., Brown, P.H., Grant, J. \& Girvetz, E.H. 2011. Climate change effects on walnut pests in California. Global Change Biology, 17: 228-238.

MA (Millennium Ecosystem Assessment). 2005. Ecosystems and buman well-being: current state and trends, ed. R. Hassan, R. Scholes \& N. Ash. Washington, DC, Island Press.

Man, R., Kayahara, G.J., Dang, Q.L. \& Rice, J.A. 2009. A case of severe frost damage prior to budbreak in young conifers in Northeastern Ontario: consequence of climate change? The Forestry Chronicle, 85(3): 453-462.

Mather, A.S. \& Needle, C.L. 1998. The forest transition: a theoretical basis. Area, 30(2): 117-124.

Mazzocchi, F. 2006. Western science and traditional knowledge. EMBO Reports, 7(5): 463-466.

Met Office. undated. PRECIS: a regional climate modelling system [online]. [Cited 7 March 2019]. www.metoffice.gov.uk/research/applied/international-development/precis

Miller, F., Osbahr, H., Boyd, E., Thomalla, F., Bharwani, S., Ziervogel, G., Walker, B., Birkmann, J., Van der Leeuw, S., Rockström, J., Hinkel, J., Downing, T., Folke, C. \& Nelson, D. 2010. Resilience and vulnerability: complementary or conflicting concepts? Ecology and Society, 15(3): 11-36.

Mimura, N., Pulwarty, R.S., Duc, D.M., Elshinnawy, I., Redsteer, M.H., Huang, H.Q., Nkem, J.N. \& Sanchez Rodriguez, R.A. 2014. Adaptation planning and implementation. In C.B. Field, V.R. Barros, D.J. Dokken, K.J. Mach, M.D. Mastrandrea, T.E. Bilir, M. Chatterjee, K.L. Ebi, Y.O. Estrada, R.C. Genova, B. Girma, E.S. Kissel, A.N. Levy, S. MacCracken, P.R. Mastrandrea \& L.L.White, eds. Climate change 2014: Impacts, adaptation and vulnerability, Part A, Global and sectoral aspects, pp. 869-898. Cambridge, UK \& New York, USA, Cambridge University Press.

Narain, U., Gupta, S. \& van 't Veld, K. 2008. Poverty and the environment: exploring the relationship between household incomes, private assets and natural assets. Land Economics, 84(1): 148-167.

Nelson, D.R., Adger, W.N. \& Brown, K. 2007. Adaptation to environmental change: contributions of a resilience framework. Annual Review of Environment and Resources, 32: 395-419.

Obeng, E.A., Owusu-Sekyere, E., Dumenu, W.K., Nutakor, E.E., Samar, S.B. \& Opoku, E.A. 2011. Climate change and forest dependent livelihoods: vulnerabilities and impacts. Technical report, Government of Ghana Project. 
O’Brien, K., Leichenko, R., Kelkar, U., Venema, H., Aandahl, G., Tompkins, H., Javed, A., Bhadwal, S., Barg, S., Nygaard, L. \& West, J. 2004. Mapping vulnerability to multiple stressors: climate change and globalization in India. Global Environmental Change, 14(4): 303-313.

O’Brien, K., Eriksen, S., Nygaard, L. P. \& Schjolden, A. 2007. Why different interpretations of vulnerability matter in climate change discourses. Climate Policy, 7(1): 73-88.

Ogden, A.E. \& Innes, J. 2007. Incorporating climate change adaptation considerations into forest management planning in the boreal forest. International Forestry Review, 9(3): 713-733.

Ostrom, E. 2011. Background on the institutional analysis and development framework. Policy Studies Journal, 39(1): 7-27.

Park, S.E., Marshall, N.A., Jakku, E., Dowd, A.M., Howden, S.M., Mendham, E. \& Fleming, A. 2012. Informing adaptation responses to climate change through theories of transformation. Global Environmental Change, 22(1): 115-126.

Parkins, J.R. \& MacKendrick, N.A. 2007. Assessing community vulnerability: a study of the mountain pine beetle outbreak in British Columbia, Canada. Global Environmental Change, 17(3): 460-471.

Parmesan, C. \& Yohe, G. 2003. A globally coherent fingerprint of climate change impacts across natural systems. Nature, 421(6918): 37-42.

Pavageau, C., Butterfield, R. \& Tiani, A.M. 2013. Current vulnerability in the Virunga landscape, Rwanda. COBAM (Climate Change and Forests in the Congo Basin: Synergies between Adaptation and Mitigation) brief. Bogor, Indonesia, CIFOR.

Picard, N. \& Garavaglia, V. 2017. Vulnerability of Mediterranean forests to climate change. Rome, FAO. Available at: www.fao.org/forestry/47152-0f593b40ebd5438a7f3e4d6eb0a Oc6385.pdf

Pokharel, B.K., Branney, P., Nurse, M. \& Malla, Y.B. 2008. Community forestry: conserving forests, sustaining livelihoods, strengthening democracy. In H. Ojha, N. Timsina, C. Kumar, B. Belcher \& M. Banjade, eds. Communities, forests, and governance: policy and institutional innovations from Nepal. New Delhi, Adroit.

Porter, J.R., Xie, L., Challinor, A.J., Cochrane, K., Howden, S.M., Iqbal, M.M., Lobell, D.B. \& Travasso, M.I. 2014. Food security and food production systems. In C.B. Field, V.R. Barros, D.J. Dokken, K.J. Mach, M.D. Mastrandrea, T.E. Bilir, M. Chatterjee, K.L. Ebi, Y.O. Estrada, R.C. Genova, B. Girma, E.S. Kissel, A.N. Levy, S. MacCracken, P.R. Mastrandrea \& L.L. White, eds. Climate change 2014: impacts, adaptation, and vulnerability, Part A, Global and sectoral aspects, pp. 485-533. Contribution of Working Group II to the Fifth Assessment Report of the Intergovernmental Panel on Climate Change. Cambridge, UK \& New York, USA, Cambridge University Press.

Potter, K. \& Crane, B.S. 2010. Forest Tree Genetic Risk Assessment System: a tool for conservation decision-making in changing times. User Guide Version 1.2. Available at: www.forestthreats.org/current-projects/project-summaries/genetic-risk-assessmentsystem-description-120610.pdf.

Pramova, E., Locatelli, B., Djoudi, H. \& Somorin, O.A. 2012. Forests and trees for social adaptation to climate variability and change. Wiley Interdisciplinary Reviews: Climate Change, 3(6): 581-596. 
PROVIA (Programme of Research on Climate Change Vulnerability, Impacts and Adaptation). 2013. PROVIA guidance on assessing vulnerability, impacts and adaptation to climate change - consultation document, by J. Hinkel, S. Bharwani, A. Bisaro, T. Carter, T. Cull, M. Davis, R. Klein, K. Lonsdale, L. Rosentrater \& K. Vincent. Nairobi, United Nations Environment Programme (UNEP).

Ranjitkar, S., Sujakhu, N.M., Lu, Y., Wang, Q., Wang, M., He, J., Mortimer, P.E., Xu, J., Kindt, R. \& Zomer, R.J. 2016a. Climate modelling for agroforestry species selection in Yunnan Province, China. Environmental Modelling \& Software, 75: 263-272.

Ranjitkar, S., Sujakhu, N.M., Merz, J., Kindt, R., Xu, J., Matin, M.A., Ali, M. \& Zomer, R.J. 2016b. Suitability analysis and projected climate change impact on banana and coffee production zones in Nepal. PLOS One, 11(9): e0163916. https://doi.org/10.1371/journal. pone. 0163916

Ribot, J.C. 2009. Authority over forests: empowerment and subordination in Senegal's democratic decentralization. Development and Change, 40: 105-129.

Robledo, C. \& Forner, C. 2005. Adaptation of forest ecosystems and the forest sector to climate change. FAO Forests and Climate Change Working Paper No. 2. Rome, FAO.

Rochester, W.A., Skewes, T.D., Suadnya, I.W., Butler, J.R.A., Lyne, V.D., Handayani, T., Habibi, P., Karnan \& Cokrowati, N. 2016. A typology of natural resource use for livelihood impact assessments in Nusa Tenggara Barat Province, Indonesia. Climate Risk Management, 12: 59-68.

Rodenberg, B. 2009. Climate change adaptation from a gender perspective: a crosscutting analysis of development-policy instruments. Discussion Paper 24/2009. Bonn, Germany, German Development Institute (DIE).

Rosenzweig, C., Casassa, G., Karoly, D.J., Imeson, A., Liu, C., Menzel, A., Rawlins, S., Root, T.L., Seguin, B. \& Tryjanowski, P. 2007. Assessment of observed changes and responses in natural and managed systems. In M.L. Parry, O.F. Canziani, J.P. Palutikof, P.J. van der Linden \& C.E. Hanson, eds. Climate change 2007: impacts, adaptation and vulnerability, pp. 79-131. Contribution of Working Group II to the Fourth Assessment Report of the Intergovernmental Panel on Climate Change. Cambridge, UK \& New York, USA, Cambridge University Press.

Rowe, G. \& Frewer, L.J. 2005. A typology of public engagement mechanisms. Science, Technology \& Human Values, 30(2): 251-290.

Salbitano, F., Borelli, S., Conigliaro, M. \& Chen, Y. 2016. Guidelines on urban and periurban forestry. FAO Forestry Paper No. 178. FAO, Rome.

Sandström, C. \& Widmark, C. 2007. Stakeholders' perceptions of consultations as tools for co-management - a case study of the forestry and reindeer herding sectors in northern Sweden. Forest Policy and Economics, 10(1): 25-35.

Schipper, L., Liu, W., Krawanchid, D. \& Chanthy, S. 2010. Review of climate change adaptation methods and tools. MRC Technical Paper No. 34. Vientiane, Mekong River Commission (MRC).

Scoones, I. 1998. Sustainable rural livelihoods: a framework for analysis. IDS Working Paper No. 72. Sussex, UK, Institute of Development Studies (IDS). 
Seppälä, R., Buck, A. \& Katila, P., eds. 2009. Adaptation of forests and people to climate change. A global assessment report. IUFRO World Series Vol. 22. Helsinki, IUFRO.

Shackleton, C. \& Shackleton, S. 2004. The importance of non-timber forest products in rural livelihood security and as safety nets: a review of evidence from South Africa. South African Journal of Science, 100(11-12): 658-664.

Shvidenko, A., Barber, C.V., Persson, R., Gonzalez, P. \& Hassan, R. 2005. Forest and woodland systems. In R. Hassan, R. Scholes \& N. Ash, eds. Ecosystems and buman well-being: current state and trends, pp. 585-622. Millennium Ecosystem Assessment. Washington, DC, Island Press.

Smit, B. \& Wandel, J. 2006. Adaptation, adaptive capacity and vulnerability. Global Environmental Change, 16(3): 282-292.

Somda, J., Sawadogo, I., Savadogo, M., Zougmoré, R., Bationo, B.A., Moussa, A.S., Nakoulma, G., Sanou, J., Barry, S., Sanou, A.O. \& Some, L. 2014. Participatory vulnerability assessment and planning of adaptation to climate change in the Yatenga, Burkina Faso. CCAFS Working Paper No. 64. Frederiksberg, Denmark, CGIAR Challenge Program on Climate Change, Agriculture and Food Security.

Spittlehouse, D.L. \& Stewart, R.B. 2003. Adaptation to climate change in forest management. $B C$ Journal of Ecosystems and Management, 4(1).

Sprintsin, M., Chen, J.M., Desai, A. \& Gough, C.M. 2012. Evaluation of leaf-to-canopy upscaling methodologies against carbon flux data in North America. Journal of Geophysical Research: Biogeosciences, 117(G1).

Sunderland, T., Achdiawan, R., Angelsen, A., Babigumira, R., Ickowitz, A., Paumgarten, F., Reyes-Garcia, V. \& Shively, G. 2014. Challenging perceptions about men, women, and forest product use: a global comparative study. World Development, (64, Suppl. 1): 56-66.

Sunderlin, W.D., Angelsen, A. \& Wunder, S. 2003. Forests and poverty alleviation. In State of the World's Forests 2003, pp. 61-73. Rome, FAO.

Svobodová, E., Trnka, M., Dubrovský, M., Semerádová, D., Eitzinger, J., Stæpánek, P. \& Zalud, Z. 2014. Determination of areas with the most significant shift in persistence of pests in Europe under climate change. Pest Management Science, 70(5): 708-715.

Sylvester, O., Segura, A.G. \& Davidson-Hunt, I.J. 2016. The protection of forest biodiversity can conflict with food access for indigenous people. Conservation and Society, 14(3): 279-290.

Te Uru Rãkau/Forestry New Zealand. 2019. Forestry pest and disease management [online]. [Cited 6 March 2019]. www.mpi.govt.nz/growing-and-harvesting/forestry/taking-careof-your-forest/forestry-pest-and-disease-management

Tiani, A.M., Besa, M.C., Devisscher, T., Pavageau, C., Butterfield, R., Bharwani, S. \& Bele, M.Y. 2015. Assessing current social vulnerability to climate change: a participatory methodology. Working Paper 169. Bogor, Indonesia, CIFOR.

Turnbull, M. \& Turvill, E. 2012. Participatory capacity and vulnerability analysis: a practitioner's guide. Oxford, UK, Oxfam International.

Turner, B.L., Kasperson, R.E., Meyer, W.B., Matson, P., McCarthy, J.J., Corell, R.W., Christensen, L., Eckley, N., Kasperson, J.X., Luers, A., Martello, M.L, Polsky, C., Pulsipher, A. \& Schiller, A. 2003. A framework for vulnerability analysis in sustainability 
science. Proceedings of the National Academy of Sciences of the United States of America, 100: 8074-8079.

UNESCO (United Nations Educational, Scientific and Cultural Organization). 2011. The cultural diversity lens: a practical tool to integrate culture in development-pedagogical guide. Paris.

UNFCCC (United Nations Framework Convention on Climate Change). 2011. Assessing climate change impacts and vulnerability, making informed adaptation decisions - bighlights of the contribution of the Nairobi Work Programme. Bonn, Germany.

USDA (United States Department of Agriculture) Climate Hubs. undated. ForeCASTS: Forecasts of climate associated shifts in tree species [online]. [Cited 7 March 2019]. www. climatehubs.oce.usda.gov/hubs/southeast/tools/forecasts-forecasts-climate-associatedshifts-tree-species

USDA Forest Service. undated. Climate wizard [online]. [Cited 6 March 2019.] www. fs.usda.gov/ccrc/tools/climate-wizard

van Breugel, P., Friis, I., Demissew, S., Lillesø, J.-P.B. \& Kindt, R. 2016. Current and future fire regimes and their influence on natural vegetation in Ethiopia. Ecosystems, 19(2): 369-386.

Vira, B., Wildburger, C. \& Mansourian, S., eds. 2015. Forests, trees and landscapes for food security and nutrition. IUFRO World Series, 33. Vienna, IUFRO.

Wang, T., Wang, G., Innes, J., Nitschke, C. \& Kang, H. 2016. Climatic niche models and their consensus projections for future climates for four major forest tree species in the Asia-Pacific region. Forest Ecology and Management, 360: 357-366.

WCRP (World Climate Research Programme) CORDEX. 2019. Coordinated Regional Climate Downscaling Experiment [online]. [Cited 7 March 2019]. www.cordex.org

Whetton, P., Hennessy, K., Clarke, J., McInnes, K. \& Kent, D. 2012. Use of Representative Climate Futures in impact and adaptation assessment. Climatic Change, 115(3-4): 433-442.

Widmark, C. 2009. Management of multiple-use commons - focusing on land use for forestry and reindeer husbandry in northern Sweden. Doctoral thesis, Umeå, Sweden, Swedish University of Agricultural Sciences.

Williams, S.E., Shoo, L.P., Isaac, J.L., Hoffmann, A.A. \& Langham, G. 2008. Towards an integrated framework for assessing the vulnerability of species to climate change. PLoS Biology, 6(12): e325.

WorldClim. 2016. WorldClim - Global Climate Data [online]. [Cited 7 March 2019]. www. worldclim.org

Young, B., Byers, E., Gravuer, K., Hall, K., Hammerson, G. \& Redder, A. 2011. Guidelines for using the NatureServe climate change vulnerability index. Arlington, Virginia, USA, NatureServe.

Yousefpour, R., Jacobsen, J.B., Thorsen, B.J., Meilby, H., Hanewinkel, M. \& Oehler, K. 2012. A review of decision-making approaches to handle uncertainty and risk in adaptive forest management under climate change. Annals of Forest Science, 69(1): 1-15. 
1 Forest utilization contracts on public Land, 1977 (E F S)

2 Planning forest roads and harvesting systems, 1977 (E F S)

3 World list of forestry schools, 1977 (E F S)

3 Rev.1 World list of forestry schools, 1981 (E F S)

3 Rev.2 World list of forestry schools, 1986 (E F S)

4/1 World pulp and paper demand, supply and trade - Vol. 1, 1977 (E F S)

4/2 World pulp and paper demand, supply and trade - Vol. 2, 1977 (E F S)

5 The marketing of tropical wood in South America, 1976 (E S)

$6 \quad$ National parks planning, 1976 (E F S)

7 Forestry for local community development, 1978 (ar E F S)

8 Establishment techniques for forest plantations, 1978 (Ar C E * F S)

9 Wood chips - production, handling, transport, 1976 (C E S)

10/1 Assessment of logging costs from forest inventories in the tropics - 1. Principles and methodology, 1978 (E F S)

10/2 Assessment of logging costs from forest inventories in the tropics -2 . Data collection and calculations, 1978 (E F S) Savanna afforestation in Africa, 1977 (E F)

12 China: forestry support for agriculture, 1978 (E)

13 Forest products prices 1960-1977, 1979 (E F S)

14 Mountain forest roads and harvesting, 1979 (E)

14 Rev.1 Logging and transport in steep terrain, 1985 (e)

15 AGRIS forestry - world catalogue of information and documentation services, 1979 (E F S)

16 China: integrated wood processing industries, 1979 (E F S)

17 Economic analysis of forestry projects, 1979 (E F S)

17 sup. 1 Economic analysis of forestry projects: case studies, 1979 (E S)
17 Sup. 2 Economic analysis of forestry projects: readings, 1980 (C E)

18 Forest products prices 1960-1978, 1980 (E F S)

19/1 Pulping and paper-making properties of fast-growing plantation wood species Vol. 1, 1980 (E)

19/2 Pulping and paper-making properties of fast-growing plantation wood species Vol. 2, 1980 (E)

20 Forest tree improvement, 1985 (C E F S)

20/2 A guide to forest seed handling, 1985 (E S)

21 Impact on soils of fast-growing species in lowland humid tropics, 1980 (E F S)

22/1 Forest volume estimation and yield prediction - Vol. 1. Volume estimation, 1980 (C E F S)

22/2 Forest volume estimation and yield prediction - Vol. 2. Yield prediction, 1980 (C E F S)

23 Forest products prices 1961-1980, 1981 (E F S)

Cable logging systems, 1981 (C E) Public forestry administrations in Latin America, 1981 (e)

Forestry and rural development, 1981 (E F S)

Manual of forest inventory, 1981 (E F)

Small and medium sawmills in developing countries, 1981 (E S)

World forest products, demand and supply 1990 and 2000, 1982 (E F S) Tropical forest resources, 1982 (E F S) Appropriate technology in forestry, 1982 (E)

Classification and definitions of forest products, 1982 (Ar E F S)

Logging of mountain forests, 1982 (E F S) Fruit-bearing forest trees, 1982 (E F S) Forestry in China, 1982 (C E) Basic technology in forest operations, 1982 (E F S)

Conservation and development of Tropical forest resources, 1982 (E F S) Forest products prices 1962-1981, 1982 $(E / F / S)$ 
Frame saw manual, 1982 (E) making, 1983 (E F S) countries, 1983 (Ar E F S) countries, 1983 (E F S)

(E F S) 1984 (E F S) (E S)

(E) (E/F/S) (C E F S) 1984 (E F) formations, 1989 (E F) guidelines, 1984 (E) 1984 (S) 1985 (E) 1985 (E S)
Circular saw manual, 1983 (E)

Simple technologies for charcoal

Fuelwood supplies in the developing

Forest revenue systems in developing

Food and fruit-bearing forest species -

1. Examples from eastern Africa, 1983

Food and fruit-bearing forest species -

2. Examples from southeastern Asia,

Food and fruit-bearing forest species -

3. Examples from Latin America, 1986

Establishing pulp and paper mills, 1983

Forest products prices 1963-1982, 1983

Technical forestry education - design and implementation, 1984 (E F S)

Land evaluation for forestry, 1984

Wood extraction with oxen and agricultural tractors, 1986 (E F S)

Changes in shifting cultivation in Africa,

Changes in shifting cultivation in Africa - seven case-studies, 1985 (E)

Studies on the volume and yield of tropical forest stands -1 . Dry forest

Cost estimating in sawmilling industries: $\quad 77$

Field manual on cost estimation in sawmilling industries, 1985 (E)

Intensive multiple-use forest management in Kerala, 1984 (E F S)

Planificación del desarrollo forestal,

Intensive multiple-use forest management in the tropics, 1985 (E F S)

Breeding poplars for disease resistance,

Coconut wood - Processing and use,

Sawdoctoring manual, 1985 (E S)

The ecological effects of eucalyptus, 1985 (C E F S)
Monitoring and evaluation of participatory forestry projects, 1985

(E F S)

Forest products prices 1965-1984, 1985

(E F S)

\section{2}

World list of institutions engaged in forestry and forest products research, 1985 (E F S)

Industrial charcoal making, 1985 (E)

64 Tree growing by rural people, 1985

(Ar E F S)

Forest legislation in selected African

countries, 1986 (E F)

Forestry extension organization, 1986

(CE S)

\section{7}

Some medicinal forest plants of Africa and Latin America, 1986 (E)

Appropriate forest industries, 1986 (E)

69
Management of forest industries, 1986

\section{(E)}

Wildland fire management terminology, 1986 (E F S)

World compendium of forestry and forest products research institutions, 1986 (E F S)

Wood gas as engine fuel, 1986 (E S)

Forest products: world outlook projections 1985-2000, 1986 (E F S)

Guidelines for forestry information processing, 1986 (E)

Monitoring and evaluation of social forestry in India - an operational guide, 1986 (E)

Wood preservation manual, 1986 (E)

Databook on endangered tree and shrub species and provenances, 1986 (E)

Appropriate wood harvesting in plantation forests, 1987 (E)

Small-scale forest-based processing enterprises, 1987 (E F S)

Forestry extension methods, 1987 (E)

Guidelines for forest policy formulation, 1987 (C E)

Forest products prices 1967-1986, 1988

(E F S)

83 Trade in forest products: a study of the barriers faced by the developing countries, 1988 (E) projections - Product and country tables 1987-2000, 1988 (E F S) 
(E F S)

Forestry policies in Europe, 1988 (E)

Small-scale harvesting operations of wood and non-wood forest products involving rural people, 1988 (E F S) Management of tropical moist forests in Africa, 1989 (E F P)

Review of forest management systems of tropical Asia, 1989 (E)

Forestry and food security, 1989 (Ar E S)

Design manual on basic wood

harvesting technology, 1989 (E F S)

(Published only as FAO Training Series, No. 18)

Forestry policies in Europe - An analysis, 1989 (E)

Energy conservation in the mechanical forest industries, 1990 (E S)

Manual on sawmill operational

maintenance, 1990 (E)

Forest products prices 1969-1988, 1990

(E F S)

Planning and managing forestry

research: guidelines for managers, 1990

(E)

Non-wood forest products: the way ahead, 1991 (E S)

Timber plantations in the humid tropics of Africa, 1993 (E F)

Cost control in forest harvesting and road construction, 1992 (E)

Introduction to ergonomics in forestry in developing countries, 1992 (E F I)

Management and conservation of closed forests in tropical America, 1993 (E F P S)

Research management in forestry, 1992 (E F S)

Mixed and pure forest plantations in the tropics and subtropics, 1992 (E F S)

Forest products prices 1971-1990, 1992 (E F S)

Compendium of pulp and paper training and research institutions, 1992

(E)

Economic assessment of forestry project impacts, 1992 (E F)

Conservation of genetic resources in tropical forest management - Principles and concepts, 1993 (E F S)
A decade of wood energy activities within the Nairobi Programme of Action, 1993 (E)

\section{Directory of forestry research} organizations, 1993 (E)

Proceedings of the Meeting of Experts on Forestry Research, 1993 (E F S)

\section{Forestry policies in the Near East region}

- analysis and synthesis, 1993 (E)

Forest resources assessment 1990 tropical countries, 1993 (E)

Ex situ storage of seeds, pollen and in vitro cultures of perennial woody plant species, 1993 (E)

Assessing forestry project impacts:

issues and strategies, 1993

(E F S)

Forestry policies of selected countries in Asia and the Pacific, 1993 (E)

Les panneaux à base de bois, 1993 (F)

Mangrove forest management

guidelines, 1994 (E)

\section{Biotechnology in forest tree} improvement, 1994 (E)

Numéro non assigné

Decline and dieback of trees and forests - a global overview, 1994 (E)

Ecology and rural education - Manual for rural teachers, 1995 (E S)

Readings in sustainable forest management, 1994 (E F S)

Forestry education - New trends and prospects, 1994 (E F S)

Forest resources assessment 1990 -

Global synthesis, 1995 (E F S)

Forest products prices 1973-1992, 1995 (E F S)

Climate change, forests and forest management - An overview, 1995 (E F S)

Valuing forests: context, issues and guidelines, 1995 (E F S)

Forest resources assessment 1990 -

Tropical forest plantation resources, 1995 (E)

Environmental impact assessment and environmental auditing in the pulp and paper industry, 1996 (E) Forest resources assessment 1990 Survey of tropical forest cover and study of change processes, 1996 (E) 
ambientales básicas para profesores

rurales y extensionistas, 1996 (S)

Forestry policies of selected countries in Africa, 1996 (E F)

Forest codes of practice - Contributing

to environmentally sound forest

operations, 1996 (E)

137/1 Forestry policies in the Caribbean -

137/2 Forestry policies in the Caribbean -

140 Global Forest Resources Assessment

141 Forestry Outlook Study for Africa -
Estimating biomass and biomass change of tropical forests - A primer, 1997 (E)

Guidelines for the management of tropical forests -1 . The production of wood, 1998 (E S)

Managing forests as common property, $1998(E)$ Volume 1: Proceedings of the expert consultation, 1998 (E) Volume 2: Reports of 28 selected countries and territories, 1998 (E)

FAO Meeting on Public Policies Affecting Forest Fires, 2001 (E F S) Governance principles for concessions and contacts in public forests, 2003 (E F S) 2000 - Main report, 2002 (E F S) Regional report: opportunities and challenges towards 2020, 2003 (Ar E F)

Cross-sectoral policy impacts between forestry and other sectors, 2003 (E F S) Sustainable management of tropical forests in Central Africa - In search of excellence, 2003 (E F)

Climate change and the forest sector Possible national and subnational legislation, 2004 (E)

Best practices for improving law compliance in the forest sector, 2005 (E F R S)

Microfinance and forest-based smallscale enterprises, 2005 (Ar E F S) Global Forest Resources Assessment 2005 - Progress towards sustainable forest management, 2006 (E F S) Tendencias y perspectivas del sector forestal en América Latina y el Caribe, 2006 (S)

Better forestry, less poverty - a practitioner's guide, 2006 (Ar E F S)
The new generation of watershed management programmes and projects, 2006 (E F S)

Fire management - Global assessment 2006, 2007 (E)

People, forests and trees in West and Central Asia - Outlook for 2020, 2007 (Ar E R)

The world's mangroves 1980-2005, 2007 (E)

Forests and energy - Key issues, 2008 (Ar C E F R S)

\section{Forests and water, 2008 (E F S)}

Global review of forest pests and diseases, 2009 (E)

Human-wildlife conflict in Africa -

Causes, consequences and management strategies, 2009 (E F)

Fighting sand encroachment - Lessons from Mauritania, 2010 (E F)

Impact of the global forest industry on atmospheric greenhouse gases, 2010 (E) Criteria and indicators for sustainable woodfuels, 2010 (E)

\section{Developing effective forest policy -} A guide, 2010 (E F S)

What woodfuels can do to mitigate climate change, 2010 (E)

Global Forest Resources Assessment 2010 - Main report (Ar C E F R S)

Guide to implementation of phytosanitary standards in forestry, 2011 (C E F R)

165 Reforming forest tenure - Issues, principles and process, 2011 (E S)

166 Community-based fire management a review $(\mathrm{E})$

167 Wildlife in a changing climate (E)

168 Soil carbon monitoring using surveys and modelling $-(E)$

169 Global forest land-use change 19902005 (E F S)

170 Sustainable management of Pinus radiata plantations $(E)$

171 Edible insects - Future prospects for food and feed security (E F)

172 Climate change guidelines for forest managers (E F S)

173 Multiple-use forest management in the humid tropics (E S)

174 Towards effective national forest funds, 2015 (E) 

of degraded forests and landscapes in drylands - Building resilience and benefiting livelihoods, 2015 (E)

176 Forty years of community-based forestry - A review of its extent and effectiveness, 2016 (E)

177 Forestry for a low-carbon future Integrating forests and wood products in climate change strategies, 2016 (E)

178 Guidelines on urban and peri-urban forestry, 2016 (E)

179 National socioeconomic surveys in forestry - Guidance and survey modules for measuring the multiple roles of forests in household welfare and livelihoods, 2016 (E F S)

180 Making forest concessions in the tropics work to achieve the 2030 Agenda:

Voluntary Guidelines, 2018 (E)

181 Climate change for forest policymakers - An approach for integrating climate change into national forest policy in support of sustainable forest management - Version 2.0, 2018 (E)

182 Guide to the classical biological control of insect pests in planted and natural forests (E)

183 Climate change vulnerability assessment of forests and forest-dependent people - a framework methodology (E)

Ar-Arabic

C - Chinese

E - English

I - Italian

$\mathrm{F}-$ French

K-Korean

$\mathrm{P}$ - Portuguese

S-Spanish

R - Russian

$M$ - Multilingual

* - Out of print

FAO Forestry Papers are available through the authorized FAO Sales agents or directly from Sales and Marketing Group, FAO, Viale delle Terme di Caracalla, 00153 Rome, Italy, or at www.fao.org/forestry/58718/en/ 


\title{
Climate change vulnerability assessment of forests and forest-dependent people
}

\author{
A framework methodology
}

Negative impacts of climate change on forests threaten the delivery of crucial wood and non-wood goods and environmental services on which an estimated 1.6 billion people fully or partly depend. Assessment of the vulnerability of forests and forest-dependent people to climate change is a necessary first step for identifying the risks and the most vulnerable areas and people, and for developing measures for adaptation and targeting them for specific contexts. This publication provides practical technical guidance for forest vulnerability assessment in the context of climate change.

It describes the elements that should be considered for different time horizons and outlines a structured approach for conducting these assessments. The framework will guide practitioners in conducting a step-by-step analysis and will facilitate the choice and use of appropriate tools and methods.

Background information is provided separately in text boxes, to assist readers with differing amounts of experience in forestry, climate change and assessment practices. The publication will provide useful support to any vulnerability assessment with a forest- and tree-related component.
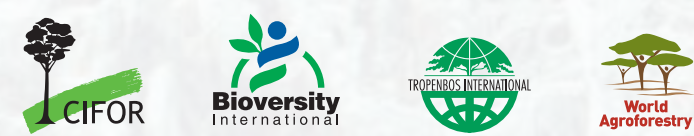

ISBN 978-92-5-131981-9 ISSN 0258-6150

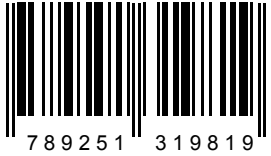

CA7064EN/1/11.19 